\title{
Highly Porous Hybrid Metallosilicate Materials Prepared by Non-Hydrolytic Sol-Gel: Hydrothermal Stability and Catalytic Properties in Ethanol Dehydration
}

Ales Styskalik, Imene Kordoghli, Claude Poleunis, Arnaud Delcorte, Carmela Aprile, Luca Fusaro, Damien Debecker

Submitted date: 26/07/2019 - Posted date: 26/07/2019

Licence: CC BY-NC 4.0

Citation information: Styskalik, Ales; Kordoghli, Imene; Poleunis, Claude; Delcorte, Arnaud; Aprile, Carmela; Fusaro, Luca; et al. (2019): Highly Porous Hybrid Metallosilicate Materials Prepared by Non-Hydrolytic Sol-Gel: Hydrothermal Stability and Catalytic Properties in Ethanol Dehydration. ChemRxiv. Preprint.

Herein, we present novel phenylene- and xylylene-bridged silica and metallosilicate materials prepared by non-hydrolytic sol-gel. The hybrid silica are highly porous, chemically similar to periodic mesoporous organosilica (PMO), but amorphous. Analogous hybrid metallosilicates are obtained by directly incorporating $\mathrm{Al}, \mathrm{Nb}$, or $\mathrm{Sn}$ in the hybrid silica framework. Exhibiting open texture, surface acidity and tunable hydrophobicity, these materials are excellent candidates for catalytic alcohol dehydration reactions. The gas-phase hydrothermal and thermal stability of these materials is examined. While the hybrid silica is expectedly stable, a stark decrease in stability is observed for phenylene bridged silsesquioxanes upon metal introduction. The extent of the hydrolytic $\mathrm{Si}-\mathrm{C}\left(\mathrm{sp}^{2}\right)$ bond cleavage is quantitatively followed by ${ }^{29} \mathrm{Si} \mathrm{MAS}$ NMR, TG analysis, and GC-FID analysis of effluent coming from samples exposed to water vapor. Two important features affecting the hydrothermal and thermal stability are identified: (i) the homogeneity of metal dispersion within the silica matrix, and (ii) the electronegativity of the incorporated metal. The stability of hybrid metallosilicates is significantly improved by replacing the phenylene bridges with xylylene bridges, due to the presence of more stable $\mathrm{Si}-\mathrm{C}\left(\mathrm{sp}^{3}\right)$ bonds. Interestingly, the latter hybrid metallosilicate proves to be an active catalyst for the dehydration of ethanol to ethylene. Unlike the other hybrid materials presented here, it reaches high ethylene yields without undergoing degradation and deactivation.

File list (4)

Styskalik Debecker - Stability of hybrid metallosilicate - pre... (7.21 MiB) view on ChemRxiv • download file graph abstract - preprint.jpg (303.03 KiB) view on ChemRxiv • download file Styskalik Debecker - Stability of hybrid metallosilicate - pre... (1.54 MiB) view on ChemRxiv • download file 
Styskalik Debecker - Stability of hybrid metallosilicate - pre... (1.00 MiB) view on ChemRxiv $\cdot$ download file 


\section{Highly porous hybrid metallosilicate materials prepared by non-hydrolytic sol-gel: hydrothermal stability and catalytic properties in ethanol dehydration}

Ales Styskalik, ${ }^{\mathrm{a}, \mathrm{b}, \mathrm{c}}$ Imene Kordoghli, ${ }^{\text {C }}$ Claude Poleunis, ${ }^{\mathrm{a}}$ Arnaud Delcorte, ${ }^{\mathrm{a}}$ Carmela Aprile, ${ }^{\mathrm{d}}$ Luca Fusaro, ${ }^{\mathrm{d}}$ Damien P. Debecker*a

${ }^{a}$ Institute of Condensed Matter and Nanoscience (IMCN), UCLouvain, Place Louis Pasteur 1, 1348 Louvain-La-Neuve, Belgium

${ }^{b}$ Masaryk University, Department of Chemistry, Kotlarska 2, CZ-61137 Brno, Czech Republic

'Masaryk University, CEITEC MU, Kamenice 5, CZ-62500 Brno, Czech Republic

${ }^{d}$ Department of Chemistry, Unit of Nanomaterials Chemistry, University of Namur, 5000 Namur, Belgium

${ }^{*}$ Corresponding author (damien.debecker@uclouvain.be). 


\section{ABSTRACT}

Herein, we present novel phenylene- and xylylene-bridged silica and metallosilicate materials prepared by non-hydrolytic sol-gel. The hybrid silica are highly porous, chemically similar to periodic mesoporous organosilica (PMO), but amorphous. Analogous hybrid metallosilicates are obtained by directly incorporating $\mathrm{Al}, \mathrm{Nb}$, or $\mathrm{Sn}$ in the hybrid silica framework. Exhibiting open texture, surface acidity and tunable hydrophobicity, these materials are excellent candidates for catalytic alcohol dehydration reactions. The gas-phase hydrothermal and thermal stability of these materials is examined. While the hybrid silica is expectedly stable, a stark decrease in stability is observed for phenylene bridged silsesquioxanes upon metal introduction. The extent of the hydrolytic $\mathrm{Si}-\mathrm{C}\left(\mathrm{sp}^{2}\right)$ bond cleavage is quantitatively followed by ${ }^{29} \mathrm{Si} \mathrm{MAS} \mathrm{NMR}$, TG analysis, and GC-FID analysis of effluent coming from samples exposed to water vapor. Two important features affecting the hydrothermal and thermal stability are identified: (i) the homogeneity of metal dispersion within the silica matrix, and (ii) the electronegativity of the incorporated metal. The stability of hybrid metallosilicates is significantly improved by replacing the phenylene bridges with xylylene bridges, due to the presence of more stable Si-C(sp $\left.{ }^{3}\right)$ bonds. Interestingly, the latter hybrid metallosilicate proves to be an active catalyst for the dehydration of ethanol to ethylene. Unlike the other hybrid materials presented here, it reaches high ethylene yields without undergoing degradation and deactivation.

Keywords: non-hydrolytic sol-gel, hybrid metallosilicate; hydrothermal stability; heterogeneous catalysis; ethanol dehydration 


\section{Introduction}

Hybrid organic-inorganic materials based on silica have recently attracted considerable attention because of their possible application in catalysis, adsorption, gas sensing, etc. ${ }^{1}$ The thermal stability of these materials depends on the nature of the organic group which is incorporated, e.g. ethylene bridges $\left(-\mathrm{CH}_{2} \mathrm{CH}_{2}^{-}\right)$are stable up to $300{ }^{\circ} \mathrm{C}$, methylene bridges $\left(-\mathrm{CH}_{2}^{-}\right)$up to 400 ${ }^{\circ} \mathrm{C}$, and phenylene bridges $\left(-\mathrm{C}_{6} \mathrm{H}_{4}-\right)$ up to $550{ }^{\circ} \mathrm{C} .{ }^{2-4}$ Hydrothermal $(\mathrm{HT})$ stability was tested thoroughly in batch (boiling water, various $\mathrm{pH}, \ldots$ )..$^{5} \mathrm{HT}$ stability of periodic mesoporous organosilica networks (PMO) is generally evaluated by boiling the samples in water for up to several days and monitoring the mesostructural order by X-ray diffraction and is reported to be higher than for plain inorganic silica materials. ${ }^{5}$ Dral et al. suggested, that the improved hydrothermal stability of silica with organic bridges is caused by the higher connectivity of Si precursors and by the relaxation of strained siloxane bonds (due to the incorporation of flexible bridges) rather than by increased hydrophobicity. ${ }^{5}$

Hydrothermal stability tests in flow (gas phase) were reported only scarcely. It was shown that both methylene and phenylene bridged silica start to decompose at $400{ }^{\circ} \mathrm{C}$ in a flow of humid air. ${ }^{3,6}$ The degradation was observed by ${ }^{13} \mathrm{C}$ and ${ }^{29}$ Si MAS NMR: methylene and phenylene bridges transformed to terminal methyl and phenyl groups, respectively, and $\mathrm{Q}$ signals of silicon appeared at the expense of T signals in ${ }^{29} \mathrm{Si}$ NMR spectra. It was concluded that the hydrolysis of $\mathrm{Si}-\mathrm{C}$ bonds is responsible for the degradation.,

The catalytic activity is brought to hybrid silica materials in most cases by grafting or cocondensation of organosilanes with reactive organic groups (e.g. benzene sulphonic acid, propyl sulphonic acid, propyl amine, metal porphyrin complexes, etc.). ${ }^{7-10}$ These materials were shown to be very promising catalysts in many liquid phase reactions performed in batch (e.g. transesterification of fatty acids, condensation of aldehydes with alcohols, alkylation of phenols, etc.). Hydrophobic catalysts exhibited improved performance, when bulky organic molecules need to be transformed, while water should be repelled. ${ }^{7,8}$ As a rare example of catalysis in gas phase, Rác et al. performed the alkylation of phenol by isopropyl alcohol over sulfonated phenylene bridged silica at $150{ }^{\circ} \mathrm{C}$; the studied materials were stable under these conditions. ${ }^{11}$ 
The incorporation of a catalytically active metal into the structure of hybrid silica-based materials is less common. On the first hand, a recent field of research is focused on hybrid zeolites. ${ }^{12,13}$ These materials require elaborate procedures and precise conditions and are relatively unstable, possibly owing to the rapid hydrolysis of $\mathrm{Si}-\mathrm{C}$ bonds by water molecules trapped in the pores of zeolites. ${ }^{14}$ On the second hand, amorphous hybrid metallosilicate are also attracting a lot of attention. Al, Ti, V, and $\mathrm{Zr}$ were successfully incorporated in ethylenebridged silica. ${ }^{15-22}$ Remarkably, these hybrid metallosilicates showed high hydrothermal stability in boiling water, even higher than corresponding metal-free mesoporous organosilica. Phenylene-bridged silicas with Al and Zr were also prepared and their stability in boiling water was again improved in comparison to plain hybrid silica. ${ }^{23,24}$ The generally accepted explanation of this phenomenon is based on a lower amount of $\mathrm{Si}-\mathrm{O}-\mathrm{Si}$ bonds (unstable in hot liquid water); these bridges are substituted by $\mathrm{Si}-\mathrm{O}-\mathrm{M}$ and $\mathrm{Si}-\mathrm{C}-\mathrm{Si}$ linkages in hybrid metallosilicates. ${ }^{25}$ Catalytic applications included epoxidation of cyclooctene, alkylation of 2,4-di-tert-butylphenol, methanolysis of palm oil, etc. ${ }^{17,19,21,23}$ However, to the best of our knowledge, the gas phase stability and catalytic performance of hybrid metallosilicates have not been assessed yet.

Here, our intention was to apply hybrid metallosilicates ( $\mathrm{Al}, \mathrm{Nb}$ ) in the gas phase dehydration of (bio)ethanol to (bio)ethylene - an important reaction in the perspective of integrated biorefineries $^{26}$ - and to study the effect of hydrophobicity on catalytic performance. To do so, highly porous hybrid metallosilicate catalysts were prepared by non-hydrolytic sol-gel chemistry (NHSG). ${ }^{27-29}$ The introduction of organic groups and of the metal took place directly during the polycondensation reactions, using either the acetamide elimination route or the alkyl halide elimination route. Phenylene bridged materials were selected because of the well-known high thermal stability of this organic moiety. However after performing some preliminary catalytic experiments, it appeared that the (hydro)thermal stability of these materials was very low in comparison to reported data on hybrid silica without metal. ${ }^{3}$ Therefore we conducted a systematic study on the stability of hybrid metallosilicates. Using XPS and ToF-SIMS, we show here that the homogeneity of active metal sites distribution is the key property which dictates both the catalytic activity and the (hydro)thermal stability of these hybrid catalysts. We also propose a strategy to obtain more stable hybrid catalysts, active in ethanol dehydration. 


\section{Experimental}

General. All manipulations were performed under high vacuum or dry $\mathrm{N}_{2}$ atmospheres using Schlenk techniques or in a dry box with $\mathrm{H}_{2} \mathrm{O}$ and $\mathrm{O}_{2}$ levels below $1 \mathrm{ppm}$. Diisopropylether and benzene- $\mathrm{d}_{6}$ were dried over $\mathrm{Na}$ metal. $\mathrm{CH}_{2} \mathrm{Cl}_{2}$ was dried with $\mathrm{P}_{4} \mathrm{O}_{10}$. All solvents were distilled, and stored in a glovebox over molecular sieves. Aluminum chloride ( $\left.\mathrm{ABCR}, \mathrm{AlCl}_{3}, 99.999 \%\right)$, niobium(V) chloride ( $\mathrm{ABCR}, \mathrm{NbCl}_{5}, 99.99 \%$ ), tris(dimethylamido)aluminum (Aldrich, $\mathrm{Al}\left(\mathrm{NMe}_{2}\right)_{3}$ ), niobium(V) ethoxide (ABCR, $\mathrm{Nb}(\mathrm{OEt})_{5}, 99.9 \%$ ), tetrakis(diethylamido)tin (ABCR, $\mathrm{Sn}\left(\mathrm{Net}_{2}\right)_{4}, 99.99$ $\%$ ), and 1,4-bis(triethoxysilyl)benzene (ABCR, $95 \%$ ) were stored in a glovebox and used as received. Ethanol absolute (AnalaR NORMAPUR, $99.95 \%$ ), acetic acid anhydride (Acros, 99\%), a, $a^{\prime}$-dichloro-p-xylene (TCl $98.0 \%$ ), tripropylamine ( $\mathrm{TCl}, 98 \%$ ), thionyl chloride (Roth, $98 \%$ ), and trichlorosilane (Sigma, $99 \%$ ) were used as received. 1,4-Bis(trichlorosilyl)benzene was prepared from 1,4-bis(triethoxysilyl)benzene according to a patent. ${ }^{30}$ 1,4-Bis(trichlorosilylmethyl)benzene was prepared from trichlorosilane and $a, a^{\prime}$-dichloro-p-xylene according to literature. ${ }^{31} 1,4-$ Bis(triacetoxysilyl)benzene and 1,4-bis(triacetoxysilylmethyl)benzene were prepared from their corresponding trichlorosilyl- derivatives by an action of acetic acid anhydride. ${ }^{32,33}$ Silica-alumina catalyst support (grade 135, SSA $=600 \mathrm{~m}^{2} \mathrm{~g}^{-1}, \mathrm{~V}_{\mathrm{p}}=0.76 \mathrm{~cm}^{3} \mathrm{~g}^{-1}$, Si/Al ratio $~ 8$ ) was purchased from Sigma-Aldrich.

Characterization. Transmission IR spectra $\left(4000-400 \mathrm{~cm}^{-1}\right)$ were recorded on a Bruker Equinox 55 spectrometer from $\mathrm{KBr}$ pellets or on a Bruker Alpha-Platinum ATR system. Thermal analysis (TG/DSC) was performed on a Mettler Toledo TGA/DSC 3+ apparatus in the stream of air $\left(100 \mathrm{~cm}^{3} \mathrm{~min}^{-1}\right.$ ) with a temperature ramp of $5{ }^{\circ} \mathrm{C} \mathrm{min}^{-1}$ to $1000{ }^{\circ} \mathrm{C}$, in an alumina crucible. Surface areas (SA) and pore volumes were determined by nitrogen adsorption at $77.4 \mathrm{~K}$ by volumetric techniques ${ }^{34,35}$ on a Tristar 3000 instrument (Micromeritics, USA). Prior to measurement, the samples were degassed at $150{ }^{\circ} \mathrm{C}$ for at least $8 \mathrm{~h}$. The specific surface area was determined by the multipoint BET method with at least five data points with relative pressures between 0.05 and 0.30 . Aluminum and silicon contents were determined on an ICP optical emission spectrometer iCAP 6500 Duo (Thermo, UK) equipped with a solid-state generator with a frequency of $27.12 \mathrm{MHz}$ and a maximum power input of $1350 \mathrm{~W}$. The 
measurements of Al were performed at 167.0, 308.2, and $309.2 \mathrm{~nm}$. For Si analysis, wavelengths 212.4 and 251.6 nm were used. Solution NMR spectra were recorded on a Bruker $300 \mathrm{MHz}$ NMR spectrometer at frequencies $299.8 \mathrm{MHz}$ for proton and $75.4 \mathrm{MHz}$ for carbon with deuterated solvents as the external lock. The proton and carbon NMR spectra were referenced to the residual proton signals or carbon resonances of benzene- $\mathrm{d}_{6}$ (7.15 and $128.0 \mathrm{ppm}$, respectively). Solid-state ${ }^{27} \mathrm{Al},{ }^{29} \mathrm{Si}$, and ${ }^{13} \mathrm{C}$ solid state MAS NMR spectra were acquired on Bruker Avance-500 NMR spectrometer with a 4 mm CP-MAS Bruker probe at frequencies $99.4 \mathrm{MHz}$ for silicon, 130.3 $\mathrm{MHz}$ for aluminum, and $125.8 \mathrm{MHz}$ for carbon. Magic angle spinning rates were $8 \mathrm{kHz}$ for ${ }^{29} \mathrm{Si}$ and ${ }^{13} \mathrm{C}(\mathrm{CP}) \mathrm{MAS}$ and $10 \mathrm{kHz}$ for ${ }^{27} \mathrm{Al}$ MAS spectra. Quantitative ${ }^{29} \mathrm{Si}$ MAS spectra were recorded using a $300 \mathrm{~s}$ relaxation delay, a $3 \mu \mathrm{s}\left(90^{\circ}\right)$ excitation pulse, and a $52 \mathrm{~ms}$ acquisition time. Chemical shifts were referenced externally to ${ }^{29} \mathrm{Si} \delta[3$-(trimethylsilyl)-1-propanesulfonic acid sodium salt (DSS)]: $1.53 \mathrm{ppm} ;{ }^{13} \mathrm{C} \delta\left[\right.$ adamantane] $38.68 \mathrm{ppm} ;{ }^{27} \mathrm{Al} \delta\left[\left[\mathrm{Al}\left(\mathrm{H}_{2} \mathrm{O}\right)_{6}\right]{ }^{3+}\right.$ (aq. solution)]: $0.0 \mathrm{ppm}$. The quantitative analysis of ${ }^{29} \mathrm{Si}$ MAS NMR spectra (exponential line broadening value $=$ 0) was performed as follows: (i) phase correction; (ii) baseline correction using least squares method; (iii) deconvolution of signals to $\mathrm{T}^{1}, \mathrm{~T}^{2}, \mathrm{~T}^{3}, \mathrm{Q}^{2}, \mathrm{Q}^{3}$, and $\mathrm{Q}^{4}$ peaks with $100 \%$ Gaussian shape until RMS deviation characterizing the fit between calculated and measured data was below 0.05; (iv) integration. The relative integrated areas of mentioned peaks were used to calculate the percentage of $\mathrm{T}$ sites and degree of condensation (sum of weighed ratios of peak areas vs. total peak area). X-Ray photoelectron spectroscopy (XPS) measurements were carried out on a SSI X probe spectrometer (model SSI 100, Surface Science Laboratories, Mountain View, CA) equipped with a monochromatized Al-Ka radiation (1486 eV). The sample powders, pressed in small stainless troughs of $4 \mathrm{~mm}$ diameter, were placed on an insulating home-made ceramic carousel. The pressure in the analysis chamber was around $10^{-6} \mathrm{~Pa}$. The analyzed area was approximately $1.4 \mathrm{~mm}^{2}$ and the pass energy was set at $150 \mathrm{eV}$. The $\mathrm{C} 1 \mathrm{~s}$ peak of carbon has been fixed to $284.8 \mathrm{eV}$ to set the binding energy scale. ${ }^{36}$ Data treatment was performed with the CasaXPS program (Casa Software Ltd, UK) and spectra were decomposed with the least squares fitting routine provided by the software with a Gaussian/Lorentzian (85/15) product function and after baseline was subtracted. Time of flight secondary ion mass spectrometry (ToF-SIMS) analyses were carried out by using a TOF.SIMS ${ }^{5}$ instrument (IONTOF GmbH, Münster, Germany). 
A pulsed $\mathrm{Bi}_{5}{ }^{+}$metal ion source was used to produce a primary beam using an acceleration voltage of $30 \mathrm{kV}$. An AC target current of $0.07 \mathrm{pA}$ with a bunched pulse width lower than $1 \mathrm{~ns}$ was used. Both positive and negative secondary ion species were analysed. For spectra, a raster of $128 \times 128$ data points over an area of $250 \times 250 \mu \mathrm{m}^{2}$ was used. The total primary ion beam dose for each analysed area was always kept below $5 \bullet 10^{10}$ ions $\mathrm{cm}^{-2}$, ensuring static conditions. Lateral resolution of $\sim 3 \mu \mathrm{m}$ and mass resolution $\mathrm{m} / \Delta \mathrm{m}>4000$ at $29 \mathrm{~m} / \mathrm{z}$ were maintained for positive and negative spectra acquisition. Charge compensation was done by interlaced electron flood gun $\left(E_{k}=20 \mathrm{eV}\right)$. All data analyses were carried out using the software supplied by the instrument manufacturer, SurfaceLab (version 6.5). Sample powders were pressed onto adhesive part of Post-it papers.

Xerogel synthesis - acetamide elimination route. $4.565 \mathrm{~g}$ (9.383 mmol) 1,4bis(triacetoxysilyl)benzene was loaded in an autoclave in a glove box and dissolved in $25 \mathrm{~cm}^{3}$ $\mathrm{CH}_{2} \mathrm{Cl}_{2}$. In a separate vial, a $\mathrm{CH}_{2} \mathrm{Cl}_{2}$ solution $\left(5 \mathrm{~cm}^{3}\right)$ of $0.1931 \mathrm{~g}(1.213 \mathrm{mmol}) \mathrm{Al}\left(\mathrm{NMe}_{2}\right)_{3}$ was prepared and stirred at RT for 5 min. The solution of $\mathrm{Al}\left(\mathrm{NMe}_{2}\right)_{3}$ was then added to the solution of the 1,4-bis(triacetoxysilyl)benzene with vigorous stirring $(5 \mathrm{~min}$ ). The autoclave was sealed and kept in an oven at $130{ }^{\circ} \mathrm{C}$ for $72 \mathrm{hrs}$. During this time, gelation occurred. After cooling down, the autoclave was put back into the glovebox, opened and the gel was transferred into a Schlenk vessel. The gel was then dried under vacuum at $60^{\circ} \mathrm{C}$ overnight in order to remove the solvent and volatile condensation products ( $N, N^{\prime}$-dimethylacetamide and acetic acid anhydride). The resulting powder was annealed in flow of dry nitrogen at $250^{\circ} \mathrm{C}\left(1{ }^{\circ} \mathrm{C} \mathrm{min}^{-1}, 6 \mathrm{hrs}\right.$ ) yielding a pale brown xerogel sample (Al-8SiPhSi-Ac), where 8 is the molar ratio between the silicon precursor and the aluminum precursor (nominal Si/Al ratio $=16$ ), "Ph" stands for the phenyl bridges and "Ac" stands for "acetamide elimination route". Samples Nb-8SiPhSi-Ac and Sn-8SiPhSi-Ac, were prepared using the same procedure, but with $\mathrm{Nb}(\mathrm{OEt})_{5}$ or $\mathrm{Sn}\left(\mathrm{NMe}_{2}\right)_{4}$ respectively as the metal precursors. As a benchmark, SiPhSi-Ac (plain, no metal) was prepared without addition of metal precursor. Also, one xylylene bridged sample was prepared with bis(triacetoxysilylmethyl)benzene instead of bis(triacetoxysilyl)benzene (Al-8SiXySi-Ac) (Table 1). Higher temperatures $\left(160-190^{\circ} \mathrm{C}\right)$ were needed for SiPhSi-Ac, Sn-8SiPhSi-Ac, and Al-8SiXySi-Ac in order to obtain gels. 
Table 1: Synthesis (amount on precursors introduced in the preparation) and characterization of phenylene bridged metallosilicate catalysts by XPS, and ICP-OES.

\begin{tabular}{lcccc}
\hline Sample & $\begin{array}{c}\mathrm{n}_{\mathrm{Si}} \\
(\mathrm{mmol})\end{array}$ & $\begin{array}{c}\mathrm{n}_{\mathrm{M}} \\
(\mathrm{mmol})\end{array}$ & $\begin{array}{c}\mathrm{n}_{\text {DIPE }} \\
(\mathrm{mmol})\end{array}$ & $\begin{array}{c}\text { Si/M ratio (-) } \\
\text { Theor }^{\mathrm{a}} / \mathrm{ICP} / \mathrm{XPS}\end{array}$ \\
\hline SiPhSi-Ac & 8.910 & - & - & $-/-/-$ \\
Al-8SiPhSi-Ac & 9.383 & 1.213 & - & $15.5 / 16.4 / 15.3$ \\
Al-8SiPhSi-Et & 9.386 & 1.170 & 30.00 & $16.0 / 15.6 / 18.3$ \\
Nb-8SiPhSi-Ac & 9.392 & 1.171 & - & $16.0 / 15.2 / 19.3$ \\
Nb-8SiPhSi-Et & 9.670 & 1.223 & 32.51 & $15.8 / 16.8 / 42.9$
\end{tabular}

${ }^{a}$ The nominal $\mathrm{Si} / \mathrm{M}$ ratio is 16 ; the theoretical value presented in the table is the value calculated from the precise masses of reactants introduced during the synthesis $\left(n_{\mathrm{Si}}, \mathrm{n}_{\mathrm{M}}, \mathrm{n}_{\mathrm{DIPE}}\right)$.

Xerogel synthesis - alkylhalide elimination (ether) route. $3.238 \mathrm{~g}$ (9.386 mmol) 1,4bis(trichlorosilyl)benzene was loaded in an autoclave in a glove box and dissolved in $25 \mathrm{~cm}^{3}$ $\mathrm{CH}_{2} \mathrm{Cl}_{2}$. In a separate vial, a $\mathrm{CH}_{2} \mathrm{Cl}_{2}$ solution $\left(5 \mathrm{~cm}^{3}\right)$ of $0.1560 \mathrm{~g}(1.170 \mathrm{mmol}) \mathrm{AlCl}_{3}$ and 3.065 (30.00 mmol) diisopropylether (DIPE) was prepared and stirred at RT for $15 \mathrm{~min}$. This solution was then added to the solution of the 1,4-bis(trichlorosilyl)benzene with vigorous stirring (5 min). The autoclave was sealed and kept in an oven at $130{ }^{\circ} \mathrm{C}$ for $72 \mathrm{hrs}$ for gelation. After cooling down, the autoclave was put back into the glovebox, opened and the gel was transferred into a Schlenk vessel. The gel was then dried under vacuum at $60{ }^{\circ} \mathrm{C}$ overnight in order to remove the solvent and volatile condensation product (isopropylchloride). The resulting powder was annealed in flow of dry nitrogen at $250{ }^{\circ} \mathrm{C}\left(1{ }^{\circ} \mathrm{C} \mathrm{min}-1,6 \mathrm{hrs}\right)$ yielding a pale yellow xerogel (Al-8SiPhSi-Et, Et stands for ether route). Sample Nb-8SiPhSi-Et was prepared in the same way with $\mathrm{NbCl}_{5}$ as the metal precursor. Pure inorganic benchmarking catalyst with the same Si/Al nominal ratio was prepared in the same way utilising $\mathrm{SiCl}_{4}$ and silicon precursor (Al-16Si-Et).

Spectroscopic characterization data (IR and NMR). Complete summary can be found in the supporting material to this manuscript (ESI). These may be accessed via journal website. 
Hydrothermal stability test - dynamic. The xerogel samples $(0.192 \mathrm{~g}, 0.20-0.40 \mathrm{~mm}$ particle size) were diluted with glass beads $(0.5-1 \mathrm{~mm})$ in order to keep the volume of the catalyst bed constant. The void space of the reactor was filled with silica beads. Stability testing was carried out by feeding $0.216 \mathrm{~g} \mathrm{~h}^{-1}$ of liquid $\mathrm{H}_{2} \mathrm{O}$ by means of $\mathrm{NE}-300$ syringe pump in $40 \mathrm{~cm}^{3} \mathrm{~min}^{-1}$ of $\mathrm{N}_{2}$ (10 mol\% of water in $\mathrm{N}_{2}$ ). The tests were carried out at atmospheric pressure, WHSV $=1.1 \mathrm{~h}^{-1}$. Temperature was varied stepwise in the range from 205 to $415^{\circ} \mathrm{C}$ by steps of $35{ }^{\circ} \mathrm{C}$. One step consisted of (i) heating ramp and stabilization at the temperature (21 min) and (ii) steady temperature state (35 min). The analysis of effluent gas containing products of hydrolysis was carried out by VARIAN 3800 Gas Chromatograph (5 injections at each temperature) equipped with a flame ionization detector (FID) and a Cydex B column (25 m long, internal diameter 0.22 $\mathrm{mm}$, film thickness $0.25 \mu \mathrm{m})$.

Hydrothermal stability test - static. The fixed bed reactor was prepared in the same way as for the dynamic test. $0.216 \mathrm{~g} \mathrm{~h}^{-1}$ of $\mathrm{H}_{2} \mathrm{O}$ in $40 \mathrm{~cm}^{3} \mathrm{~N}_{2}$ was fed for $24 \mathrm{~h}$, temperature of the bed was kept at $240{ }^{\circ} \mathrm{C}$. Sample was collected after cooling down and analyzed by TGA, MAS NMR, and $\mathrm{N}_{2}$ physisorption.

Thermal stability was assessed simply by calcination of the xerogel at $400{ }^{\circ} \mathrm{C}$ in a flow of dry air (flow ca. $40 \mathrm{~cm}^{3} \mathrm{~min}^{-1}$, fixed bed, ramp $1{ }^{\circ} \mathrm{Cmin}^{-1}, 4 \mathrm{hrs}$ ) followed by analysis of calcined sample.

Catalytic dehydration of ethanol. The fixed bed reactor was prepared in the same way as for hydrothermal stability tests. $0.192 \mathrm{~g}$ of phenylene bridged samples was used; the mass of catalyst was normalized based on inorganic part in the case of samples with significantly different mass fraction of organic groups (Al-16Si-Et and Al-8SiXySi-Ac) so that the amount of metal is the same in all experiments. Catalytic testing was carried out by feeding $0.212 \mathrm{~g} \mathrm{~h}^{-1}$ of absolute ethanol by means of NE-300 syringe pump in a $\mathrm{N}_{2}$ flow of $40 \mathrm{~cm}^{3} \mathrm{~min}^{-1}(4.4 \mathrm{~mol} \%$ of ethanol in $\mathrm{N}_{2}$ ). The tests were carried out at atmospheric pressure, WHSV $=1.1 \mathrm{~h}^{-1}$. Temperature was varied stepwise in the range from 205 to $415{ }^{\circ} \mathrm{C}$ by steps of $35^{\circ} \mathrm{C}$. One step consisted of (i) heating ramp and stabilization at the temperature (21 $\mathrm{min}$ ) and (ii) steady temperature state (56 min). The analysis of reactants and products in the effluent gas was carried out by VARIAN 3800 Gas Chromatograph (8 injections at each temperature) equipped with a flame ionization 
detector (FID) and a Cydex B column (25 m long, internal diameter $0.22 \mathrm{~mm}$, film thickness $0.25 \mu \mathrm{m})$.

\section{Results and discussion}

Phenylene bridged silsesquioxane (no metal) - synthesis, characterisation, and stability Sample without any metal (SiPhSi-Ac) was synthesized by NHSG as a benchmark (eq. 1) and annealed in flow of dry $\mathrm{N}_{2}\left(250^{\circ} \mathrm{C}\right)$. This material exhibited very similar structural properties to previously reported hybrid silica with phenylene bridges prepared by conventional hydrolytic sol-gel methods. ${ }^{329} \mathrm{Si}$ and ${ }^{13} \mathrm{C}$ CPMAS NMR spectra of the as prepared sample (annealed in $\mathrm{N}_{2}$ at $250^{\circ} \mathrm{C}$ ) confirmed presence of intact phenylene bridges (Fig. 1 and $1 \mathrm{~S}$ ), only signals in the $\mathrm{T}$ region $\left(\mathrm{CSiO}_{3}\right)$ were observed for ${ }^{29} \mathrm{Si}$ species. These signals originate from the presence of 3 overlapping contributions centered at $-62,-72$, and $-78 \mathrm{ppm}$ which can be attributed respectively to $\mathrm{CSi}(\mathrm{OSi})(\mathrm{OH})_{2}(\mathrm{~T} 1), \mathrm{CSi}(\mathrm{OSi})_{2}(\mathrm{OH})(\mathrm{T} 2)$, and $\mathrm{CSi}(\mathrm{OSi})_{3}(\mathrm{~T} 3)$ species, where $\mathrm{C}$ stands for an aromatic carbon of a phenylene group bound to silicon. ${ }^{3}$ The absence of $\mathrm{Q}^{\mathrm{n}}$ signals (i.e. $\mathrm{Si}(\mathrm{OSi})_{n}(\mathrm{OH})_{4-\mathrm{n}}$ species) in region comprised between -90 and $-110 \mathrm{ppm}$ is a clear indication of the good performance of our synthesis strategy. ${ }^{3}$ Thus we can state that sample SiPhSi-Ac indeed was a phenylene bridged silsesquioxane with no traces of $\mathrm{SiO}_{2}$. XPS further attested the presence of aromatic moieties: the intensity of C1s peak was very high and accompanied by a shake-up satellite peak characteristic for aromatic groups (Fig. 2S). Furthermore Si $2 p$ peak was shifted by $1 \mathrm{eV}$ from $\mathrm{SiO}_{2}{ }^{37}$ and NHSG-prepared purely inorganic sample (Fig. 3S) supporting the fact that the close $\mathrm{Si}$ environment can be described as $\mathrm{CSiO}_{3}$. Finally, surface area and pore volume reach $260 \mathrm{~m}^{2} \mathrm{~g}^{-1}$ and $0.079 \mathrm{~cm}^{3} \mathrm{~g}^{-1}$ respectively (Table 3), which is lower than previously reported phenylene bridged PMOs. ${ }^{2}$

Importantly TGA showed high thermal stability of SiPhSi-Ac (up to $500^{\circ} \mathrm{C}$ ) similar to reported data (Fig. 2). ${ }^{3}$ The mass loss due to the burning of phenylene bridges $\left(500-725^{\circ} \mathrm{C}\right.$ ) accounted for $38 \%$ of the mass which is in a good agreement with the theoretical value (33\%, Fig. 2). This mass loss is slightly higher than expected presumably due to the presence of some unreacted acetoxy- groups, which burn at the same temperature range as phenylene bridges. For the 
sample calcined at $400{ }^{\circ} \mathrm{C}$ in dry air, the mass loss was virtually the same (35\%), showing that the organic species survived the calcination step. However, a partial cleavage of $\mathrm{Si}-\mathrm{C}$ bonds was observed by ${ }^{29} \mathrm{Si}$ MAS NMR spectroscopy, as evidenced by the presence of a combination of $\mathrm{Q}^{2}$, $\mathrm{Q}^{3}$, and $\mathrm{Q}^{4}$ sites at $-93,-100$, and $-109 \mathrm{ppm}$, respectively, with an overall proportion of $\mathrm{Q}$ sites equal to $25 \%$ (Fig. 1, Table 2). Since the mass loss did not change after calcination, it can be concluded, that the predominant reaction is a conversion of bridging phenylene moieties to terminal phenyl groups (eq. 2). This transformation has been already reported ${ }^{3}$ and is here reflected in the ${ }^{13} \mathrm{C}$ CP MAS spectrum where a shoulder of the main peak (134 ppm) characteristic for a terminal phenyl group emerged at $128 \mathrm{ppm}$ (Fig. 1S). ${ }^{3}$ Water necessary for this hydrolytic reaction (eq. 2) is either adsorbed in the pores or comes from the oxidation of residual organic groups. Thus, the data presented above confirm that NHSG preparation led to phenylene bridged silsesquioxane materials exhibiting similar thermal stability as conventional hydrolytic sol-gel technique. ${ }^{3}$

$$
(\mathrm{AcO})_{3} \mathrm{Si}-\mathrm{C}_{6} \mathrm{H}_{4}-\mathrm{Si}(\mathrm{OAC})_{3} \rightarrow \mathrm{O}_{1.5} \mathrm{Si}_{-}-\mathrm{C}_{6} \mathrm{H}_{4}-\mathrm{SiO}_{1.5}+3 \mathrm{AcOAC}
$$

Table 2: Evaluation of thermal and hydrothermal stability by TGA and ${ }^{29} \mathrm{Si}$ MAS NMR.

\begin{tabular}{|c|c|c|c|c|c|c|}
\hline \multirow[t]{2}{*}{ Sample } & \multicolumn{2}{|c|}{$\begin{array}{l}\text { As-prepared (annealed at } \\
250{ }^{\circ} \mathrm{C}, \text { dry } \mathrm{N}_{2} \text { ) }\end{array}$} & \multicolumn{2}{|c|}{$\begin{array}{c}\text { Calcined at } 400^{\circ} \mathrm{C}, \text { dry } \\
\text { air }\end{array}$} & \multicolumn{2}{|c|}{$\begin{array}{c}\text { After static HT stability } \\
\text { test }\end{array}$} \\
\hline & $M L(\%)^{a}$ & $\begin{array}{l}\text { Proportion of } \\
\text { T sites }(\%)^{b}\end{array}$ & $\mathrm{ML}(\%)^{\mathrm{a}}$ & $\begin{array}{l}\text { Proportion of } \\
\text { T sites }(\%)^{b}\end{array}$ & $\mathrm{ML}(\%)^{\mathrm{a}}$ & $\begin{array}{l}\text { Proportion of } \\
\text { T sites }(\%)^{b}\end{array}$ \\
\hline SiPhSi-Ac & 38 & $100^{c}$ & 35 & 75 & 36 & 100 \\
\hline Al-8SiPhSi-Ac & 42 & 79 & 22 & 0 & 28 & 22 \\
\hline Al-8SiPhSi-Et & 34 & 40 & 19 & 0 & 31 & 12 \\
\hline Nb-8SiPhSi-Ac & 38 & 73 & 15 & 10 & 30 & 45 \\
\hline Nb-8SiPhSi-Et & 33 & 78 & 21 & 21 & 28 & 58 \\
\hline
\end{tabular}


a Mass loss between 250 and $800{ }^{\circ} \mathrm{C}$ in TGA; ${ }^{b}$ Sum of the peak areas belonging to $\mathrm{T}$ sites $\left(\mathrm{CSiO}_{3}\right.$, $-61--77 \mathrm{ppm})$ and $\mathrm{Q}$ sites $\left(\mathrm{SiO}_{4},-90-110 \mathrm{ppm}\right)$ was set as $100 \%$; ${ }^{\mathrm{C}}$ Based on ${ }^{29} \mathrm{Si}$ CPMAS NMR (no hint of Q sites).

Table 3: Surface area evolution with different sample treatment

\begin{tabular}{|c|c|c|c|c|c|c|c|c|c|}
\hline \multirow[t]{2}{*}{ Sample } & \multicolumn{3}{|c|}{$\begin{array}{l}\text { As-prepared (annealed at } \\
250^{\circ} \mathrm{C}, \text { dry } \mathrm{N}_{2} \text { ) }\end{array}$} & \multicolumn{3}{|c|}{ Calcined at $400^{\circ} \mathrm{C}$, dry air } & \multicolumn{3}{|c|}{ After static HT stability test } \\
\hline & $\begin{array}{l}\mathrm{SA}_{\mathrm{BET}} \\
\left(\mathrm{m}^{2} \mathrm{~g}^{-1}\right)\end{array}$ & $\begin{array}{c}V_{\text {total }} \\
\left(\mathrm{cm}^{3} \mathrm{~g}^{-1}\right)\end{array}$ & $\begin{array}{c}\mathrm{D} \\
(\mathrm{nm})\end{array}$ & $\begin{array}{c}\mathrm{SA}_{\mathrm{BET}} \\
\left(\mathrm{m}^{2} \mathrm{~g}^{-1}\right)\end{array}$ & $\begin{array}{c}\mathrm{V}_{\text {total }} \\
\left(\mathrm{cm}^{3} \mathrm{~g}^{-1}\right)\end{array}$ & $\begin{array}{c}\mathrm{D} \\
(\mathrm{nm})\end{array}$ & $\begin{array}{l}\mathrm{SA}_{\mathrm{BET}} \\
\left(\mathrm{m}^{2} \mathrm{~g}^{-1}\right)\end{array}$ & $\begin{array}{c}V_{\text {total }} \\
\left(\mathrm{cm}^{3} \mathrm{~g}^{-1}\right)\end{array}$ & $\begin{array}{c}\mathrm{D} \\
(\mathrm{nm})\end{array}$ \\
\hline SiPhSi-Ac & 260 & 0.079 & 1.2 & $<10$ & - & - & 156 & 0.066 & 1.7 \\
\hline Al-8SiPhSi-Ac & 54 & 0.015 & 1.1 & 380 & 0.12 & 1.3 & $<10$ & - & - \\
\hline Al-8SiPhSi-Et & 460 & 1.0 & 9.8 & 430 & 1.27 & 12 & 320 & 0.47 & 8.3 \\
\hline $\mathrm{Nb}-8 \mathrm{SiPhSi}-\mathrm{Ac}$ & 380 & 0.14 & 1.5 & 130 & 0.036 & 1.1 & $<10$ & - & - \\
\hline Nb-8SiPhSi-Et & 880 & 1.40 & 7.4 & 650 & 0.49 & 6.2 & 710 & 0.76 & 6.7 \\
\hline
\end{tabular}

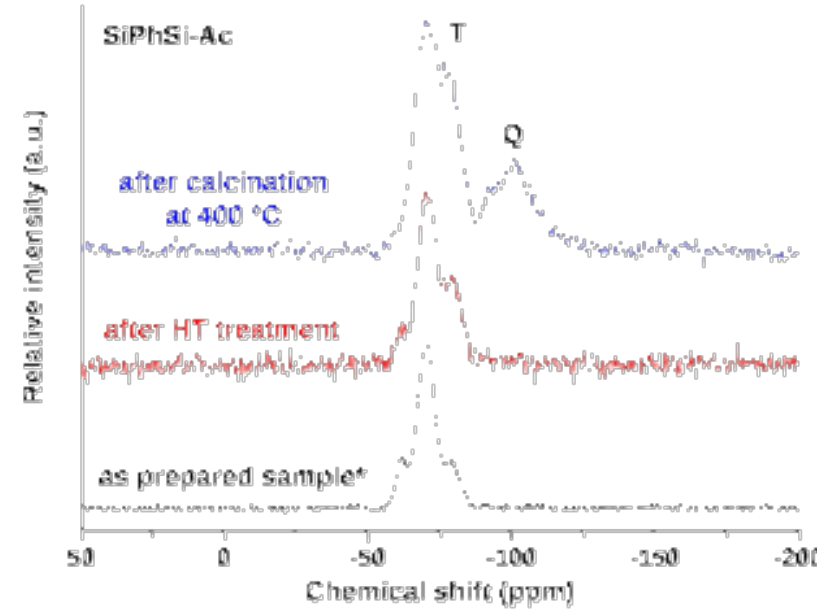

Fig. 1: ${ }^{29} \mathrm{Si}(\mathrm{CP}) \mathrm{MAS}$ NMR spectra of SiPhSi-Ac after various treatment, ${ }^{*}$ denotes CPMAS spectrum.

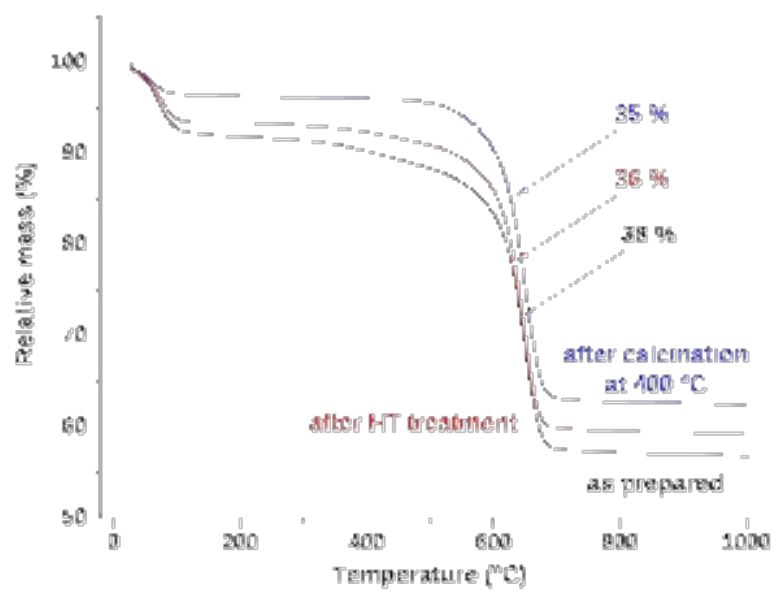

Fig. 2: TG curves of SiPhSi-Ac after various treatment..

$$
\begin{gathered}
\mathrm{O}_{1.5} \mathrm{Si}-\mathrm{C}_{6} \mathrm{H}_{4}-\mathrm{SiO}_{1.5}+\mathrm{H}_{2} \mathrm{O} \rightarrow \mathrm{O}_{1.5} \mathrm{Si}-\mathrm{C}_{6} \mathrm{H}_{5}+\mathrm{HO}-\mathrm{SiO}_{1.5} \\
\mathrm{O}_{1.5} \mathrm{Si}-\mathrm{C}_{6} \mathrm{H}_{5}+\mathrm{H}_{2} \mathrm{O} \rightarrow \mathrm{0}_{1.5} \mathrm{Si}-\mathrm{OH}+\mathrm{C}_{6} \mathrm{H}_{6}
\end{gathered}
$$


Since water is unavoidably one of the products of ethanol dehydration, we aimed for studying the gas phase hydrothermal stability of prepared materials in more detail. Two types of tests were performed. In the first test (dynamic), the sample was exposed to a wet $\mathrm{N}_{2}$ flow (10 mol\% of water) in a fixed bed reactor, the temperature was raised from 205 to $415^{\circ} \mathrm{C}$ in steps of $35{ }^{\circ} \mathrm{C}$. The product of the hydrolysis (benzene; coming from the hydrolysis of both $\mathrm{Si}-\mathrm{C}$ bonds of phenylene bridges in hybrid silica as presented in eq. 2 and 3) was observed and quantified by GC-FID (Fig. 3). Thus, we were able to identify the temperature at which the hydrolysis starts to occur. The second hydrothermal stability test (static) was performed to probe the long term stability. The samples were placed in the same humid flow at $240{ }^{\circ} \mathrm{C}$ (typical reaction temperature for EtOH dehydration) for 24 hrs. The treated catalyst was then characterized.

Sample SiPhSi-Ac showed high hydrothermal stability. It started to release benzene only from $345^{\circ} \mathrm{C}$ during the dynamic HT treatment (Fig. 3). Note, however, that this temperature is much lower than the first signs of degradation observed in dry air (see TGA results in Fig. 2). Long-term stability at $240{ }^{\circ} \mathrm{C}$ in humid atmosphere was excellent: the ${ }^{29} \mathrm{Si}$ MAS NMR spectrum did not exhibit any hint of $Q$ signals and mass loss remained virtually same as compared to the fresh catalyst (Fig 1 and 2). 


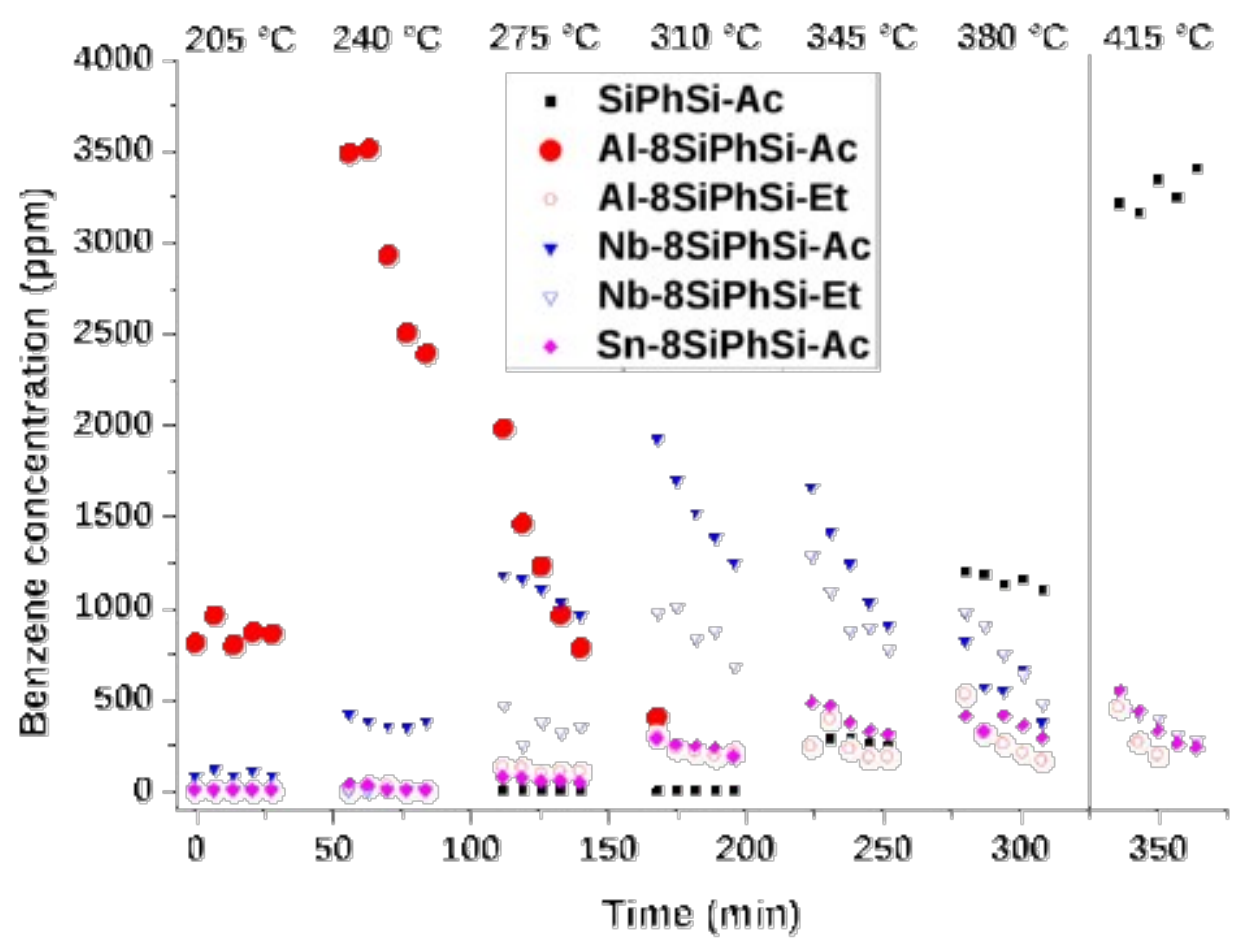

Fig. 3: Benzene release from phenylene bridged metallosilicate catalysts during dynamic HT stability test.

\section{Phenylene bridged metallosilicates - synthesis, characterization, and stability}

Hybrid metallosilicates were prepared by NHSG. This technique is known to yield highly porous mixed metal oxides. ${ }^{33,38-40}$ Another advantage is that the kinetics of condensation of different metal precursors are levelled off in NHSG (as compared to classical hydrolytic sol-gel) and therefore it allows for a good control over the homogeneity of the formed mixed metal oxide. ${ }^{27-}$ ${ }^{29}$ Here, two NHSG pathways were applied: the acetamide elimination route ${ }^{38,41}$ and the alkylhalide elimination (ether) route ${ }^{39,40}$ (eq. 4 and 5). Reactions were performed at $130^{\circ} \mathrm{C}$ in autoclaves in order to get high condensation degrees and obtain gels. This was necessary mainly in the case of acetamide elimination route, where homocondesation of two acetoxy- groups resulting in acetic acid anhydride and $\equiv \mathrm{Si}-\mathrm{O}-\mathrm{Si} \equiv$ bridge formation (eq. 4) was reported to occur slowly at lower temperatures. ${ }^{42,43}$

IR (ESI), ${ }^{13} \mathrm{C}$ (Fig. 4S) and ${ }^{29} \mathrm{Si}$ NMR (Fig. 4) spectra and XPS (Fig. 3S and 5S) confirmed presence of phenylene bridges in the hybrid metallosicate materials, similar to SiPhSi-Ac. In XP spectra phenylene bridged metallosilicates exhibited very intense C 1 s peak with a shake-up satellite 
peak characteristic for aromatic groups (Fig. 5S). The position of Si $2 p$ peak was shifted again by $1 \mathrm{eV}$ from $\mathrm{SiO}_{2}$ and NHSG-prepared purely inorganic benchmark. ${ }^{37}$ However in this case some $\mathrm{Si}-\mathrm{C}$ bond cleavage already occurred in the as-prepared samples as reflected by the larger peak width (higher FWHM) of Si 2p peak in XP spectra (Fig. 3S). Quantification of this cleavage was performed by ${ }^{29}$ Si MAS NMR and discussed in detail (see below).

Textural properties (Table 3) of prepared materials strongly depended on the chosen synthetic route. While materials prepared by the acetamide elimination route were microporous with surface areas, pore volumes and average pore diameters up to $380 \mathrm{~m}^{2} \mathrm{~g}^{-1}, 0.14 \mathrm{~cm}^{3} \mathrm{~g}^{-1}$, and $1.5 \mathrm{~nm}$, respectively, materials synthesized by the ether route were mesoporous and reached higher surface areas and pore volumes (up to $880 \mathrm{~m}^{2} \mathrm{~g}^{-1}$ and $1.4 \mathrm{~cm}^{3} \mathrm{~g}^{-1}$, respectively). All samples were XRD amorphous.

$$
\begin{gathered}
\mathrm{Al}\left(\mathrm{NMe}_{2}\right)_{3}+8(\mathrm{AcO})_{3} \mathrm{Si}-\mathrm{C}_{6} \mathrm{H}_{4}-\mathrm{Si}(\mathrm{OAC})_{3} \rightarrow \frac{1}{2} \mathrm{Al}_{2} \mathrm{O}_{3} \bullet 8 \mathrm{O}_{1.5} \mathrm{Si}_{-} \mathrm{C}_{6} \mathrm{H}_{4}-\mathrm{SiO}_{1.5}+3 \mathrm{AcNMe}_{2}+22.5 \mathrm{AcOAc} \text { (4) } \\
\mathrm{AlCl}_{3}+8 \mathrm{Cl}_{3} \mathrm{Si}-\mathrm{C}_{6} \mathrm{H}_{4}-\mathrm{SiCl}_{3}+25.5^{\mathrm{i}} \mathrm{PrO}{ }^{\mathrm{Pr}} \rightarrow \frac{1}{2} \mathrm{Al}_{2} \mathrm{O}_{3} \bullet 8 \mathrm{O}_{1.5} \mathrm{Si}_{-} \mathrm{C}_{6} \mathrm{H}_{4}-\mathrm{SiO}_{1.5}+51^{i} \mathrm{PrCl}
\end{gathered}
$$

The stability of phenylene bridges was found to be markedly affected by metal introduction. As prepared Al-8SiPhSi-Ac (annealed at $250^{\circ} \mathrm{C}$ in dry $\mathrm{N}_{2}$ ) already displayed an extensive cleavage of Si-C bonds (T site proportion was only $79 \%$, compare to $100 \%$ for SiPhSi-Ac, Fig. 4). It is worth noting that mass loss of as prepared Al-8SiPhSi-Ac was higher than the expected value (42\% vs. $32 \%)$. It can be explained by the presence of residual acetoxy- groups, which is clearly reflected in IR and NMR spectra (bands representing asymmetric valence COO vibration in IR spectra at 1535 and $1710 \mathrm{~cm}^{-1}$, signals of methyl and carboxyl groups in ${ }^{13} \mathrm{C}$ CPMAS NMR spectra at 21, and 169-177 ppm, respectively; Fig. 4S). The presence of broad signals in ${ }^{13} \mathrm{C}$ CPMAS NMR spectra in the chemical shift range comprised between 169 and 177 ppm suggests that some of the acetoxy- groups are in the bidentate form. ${ }^{44}$ This assumption can be further supported by the observation of two sets of bands originating from symmetrical and asymmetrical vibrations of COO groups in IR spectra $(E S I) .{ }^{45,46}$ The bidentate acetoxy- groups are coordinated to the aluminum atoms and make them predominantly six-coordinated. ${ }^{27} \mathrm{Al}$ MAS NMR spectra corroborate this hypothesis; a major contribution comes from $\mathrm{AlO}_{6}$ species in as-prepared 
sample, while signal for $\mathrm{AlO}_{4}$ moieties becomes the most intense peak after calcination at $400{ }^{\circ} \mathrm{C}$ (when most of the acetoxy- groups is burned, Fig. 6S.). As another consequence, these bidentate acetoxy- groups are very stable and lower the catalytic activity of Al-8SiPhSi-Ac (see below).

TG analysis showed that thermal decomposition of Al-8SiPhSi-Ac started already at ca. $400{ }^{\circ} \mathrm{C}$ in dry air (Fig. 5), ca. $100{ }^{\circ} \mathrm{C}$ earlier than for metal-free SiPhSi-Ac. ${ }^{29}$ Si MAS NMR analysis confirmed that the damage to the material was deeply progressing with thermal treatment: no T signal was observed after calcination at $400{ }^{\circ} \mathrm{C}$ (only Q signal coming from $\mathrm{SiO}_{4}$ species between -90 and $-120 \mathrm{ppm}$, Fig. 4). Yet, the mass loss of calcined sample during TGA was still relatively high (22\%, Fig. 5, Table 2). The possible contribution to high mass loss is coke formation by carbonization of phenylene bridges and residual acetoxy- groups; sample after calcination at 400 ${ }^{\circ} \mathrm{C}$ is black.

The dynamic HT stability test allowed to highlight an important release of benzene already at $205{ }^{\circ} \mathrm{C}$ for sample Al-8SiPhSi-Ac (Fig. 3). ${ }^{29} \mathrm{Si}$ MAS NMR spectra further evidenced the very low hydrothermal stability of Al-8SiPhSi-Ac: T sites proportion after static HT stability test was only $22 \%$. (Table 2, Fig. 4). Moreover the amount of organic groups after static HT treatment decreased significantly in comparison to as-prepared sample as can be deduced from TG analyses (Fig. 5, Table 2). Similar to what is observed with the calcined sample, the mass loss after static HT stability test was higher than expected on the basis of ${ }^{29} \mathrm{Si}$ MAS NMR spectra. It is probably caused by carbonization of organic groups. Finally, the poor HT stability was observed also by a loss of porosity: the solid was nonporous after static HT treatment (Table 3). 


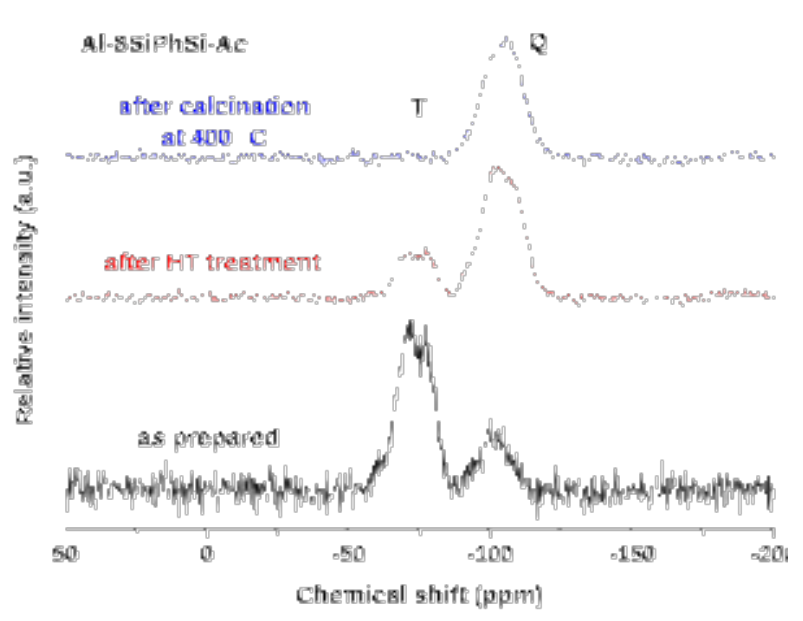

Fig. 4: ${ }^{29}$ Si MAS NMR spectra of Al-8SiPhSi-Ac after various treatment.

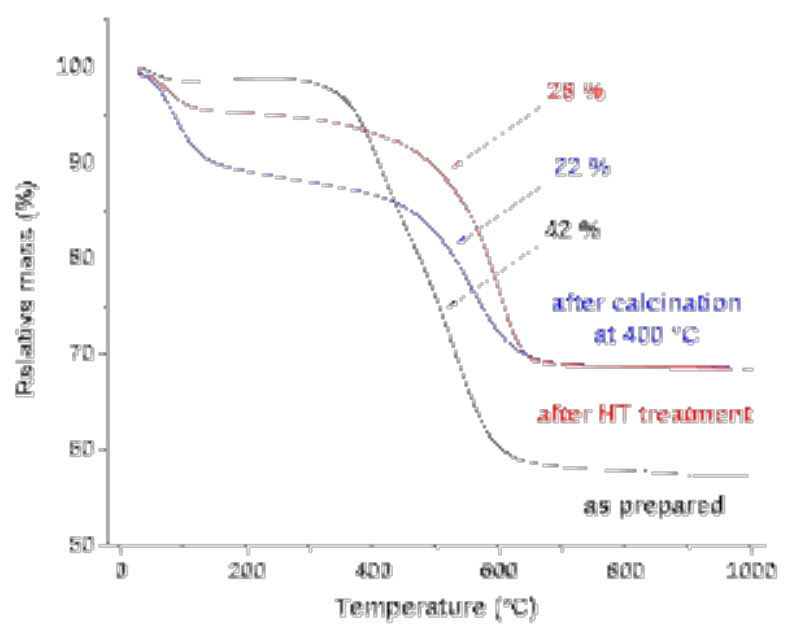

Fig. 5: TG curves of Al-8SiPhSi-Ac after various treatment.

The sample with identical composition prepared by the ether route (Al-8SiPhSi-Et) displayed also a significant stability drop. Similar to Al-8SiPhSi-Ac the as-prepared sample Al-SiPhSi-Et (annealed at $250{ }^{\circ} \mathrm{C}$ in dry $\mathrm{N}_{2}$ ) exhibited considerable $\mathrm{Si}-\mathrm{C}$ bond cleavage based on ${ }^{29} \mathrm{Si}$ MAS NMR spectra, T site proportion was $40 \%$ (Fig. 6, Table 2). However most of the organic groups were preserved within Al-SiPhSi-Et - not as phenylene bridges, but as terminal phenyl moieties these were observed as a very intense peak in ${ }^{13} \mathrm{C}$ NMR spectrum (Fig. 4S). Moreover the TGA mass loss was close to the theoretical value (34 \% vs. $32 \%$, Fig. 7) and the as-prepared sample was only slightly yellowish indicating the absence of coke coming from carbonization of organic groups.

Thermal stability of Al-SiPhSi-Et was very poor: no T signal was observed in ${ }^{29} \mathrm{Si}$ MAS NMR spectra after calcination at $400^{\circ} \mathrm{C}$ (only Q signal, Fig. 6). Mass loss exhibited by calcined sample (19\%) can be thus ascribed to coke formed by carbonization of phenylene and phenyl groups (sample after calcination at $400^{\circ} \mathrm{C}$ is black, Fig. 7, Table 2).

Interestingly, Al-8SiPhSi-Et displayed somewhat higher stability during dynamic $\mathrm{HT}$ treatment in comparison to Al-8SiPhSi-Ac. While the sample from acetamide elimination route (Al-8SiPhSiAc) released benzene already at $205^{\circ} \mathrm{C}$, the sample from ether route (Al-8SiPhSi-Et) showed first hints of benzene at $275{ }^{\circ} \mathrm{C}$ (Fig. 3). Sample Al-SiPhSi-Et showed similar extensive Si-C bond cleavage to Al-8SiPhSi-Ac after static hydrothermal stability test at $240^{\circ} \mathrm{C}$; $\mathrm{T}$ site proportion in 
${ }^{29}$ Si MAS NMR spectra dropped to $12 \%$ (Table 2). Textural properties were deteriorated after static HT treatment, surface area and pore volume dropped by 29 and $54 \%$, respectively (Table 3). Unlike Al-8SiPhSi-Ac, sample Al-SiPhSi-Et retained some porosity again pointing at its somewhat higher HT stability.

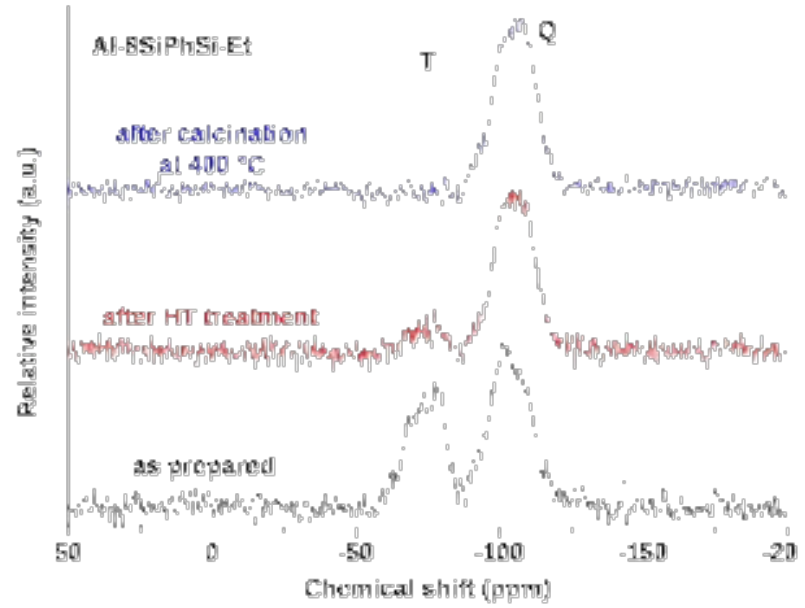

Fig. 6: ${ }^{29}$ Si MAS NMR spectra of Al-8SiPhSi-Et after various treatment.

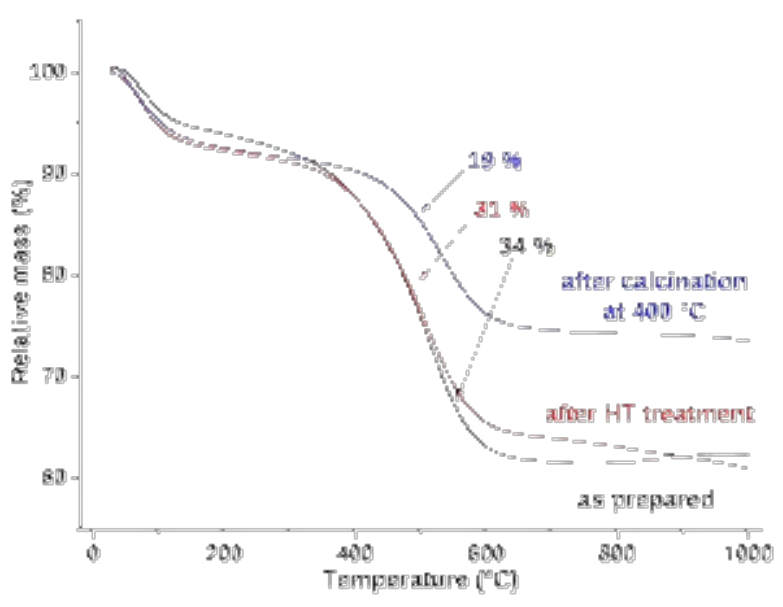

Fig. 7: TG curves of Al-8SiPhSi-Et after various treatment.

In order to better understand the observed hydrolytic reactions and release of benzene from phenylene bridged metallosilicates, $\mathrm{Nb}$ containing samples were prepared in the same manner by acetamide elimination and ether route. The obtained results closely resemble those obtained for samples containing Al. Both as-prepared samples exhibited already some $\mathrm{Si}-\mathrm{C}$ bond cleavage; T site proportions were 73 and $78 \%$ for $\mathbf{N b}-8$ SiPhSi-Ac and $\mathbf{N b - 8 S i P h S i - E t , ~ r e s p e c t i v e l y ~}$ (Fig. 8 and 9, Table 2). Thermal stability was much lower for both samples than in the case of metal free SiPhSi-Ac (Table 2). ${ }^{29}$ Si MAS NMR spectra after static HT stability test revealed that the $\mathrm{Si}-\mathrm{C}$ bond hydrolysis was considerably progressing, $\mathrm{T}$ site proportions decreased to 45 and $58 \%$ for Nb-8SiPhSi-Ac and Nb-8SiPhSi-Et, respectively (Fig. 8 and 9, Table 2). All these data were in a good agreement with TG analyses (Fig. 7S and 8S). Static HT stability test also provoked a porosity loss. Similar to Al samples $\mathbf{N b - 8 S i P h S i - A c ~ w a s ~ c o m p l e t e l y ~ n o n p o r o u s ~ a f t e r ~ s t a t i c ~ H T ~}$ treatment. Nb-8SiPhSi-Et kept some surface area and pore volume (80 and $54 \%$, respectively, as compared to the as-prepared sample, Table 3). Finally benzene release was observed at $205^{\circ} \mathrm{C}$ for sample $\mathbf{N b - 8 S i P h S i - A c ; ~ s a m p l e ~ f r o m ~ e t h e r ~ r o u t e ~ ( N b - 8 S i P h S i - E t ) ~ s t a r t e d ~ t o ~ r e l e a s e ~ b e n z e n e ~}$ 
at $275{ }^{\circ} \mathrm{C}$ (Fig. 3). It is noteworthy that the sample prepared by acetamide elimination route displays more extensive $\mathrm{Si}-\mathrm{C}$ bond cleavage after all types of treatment (as-prepared, calcination, static HT treatment). Moreover it starts to release benzene at lower temperature than $\mathbf{N b - 8 S i P h S i - E t . ~ F i n a l l y , ~ a f t e r ~ s t a t i c ~ H T ~ s t a b i l i t y ~ t e s t , ~ t h e ~ t e x t u r a l ~ p r o p e r t i e s ~ o f ~} \mathbf{N b - 8 S i P h S i - A c}$ are affected more deeply than for Nb-8SiPhSi-Et. Thus Nb-8SiPhSi-Ac clearly appears less stable than the corresponding hybrid material prepared by the ether route.



Fig. $8:{ }^{29}$ Si MAS NMR spectra of Nb-8SiPhSi-Ac after various treatment.

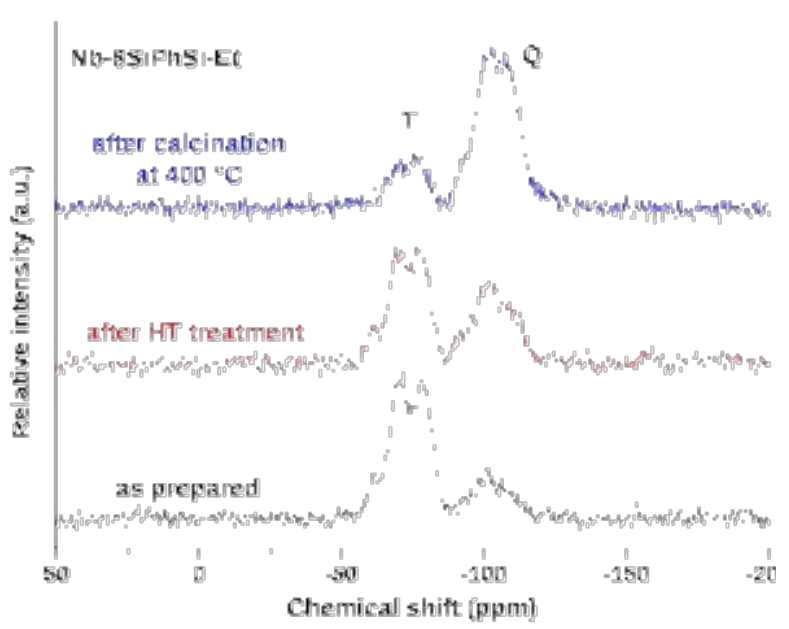

Fig. 9: ${ }^{29}$ Si MAS NMR spectra of Nb-8SiPhSi-Et after various treatment.

\section{Identification of stability drop cause - homogeneity of M/Si mixing and electronegativity}

To identify the possible reasons for the different stability of samples prepared by ether and acetamide elimination route, we inspected their properties as revealed by a variety of characterization techniques. Al-8SiPhSi-Et and Al-8SiPhSi-Ac both had similar Si:Al ratios and they both contained comparable amount of phenyl and/or phenylene groups. The degree of condensation was also very similar based on ${ }^{29} \mathrm{Si}$ MAS NMR spectra (Table 1S).The less stable Al8SiPhSi-Ac had a lower surface area than more stable Al-8SiPhSi-Et (Table 3). Thus, higher surface area as a cause for lower hydrothermal stability can be ruled out. Both samples could in principle exhibit different amounts of Brønsted acid sites $\left(\mathrm{H}^{+}\right.$could promote $\mathrm{Si}-\mathrm{C}$ bond scission by an electrophilic aromatic substitution) ${ }^{47}$. A possible role of acidic protons on the instability of 
the hybrids was however excluded by a specific experiment: Al-8SiPhSi-Ac and Al-8SiPhSi-Et were exposed to a mixture of EtOH and 2,6-ditertbutyl pyridine (a strong base known to interact selectively with $\mathrm{H}^{+}$due to its steric constraints) ${ }^{48}$ and compared to a catalytic run with EtOH only. For both catalysts, while activity in ethanol dehydration decreased (i.e. Brønsted acid sites were selectively poisoned), the production of benzene remained unaffected (Fig. 9S).

The homogeneity of these hybrid Si-Al materials (which can be viewed as the degree of dispersion of $\mathrm{Al}$ in the hybrid silica matrix) was clearly different, depending on the synthesis route. For Al-8SiPhSi-Ac the surface molar Si:Al ratio determined by XPS fitted almost perfectly with the bulk molar Si:Al ratio determined by ICP-OES, indicating a high homogeneity for this material. For Al-8SiPhSi-Et, the amount of Al detected at the surface layer was slightly lower, hinting at its lower homogeneity (Table 1).

The homogeneity of Al mixing within silica matrices was further studied using ToF-SIMS. Peaks of $\left(\mathrm{AlSiO}_{3}\right)^{-},\left(\mathrm{AlSi}_{2} \mathrm{O}_{5}\right)^{-},\left(\mathrm{Al}_{2} \mathrm{O}_{4}\right)^{-}$, and $\left(\mathrm{AlO}_{2}\right)^{-}$were followed at $\mathrm{m} / \mathrm{z}=102.94,162.92,117.95$, and 58.967, respectively (relevant parts of mass spectra Fig. 10S). These signals were well resolved, without any overlap, and undoubtedly assigned. The peak area for the first two masses is taken as an indication of the presence of homogeneously dispersed Al in silica. The peak area of the third mass is taken as an indication of the presence of alumina clusters (poorly dispersed Al oxide species). Finally the peak area of the last mass is a function of Al concentration in the surface layer. Reporting the peak areas of the Al-Si moieties vs. alumina clusters it appears that the sample prepared by acetamide elimination route (Al-8SiPhSi-Ac) shows relatively more mixed Al-Si clusters than the sample prepared by the ether route (Al-8SiPhSi-Et) (Fig. 10a and b). In a very good agreement, the peak area ratio of $\left(\mathrm{Al}_{2} \mathrm{O}_{4}\right)^{-}$vs. $\left(\mathrm{AlO}_{2}\right)^{-}$shows a higher proportion of alumina clusters per aluminum atoms in surface layer for Al-8SiPhSi-Et in comparison to Al8SiPhSi-Ac (Fig. 10c). Therefore we suggest that Al dispersion in hybrid silica in sample Al8SiPhSi-Ac is better than in Al-8SiPhSi-Et. Thus, it seems that the homogeneity of Si-Al mixing has a direct influence on $\mathrm{Si}-\mathrm{C}$ bond hydrolytic stability. We propose that the more homogeneous distribution of $\mathrm{Al}$ in phenylene silsequioxane matrices, the less stable these materials are. Our hypothesis works with the fact that a homogeneous Al dispersion implies higher amount of Si-O-Al bridges, which introduce instability into hybrid metallosilicates similar to pure inorganic 
metallosilicates and zeolites under gas-phase hydrothermal conditions. ${ }^{25}$ Unlike inorganic materials, where the highly polar Al-O bond is reported to have the lowest stability (leading in turn to dealumination), ${ }^{25}$ we observe the most striking difference in $\mathrm{Si}-\mathrm{C}$ bond stability upon $\mathrm{Al}$ introduction in hybrid metallosilicates.
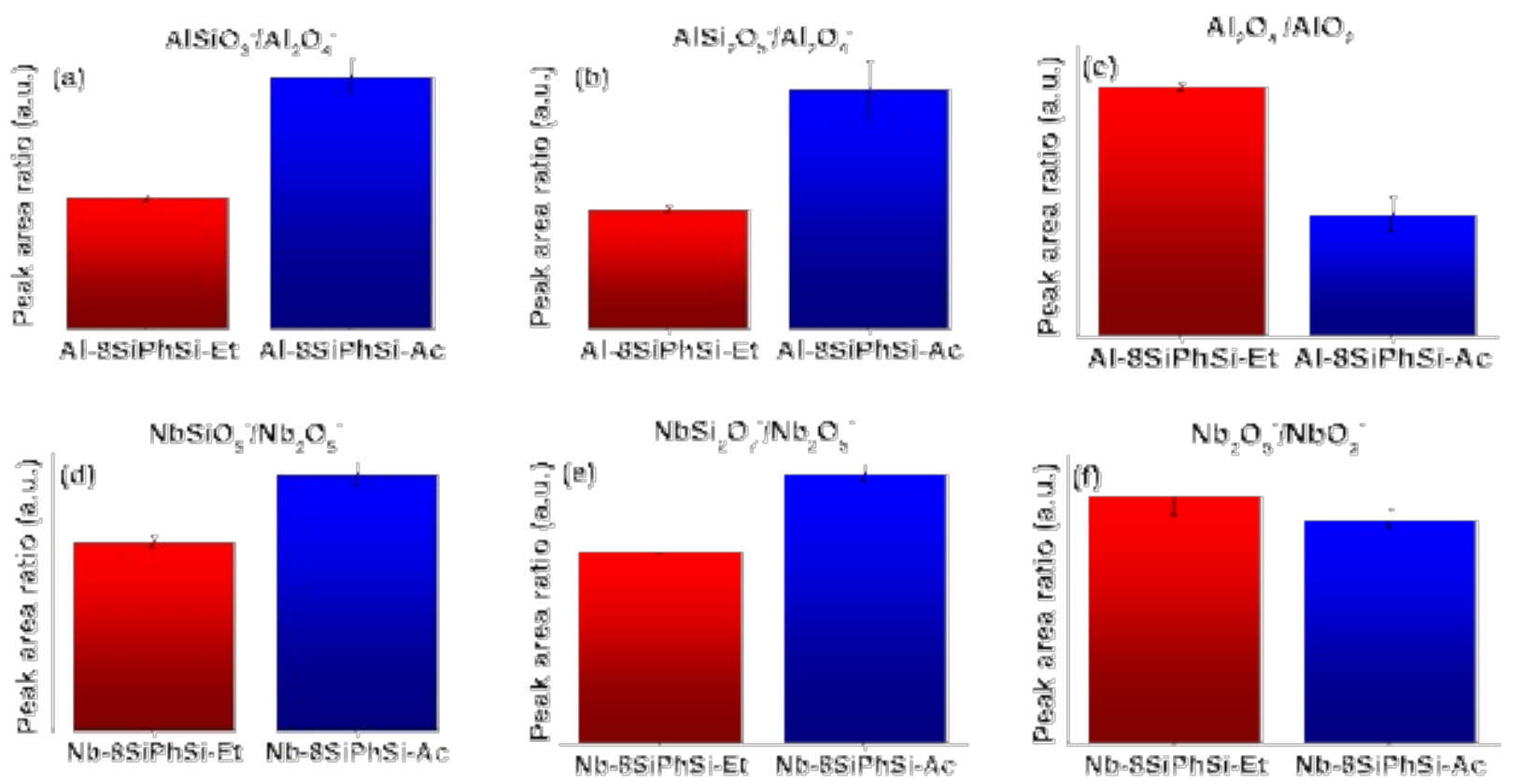

Fig. 10: Comparison of samples prepared by acetamide elimination (blue) and ether route (red) in terms of peak area ratios of various masses in mass spectra obtained by ToF-SIMS. Plots $a, b$, and $c$ refer to Al containing samples, plots $\mathrm{d}$, e, and $\mathrm{f}$ to $\mathrm{Nb}$ containing samples.

The possible reasons for different hydrothermal and thermal stabilities of $\mathbf{N b}$-8SiPhSi-Ac vs. Nb8SiPhSi-Et were also analyzed. On the one hand, influence of degree of condensation (which is similar for both samples according to ${ }^{29} \mathrm{Si}$ MAS NMR, Table 1S) and surface area (which is lower for less stable material) was ruled out, similar to Al containing samples. On the other hand, striking difference in $\mathrm{Nb}$ dispersion within hybrid silica matrices was again observed. $\mathrm{Nb}$ content in the surface layer was much lower than in bulk material in the sample prepared by ether route, while well corresponding values were observed for the sample prepared by acetamide elimination route (XPS, ICP-OES, Table 1). Moreover ToF-SIMS revealed that Nb-8SiPhSi-Et contained less mixed $\mathrm{Nb}$-Si moieties $\left(\mathrm{NbSiO}_{5}{ }^{-}\right.$and $\mathrm{NbSi}_{2} \mathrm{O}_{7}{ }^{-}, \mathrm{m} / \mathrm{z}=200.89$ and 260.86, respectively) and more niobia clusters $\left(\mathrm{Nb}_{2} \mathrm{O}_{5}{ }^{-}, \mathrm{m} / \mathrm{z}=265.81\right)$ per $\mathrm{Nb}$ atoms in surface layer $\left(\mathrm{NbO}_{3}{ }^{-}, \mathrm{m} / \mathrm{z}=140.90\right)$ in comparison to $\mathrm{Nb}-8 \mathrm{SiPhSi}-\mathrm{Ac}$ (Fig. 10d, e, and f). Thus it is possible to 
suggest again that the degree of homogeneity plays a significant role in hydrothermal and thermal stability of hybrid metallosilicates (based on the results for both $\mathrm{Al}$ and $\mathrm{Nb}$ containing samples).

It is noteworthy, that the abrupt decrease of gas phase HT stability of phenylene bridged silsesquioxane matrices upon metal introduction is in striking contrast to what was observed in boiling water, where an improvement of HT stability was observed upon metal insertion (based on BET and XRD analyses). ${ }^{23,24}$ Moreover the bonds reported to cleave in boiling water are Si-OSi bridges, while in our case we observe the hydrolysis to occur at the expense of Si-C bonds. However it is useful to realize that gas phase and liquid phase hydrothermal stabilities of zeolites are also two completely different cases with $\mathrm{Al}-\mathrm{O}$ bonds being cleaved in the former, while the latter causes the $\mathrm{Si}-\mathrm{O}-\mathrm{Si}$ or $\mathrm{Si}-\mathrm{O}-\mathrm{M}$ bridges to hydrolyze (depending on $\mathrm{pH}$ ). ${ }^{25}$

At this point we intend to identify the cause of such an abrupt decrease of (hydro)thermal stability upon introduction of metals into the silsesquioxane matrices. While $\mathrm{Al}$ and $\mathrm{Nb}$ have very similar electronegativities (1.61 and 1.60 according to Pauling, respectively), Si exhibits different electronegativity value (1.90). The differences in electron withdrawing properties between $\mathrm{Si}$ and guest elements $(\mathrm{Al}, \mathrm{Nb})$ can introduce partial charges into the silsesquioxane matrices making them prone to attack by polar water molecules. This is in a good agreement with our hypothesis that the higher content of polar $\mathrm{Si}-\mathrm{O}-\mathrm{Al} / \mathrm{Nb}$ bridges in materials with better metal dispersion causes their lower stability.

To prove the effect of electronegativity phenylene bridged silsesquioxane with tin was synthesized by acetamide elimination route (Sn-8SiPhSi-Ac; details on synthesis and characterization in ESI). Tin has an electronegativity value close to silicon (1.96). Indeed, sample Sn-8SiPhSi-Ac was more stable than its corresponding Al and $\mathrm{Nb}$ derivatives. The as-prepared sample contained intact phenylene bridges as deduced from ${ }^{29}$ Si MAS NMR spectra where only signals of T sites were observed (compare with T site proportion ranging from 44 to $85 \%$ for Al and $\mathrm{Nb}$ containing samples, Fig. 11). Calcination at $400^{\circ} \mathrm{C}$ only led to a mild $\mathrm{Si}-\mathrm{C}$ bond cleavage in comparison to Al-8SiPhSi-Ac and Nb-8SiPhSi-Ac (T site proportion $41 \%$, Fig. 11). Finally, Sn8SiPhSi-Ac started to release low amounts of benzene at $275^{\circ} \mathrm{C}$ (Fig. 3) during dynamic HT treatment (compared to substantial evolution of benzene from Al-8SiPhSi-Ac and Nb-8SiPhSi-Ac 
already at $205^{\circ} \mathrm{C}$ ). In a good agreement, lower amount of Si-C bonds was cleaved after static $\mathrm{HT}$ stability test in comparison to Al-8SiPhSi-Ac and Nb-8SiPhSi-Ac (T site proportion $77 \%$ according to ${ }^{29}$ Si MAS NMR spectra, Fig. 11). Electronegativity of inserted metal was thus identified to be a second important parameter (after homogeneity of M/Si dispersion) influencing stability of hybrid metallosilicates.

\section{Increasing stability of hybrid metallosilicates - xylylene bridged material}

It is known that $\mathrm{Si}-\mathrm{C}\left(\mathrm{sp}^{3}\right)$ bonds are more resistant towards both electrophilic and nucleophilic substitution than $\mathrm{Si}-\mathrm{C}\left(\mathrm{sp}^{2}\right)$ bonds. ${ }^{47,49}$ In order to increase the stability of our materials, but retain hydrophobic aromatic groups, aluminum-containing $p$-xylylene $\left(-\mathrm{CH}_{2}-\mathrm{C}_{6} \mathrm{H}_{4}-\mathrm{CH}_{2}-\right)$ bridged silsesquioxane was prepared by acetamide elimination route (Al-8SiXySi-Ac; details on synthesis and characterization in ESI). SS NMR unambiguously proved the presence of $\mathrm{Si}-\mathrm{CH}_{2}-\mathrm{C}_{6} \mathrm{H}_{4}-\mathrm{CH}_{2}-\mathrm{Si}$ moieties in the as-prepared sample, new intense signal ascribed to methylene species was observed at $22 \mathrm{ppm}$ in ${ }^{13} \mathrm{C} \mathrm{CP}$ MAS NMR spectra. $\mathrm{N}_{2}$ physisorption measurements indicated presence of both micro- and mesopores in contrary to phenylene bridged samples prepared by acetamide elimination route, which were completely microporous. Surface area reached $520 \mathrm{~m}^{2}$ $\mathrm{g}^{-1}$, pore volume $0.33 \mathrm{~cm}^{3} \mathrm{~g}^{-1}$, and average pore diameter $2.5 \mathrm{~nm}$ for Al-8SiXySi-Ac. According to t-plot analysis $46 \%$ of pore volume was microporous. Varying bridging groups (length and flexibility) has been already reported as a way to change textural properties in hybrid materials made via NHSG. ${ }^{33}$ Finally, similar to Al-SiPhSi-Ac two sets of signals of acetoxy- groups were observed in IR spectra and COO peak was broadened towards lower field in ${ }^{13} \mathrm{C}$ NMR spectra indicating the presence of bidentate acetoxy- moieties. Again, these groups coordinated to Al atoms, made them predominantly six-coordinated ( ${ }^{27}$ Al MAS NMR spectra Fig. 6S), and impaired catalytic activity of Al-8SiXySi-Ac (see below).

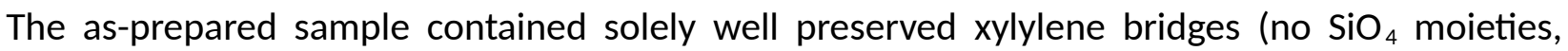
compare with T site proportion of $79 \%$ for Al-SiPhSi-Ac, Fig. 12). On the contrary, Si-C bonds in the sample calcined at $400{ }^{\circ} \mathrm{C}$ were almost completely cleaved (Fig. 12). Importantly, the first hints of xylene (product of hydrolysis of $\mathrm{Si}-\mathrm{C}$ bonds) were observed at $345{ }^{\circ} \mathrm{C}$ only during the dynamic HT stability test (not shown); moreover no Si-C bond hydrolysis was observed after 24 
hrs at $240^{\circ} \mathrm{C}$ on stream (static HT treatment, Fig. 12). Based on these results it can be concluded that the hydrothermal stability of Al-8SiXySi-Ac was significantly improved in comparison to phenylene bridged metallosilicates and was close to SiPhSi-Ac (metal free phenylene bridged sample). The hydrothermal as well as thermal stability limit temperature is ca. $345{ }^{\circ} \mathrm{C}$ for xylylene bridged hybrid metallosilicates. It is worth noting that this value is close to the temperature $\left(400{ }^{\circ} \mathrm{C}\right)$, at which a transformation of bridging methylene moieties to terminal methyl groups was observed in metal free hybrid silica samples. ${ }^{6}$ At the same time, it is above the thermal stability limit $\left(300^{\circ} \mathrm{C}\right)$ of ethylene bridged silsesquioxanes (no metal). ${ }^{2}$

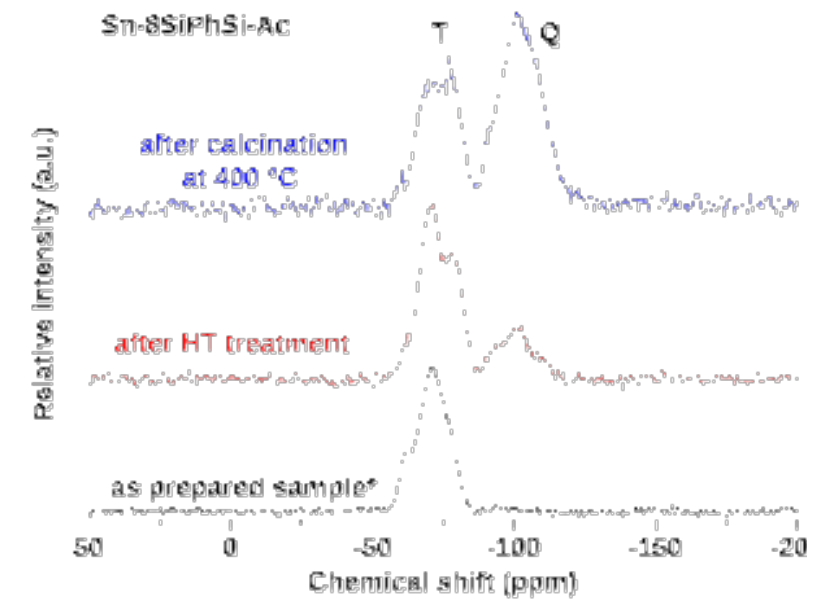

Fig. 11: ${ }^{29} \mathrm{Si}(\mathrm{CP}) \mathrm{MAS}$ NMR spectra of Sn-8SiPhSiAc after various treatment, ${ }^{*}$ denotes CPMAS spectrum.

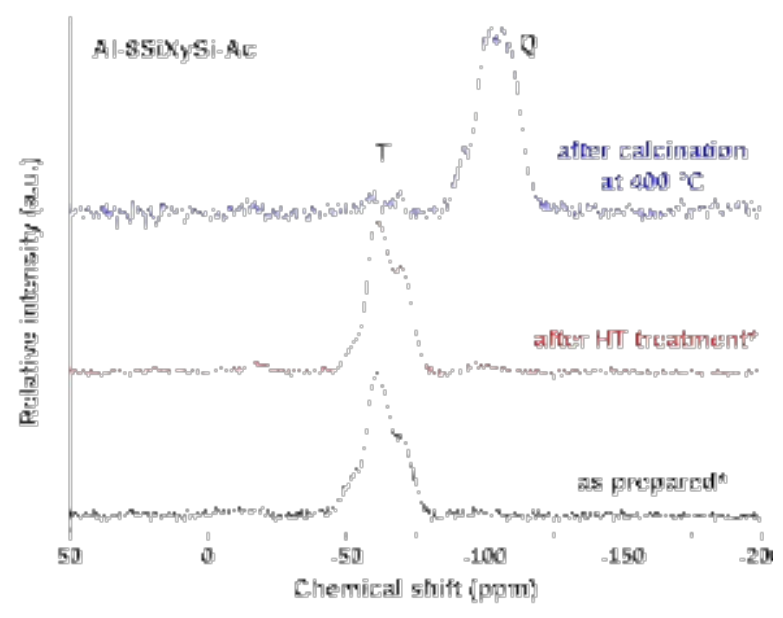

Fig. $12:{ }^{29} \mathrm{Si}(\mathrm{CP}) \mathrm{MAS}$ NMR spectra of Al-8SiXySiAc after various treatment, ${ }^{*}$ denotes CPMAS spectra.

\section{Catalysis}

As-prepared materials were tested as catalysts for the gas-phase ethanol dehydration in the temperature range between 205 and $400{ }^{\circ} \mathrm{C}$. The major products of catalytic reaction were ethylene and diethylether with carbon balances 95-100\%, other observed products in very low amounts were acetaldehyde, butenes, and butadiene (mainly at higher temperatures). Ethylene selectivity was high and similar for all samples prepared by NHSG (80-100\%) and was substantially higher than for commercial benchmarking catalyst (Silica alumina catalyst support grade 135), which was the only sample producing vast amounts of diethylether. 
The activity of hybrid Al samples was as follows: Al-8SiPhSi-Et > Al-8SiPhSi-Ac > Al-8SiXySi-Ac (Fig. 13). While higher activity was expected for samples prepared by acetamide elimination route (since they display high homogeneity of Si-Al mixing, and therefore putatively a high density of active sites for dehydration), one factor strongly impaired their performance: the strong binding of acetoxy- groups to aluminum causing high amounts of six-coordinated Al atoms (Fig. 6S).

Hybrid Al-containing samples were compared to pure inorganic catalyst prepared by the ether route (Al-16Si-Et). Similar high catalytic activity and ethylene yields were observed for hybrid Al8SiPhSi-Et and pure inorganic Al-16Si-Et. The commercial benchmarking silica-alumina exhibited slightly lower ethanol conversion than the best NHSG catalysts (Al-8SiPhSi-Et and Al-16Si-Et), however due to its low ethylene selectivity the ethylene yields were much lower.

Niobium samples exhibited lower catalytic activity than their Al analogues, as expected, due to generally lower acid strength of niobium silicates in comparison to aluminosilicates. ${ }^{50,51}$ In this case, more homogeneous sample (Nb-8SiPhSi-Ac) was more active than the less homogeneous catalyst (Nb-8SiPhSi-Et). The amount of acetoxy- groups in as-prepared Nb-8SiPhSi-Ac was much lower than in Al-8SiPhSi-Ac meaning that the affinity of acetoxy- groups to $\mathrm{Nb}$ atoms is not as high as it is in the case of aluminum.

It is important to make a connection between the HT stability and catalytic activity. Al-8SiXySi-Ac (xylylene bridged material) was the only hybrid catalyst which was able to reach high ethanol conversion without any observation of hydrolytic products (xylene); substantial release of benzene was observed for all phenylene bridged metallosilicates during catalytic experiments. The improved hydrothermal stability of xylylene bridges makes Al-8SiXySi-Ac promising as a starting point for further studies (e.g. lower loading of hydrophobic organic groups, etc.). 

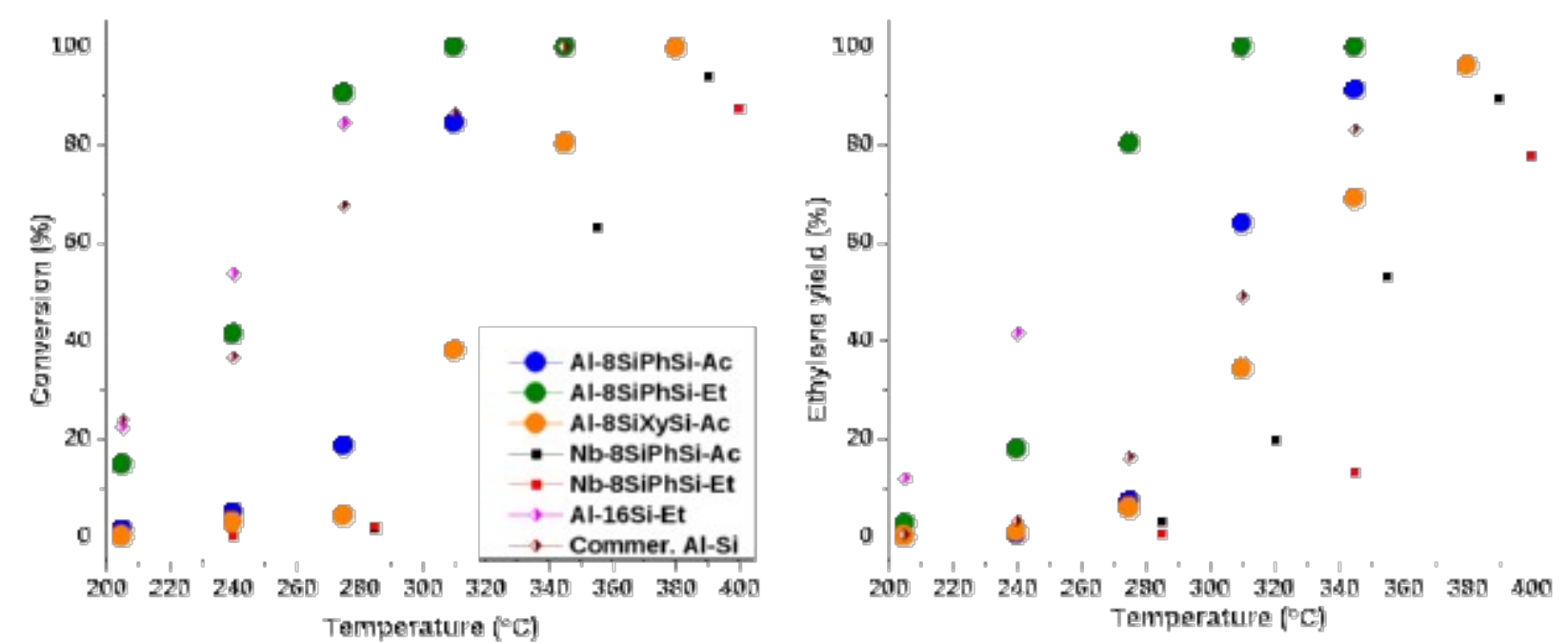

Fig. 13: Ethanol conversion and ethylene yield at different temperatures over hybrid metallosilicate catalysts.

\section{Conclusions}

In this paper we have shown that the hydrothermal gas-phase and thermal stability of hybrid phenylene bridged silica materials abruptly decrease upon metal introduction $(M=A l, N b, S n)$. The degradation of hybrid materials was reflected mainly in the hydrolysis of $\mathrm{Si}-\mathrm{C}$ bonds, which was followed by analysis of the effluent during HT stability test (amount of benzene evolved), by TGA, and by ${ }^{29} \mathrm{Si}$ MAS NMR. While the first hint of Si-C bonds cleavage was observed at $345{ }^{\circ} \mathrm{C}$ for metal free silica, extensive hydrolysis took place between 205 and $275{ }^{\circ} \mathrm{C}$ for hybrid metallosilicates. These results are complementary to previously reported data on hydrothermal stability of Al and Zr containing PMOs in boiling water where an improvement of stability was observed upon metal insertion. ${ }^{23,24}$ The gas phase HT stability of hybrid metallosilicates with aromatic groups was improved by the introduction of xylylene instead of phenylene bridges due to better stability of $\mathrm{Si}-\mathrm{C}\left(\mathrm{sp}^{2}\right)$ bonds.

Among the phenylene bridged metallosilicates studied, Sn-containing sample was the most stable. It was concluded that this is due to its electronegativity value, close to that of Si. Al and $\mathrm{Nb}$ differ more in electronegativity from $\mathrm{Si}$, thus introducing higher partial charges into the silsesquioxane networks and making them prone to attack by polar water molecules. Homogeneity of metal dispersion in hybrid silica (and consequently the number of Si-O-M 
bridges) was identified as the other key factor influencing stability. Influence of surface area, degree of condensation, and Brønsted acid sites was discarded.

In the gas-phase ethanol dehydration reaction, the most active hybrid catalysts made by NHSG markedly outperformed a commercial silica-alumina benchmark catalyst, mainly owing to a much higher ethene selectivity. Yet, a similar catalytic activity was also achieved with a purely inorganic catalyst prepared in the same way. Also, in terms of stability, we show that all phenylene bridged metallosilicates hydrolyzed in the course of the reaction and released benzene. The only stable hybrid metallosilicate able to achieve high ethanol conversion under

reaction conditions was the xylylene bridged aluminosilicate. It is suggested that this functionality should be investigated further - possibly with a lower degree of organic groups content - in a search for higher performance in ethanol dehydration.

\section{Acknowledgements}

A.S. acknowledges funding from the European Union's Horizon 2020 research and innovation programme under the Marie Skłodowska-Curie grant agreement No 751774. F.R.S.-F.N.R.S. is thanked for the acquisition of the physi-chemisorption equipment used here (project "EQP U.N030.18"). Authors acknowledge the 'Communauté française de Belgique' for the financial support through the ARC programme (15/20-069). This research used resources of the "Plateforme Technologique Physico-Chemical Characterization" - PC ${ }^{2}$, the SIAM platform (Synthesis, Irradiation \& Analysis of Materials) and the MORPH-IM platform (Morphology \& Imaging) located at the University of Namur. Authors thank L. Simonikova for performing ICPOES analyses. 


\section{References}

(1) Faustini, M.; Nicole, L.; Ruiz-Hitzky, E.; Sanchez, C. History of Organic-Inorganic Hybrid Materials: Prehistory, Art, Science, and Advanced Applications. Adv. Funct. Mater. 2018, 28 (27), 1704158. https://doi.org/10.1002/adfm.201704158.

(2) Esquivel, D.; Jiménez-Sanchidrián, C.; Romero-Salguero, F. J. Comparison of the Thermal and Hydrothermal Stabilities of Ethylene, Ethylidene, Phenylene and Biphenylene Bridged Periodic Mesoporous Organosilicas. Mater. Lett. 2011, 65 (10), 1460-1462. https://doi.org/10.1016/J.MATLET.2011.02.037.

(3) Esquivel, D.; Jiménez-Sanchidrián, C.; Romero-Salguero, F. J. Thermal Behaviour, Sulfonation and Catalytic Activity of Phenylene-Bridged Periodic Mesoporous Organosilicas. J. Mater. Chem. 2011, 21 (3), 724-733. https://doi.org/10.1039/C0JM02980G.

(4) Van Der Voort, P.; Esquivel, D.; De Canck, E.; Goethals, F.; Van Driessche, I.; Romero-Salguero, F. J. Periodic Mesoporous Organosilicas: From Simple to Complex Bridges; a Comprehensive Overview of Functions, Morphologies and Applications. Chem. Soc. Rev. 2013, 42 (9), 3913-3955. https://doi.org/10.1039/C2CS35222B.

(5) Dral, A. P.; Lievens, C.; Ten Elshof, J. E. Influence of Monomer Connectivity, Network Flexibility, and Hydrophobicity on the Hydrothermal Stability of Organosilicas. Langmuir 2017, 33 (22), 55275536. https://doi.org/10.1021/acs.langmuir.7b00971.

(6) Asefa, T.; MacLachlan, M. J.; Grondey, H.; Coombs, N.; Ozin, G. A. Metamorphic Channels in Periodic Mesoporous Methylenesilica. Angew. Chemie - Int. Ed. 2000, 39 (10), 1808-1811. https://doi.org/10.1002/(SICI)1521-3773(20000515)39:10<1808::AID-ANIE1808>3.0.CO;2-G.

(7) Bispo, C.; Ferreira, P.; Trouvé, A.; Batonneau-Gener, I.; Liu, F.; Jérôme, F.; Bion, N. Role of Acidity and Hydrophobicity in the Remarkable Catalytic Activity in Water of Sulfonic Acid-Functionalized Phenyl-PMO Materials. Catal. Today 2013, 218-219, 85-92.

https://doi.org/10.1016/j.cattod.2013.06.004.

(8) An, S.; Sun, Y.; Song, D.; Zhang, Q.; Guo, Y.; Shang, Q. Arenesulfonic Acid-Functionalized AlkylBridged Organosilica Hollow Nanospheres for Selective Esterification of Glycerol with Lauric Acid to Glycerol Mono- and Dilaurate. J. Catal. 2016, 342, 40-54.

https://doi.org/10.1016/j.jcat.2016.07.004.

(9) Melero, J. A.; van Grieken, R.; Morales, G. Advances in the Synthesis and Catalytic Applications of Organosulfonic-Functionalized Mesostructured Materials. Chem. Rev. 2006, 106 (9), 3790-3812. https://doi.org/10.1021/cr050994h.

(10) Manayil, J.; Lee, A.; Wilson, K. Functionalized Periodic Mesoporous Organosilicas: Tunable Hydrophobic Solid Acids for Biomass Conversion. Molecules 2019, 24 (2), 239. https://doi.org/10.3390/molecules24020239.

(11) Rác, B.; Hegyes, P.; Forgo, P.; Molnár, Á. Sulfonic Acid-Functionalized Phenylene-Bridged Periodic Mesoporous Organosilicas as Catalyst Materials. Appl. Catal. A Gen. 2006, 299 (1-2), 193-201. https://doi.org/10.1016/j.apcata.2005.10.026.

(12) Corma, A.; Díaz, U.; García, T.; Sastre, G.; Velty, A. Multifunctional Hybrid Organic-Inorganic Catalytic Materials with a Hierarchical System of Well-Defined Micro- and Mesopores. J. Am. Chem. Soc. 2010, 132 (42), 15011-15021. https://doi.org/10.1021/ja106272z.

(13) Millini, R.; Bellussi, G. Hybrid Organic-Inorganic Zeolites: Status and Perspectives. Catal. Sci. 
Technol. 2016, 6 (8), 2502-2527. https://doi.org/10.1039/c5cy02057c.

(14) Zanardi, S.; Parker, W. O.; Carati, A.; Botti, G.; Montanari, E. On the Thermal Behaviour of the Crystalline Hybrid Organic-Inorganic Aluminosilicate ECS-3. Microporous Mesoporous Mater. 2013, 172, 200-205. https://doi.org/10.1016/J.MICROMESO.2013.01.029.

(15) Xia, Y.; Wang, W.; Mokaya, R. Bifunctional Hybrid Mesoporous Organoaluminosilicates with Molecularly Ordered Ethylene Groups. J. Am. Chem. Soc. 2005, 127 (2), 790-798. https://doi.org/10.1021/ja0453230.

(16) Hughes, B. J.; Guilbaud, J.-B.; Allix, M.; Khimyak, Y. Z. Synthesis of Periodic Mesoporous Organosilicas with Incorporated Aluminium. J. Mater. Chem. 2005, 15 (44), 4728. https://doi.org/10.1039/b510700h.

(17) Melero, J. A.; Iglesias, J.; Arsuaga, J. M.; Sainz-Pardo, J.; de Frutos, P.; Blazquez, S. Synthesis and Catalytic Activity of Organic-Inorganic Hybrid Ti-SBA-15 Materials. J. Mater. Chem. 2007, 17 (4), 377-385. https://doi.org/10.1039/B610868G.

(18) Shylesh, S.; Samuel, P. P.; Singh, A. P. Synthesis of Hydrothermally Stable Aluminium-Containing Ethane-Silica Hybrid Mesoporous Materials Using Different Aluminium Sources. Microporous Mesoporous Mater. 2007, 100 (1-3), 250-258. https://doi.org/10.1016/J.MICROMESO.2006.11.010.

(19) Shylesh, S.; Samuel, P. P.; Singh, A. P. Cyclooctene Epoxidation over Mesoporous Organo Vanadosilicates Having - $\mathrm{CH} 2-\mathrm{CH} 2-$ Groups in the Frame Wall Positions. Catal. Commun. 2007, 8 (6), 894-898. https://doi.org/10.1016/J.CATCOM.2006.08.038.

(20) Guo, W.; Zhao, X. S. Room-Temperature Synthesis of Hydrothermally Stable Aluminum-Rich Periodic Mesoporous Organosilicas with Wormlike Pore Channels. Microporous Mesoporous Mater. 2005, 85 (1-2), 32-38. https://doi.org/10.1016/J.MICROMESO.2005.06.004.

(21) Yang, Q.; Li, Y.; Zhang, L.; Yang, J.; Liu, J.; Li, C. Hydrothermal Stability and Catalytic Activity of Aluminum-Containing Mesoporous Ethane-Silicas. J. Phys. Chem. B 2004, 108 (23), 7934-7937. https://doi.org/10.1021/jp0401240.

(22) Zhai, S.-R.; Park, S. S.; Park, M.; Ullah, M. H.; Ha, C.-S. Direct Synthesis of Zr-Containing Hybrid Periodic Mesoporous Organosilicas with Tunable Zirconium Content. Eur. J. Inorg. Chem. 2007, 2007 (35), 5480-5488. https://doi.org/10.1002/ejic.200700775.

(23) Sánchez-Vázquez, R.; Pirez, C.; Iglesias, J.; Wilson, K.; Lee, A. F.; Melero, J. A. Zr-Containing Hybrid Organic-Inorganic Mesoporous Materials: Hydrophobic Acid Catalysts for Biodiesel Production. ChemCatChem 2013, 5 (4), 994-1001. https://doi.org/10.1002/cctc.201200527.

(24) Yang, Q.; Yang, J.; Feng, Z.; Li, Y. Aluminium-Containing Mesoporous Benzene-Silicas with Crystallike Pore Wall Structure. J. Mater. Chem. 2005, 15 (39), 4268. https://doi.org/10.1039/b507437a.

(25) Gounder, R. Hydrophobic Microporous and Mesoporous Oxides as Brønsted and Lewis Acid Catalysts for Biomass Conversion in Liquid Water. Catal. Sci. Technol. 2014, 4 (9), 2877-2886. https://doi.org/10.1039/c4cy00712c.

(26) Angelici, C.; Weckhuysen, B. M.; Bruijnincx, P. C. A. Chemocatalytic Conversion of Ethanol into Butadiene and Other Bulk Chemicals. ChemSusChem 2013, 6 (9), 1595-1614. https://doi.org/10.1002/cssc.201300214.

(27) Styskalik, A.; Skoda, D.; Barnes, C. E.; Pinkas, J. The Power of Non-Hydrolytic Sol-Gel Chemistry: A Review. Catalysts 2017, 7 (6), 168. https://doi.org/10.3390/catal7060168. 
(28) Debecker, D. P.; Hulea, V.; Mutin, P. H. Mesoporous Mixed Oxide Catalysts via Non-Hydrolytic SolGel: A Review. Appl. Catal. A Gen. 2013, 451, 192-206.

https://doi.org/10.1016/j.apcata.2012.11.002.

(29) Debecker, D. P.; Mutin, P. H. Non-Hydrolytic Sol-Gel Routes to Heterogeneous Catalysts. Chem. Soc. Rev. 2012, 41 (9), 3624-3650. https://doi.org/10.1039/C2CS15330K.

(30) Katsoulis, D. E.; Kenney, M. E.; Vassilaras, P. E. Alternative Methods for the Synthesis of Organosilicon Compounds. WO2013137904A1, September 20, 2013.

(31) Motevalli, M.; Ou, D. L.; Sullivan, A. C. Synthesis and Characterization of Bis(Trichlorosilylmethyl)Benzenes. J. Organomet. Chem. 1993, 445 (1-2), 35-38. https://doi.org/10.1016/0022-328X(93)80183-C.

(32) Balthis, J. H.; Rochow, E. G.; White, D. G. Silicon Tetraacetate. In Inorganic Syntheses; Jr, J. C. B., Ed.; John Wiley \& Sons, Inc., 2007; pp 45-47.

(33) Styskalik, A.; Skoda, D.; Moravec, Z.; Babiak, M.; Barnes, C. E.; Pinkas, J. Control of Micro/Mesoporosity in Non-Hydrolytic Hybrid Silicophosphate Xerogels. J. Mater. Chem. A 2015, 3 (14), 7477-7487. https://doi.org/10.1039/c4ta06823h.

(34) Rouquerol, J.; Rouquerol, F.; Sing, K. S. W. Adsorption by Powders and Porous Solids; Academic Press, 1998.

(35) Lowell, S. Characterization of Porous Solids and Powders: Surface Area, Pore Size and Density; Springer, 2004.

(36) Shirley, D. A. High-Resolution X-Ray Photoemission Spectrum of the Valence Bands of Gold. Phys. Rev. B 1972, 5 (12), 4709-4714. https://doi.org/10.1103/PhysRevB.5.4709.

(37) Wagner, C. D.; Naumkin, A. V; Kraut-Vass, A.; Allison, J. W.; Powell, C. J.; Rumble Jr, J. R. NIST Standard Reference Database 20, Version 3.4 (Web Version). Natl. Inst. Stand. Technol. Gaithersburg, MD 2003, 20899.

(38) Skoda, D.; Styskalik, A.; Moravec, Z.; Bezdicka, P.; Babiak, M.; Klementova, M.; Barnes, C. E.; Pinkas, J. Novel Non-Hydrolytic Templated Sol-Gel Synthesis of Mesoporous Aluminosilicates and Their Use as Aminolysis Catalysts. RSC Adv. 2016, 6 (29). https://doi.org/10.1039/c5ra24563j.

(39) Lafond, V.; Mutin, P. H.; Vioux, A. Control of the Texture of Titania-Silica Mixed Oxides Prepared by Nonhydrolytic Sol-Gel. Chem. Mater. 2004, 16 (25), 5380-5386.

https://doi.org/10.1021/cm0490569.

(40) Debecker, D. P.; Bouchmella, K.; Stoyanova, M.; Rodemerck, U.; Gaigneaux, E. M.; Hubert Mutin, P. A Non-Hydrolytic Sol-Gel Route to Highly Active $\mathrm{MoO}_{3}-\mathrm{SiO}_{2}-\mathrm{Al}_{2} \mathrm{O}_{3}$ Metathesis Catalysts. Catal. Sci. Technol. 2012, 2 (6), 1157. https://doi.org/10.1039/c2cy00475e.

(41) Styskalik, A.; Skoda, D.; Pinkas, J.; Mathur, S. Non-Hydrolytic Synthesis of Titanosilicate Xerogels by Acetamide Elimination and Their Use as Epoxidation Catalysts. J. Sol-Gel Sci. Technol. 2012, 63 (3), 463-472. https://doi.org/10.1007/s10971-012-2808-5.

(42) Skoda, D.; Styskalik, A.; Moravec, Z.; Bezdicka, P.; Bursik, J.; Mutin, P. H.; Pinkas, J. Mesoporous $\mathrm{SnO}_{2}-\mathrm{SiO}_{2}$ and $\mathrm{Sn}$-Silica-Carbon Nanocomposites by Novel Non-Hydrolytic Templated Sol-Gel Synthesis. RSC Adv. 2016, 6 (73), 68739-68747. https://doi.org/10.1039/C6RA16556G.

(43) Skoda, D.; Styskalik, A.; Moravec, Z.; Bezdicka, P.; Pinkas, J. Templated Non-Hydrolytic Synthesis of Mesoporous Zirconium Silicates and Their Catalytic Properties. J. Mater. Sci. 2015, 50 (9), 3371- 
3382. https://doi.org/10.1007/s10853-015-8888-1.

(44) Styskalik, A.; Skoda, D.; Moravec, Z.; Abbott, J. G.; Barnes, C. E.; Pinkas, J. Synthesis of Homogeneous Silicophosphate Xerogels by Non-Hydrolytic Condensation Reactions. Microporous Mesoporous Mater. 2014, 197, 204-212.

(45) Deacon, G. B.; Phillips, R. J. Relationships between the Carbon-Oxygen Stretching Frequencies of Carboxylato Complexes and the Type of Carboxylate Coordination. Coord. Chem. Rev. 1980, 33 (3), 227-250. https://doi.org/10.1016/S0010-8545(00)80455-5.

(46) Nara, M.; Torii, H.; Tasumi, M. Correlation between the Vibrational Frequencies of the Carboxylate Group and the Types of Its Coordination to a Metal Ion: An Ab Initio Molecular Orbital Study. J. Phys. Chem. 1996, 100 (51), 19812-19817. https://doi.org/10.1021/jp9615924.

(47) Eaborn, C. Cleavages of Aryl-Silicon and Related Bonds by Electrophiles. J. Organomet. Chem. 1975, 100 (1), 43-57. https://doi.org/10.1016/S0022-328X(00)88933-0.

(48) Carr, R. T.; Neurock, M.; Iglesia, E. Catalytic Consequences of Acid Strength in the Conversion of Methanol to Dimethyl Ether. J. Catal. 2011, 278 (1), 78-93.

https://doi.org/10.1016/j.jcat.2010.11.017.

(49) Eaborn, C.; Stamper, J. G.; Seconi, G. Calculations of the Deprotonation Energies of MonoSubstituted Benzenes, and Their Significance for the Mechanisms of Base-Catalysed Cleavages of Aryl-Silicon and Aryl-Tin Bonds and Hydrogen-Exchange in Substituted Benzenes. J. Organomet. Chem. 1981, 204 (1), 27-45. https://doi.org/10.1016/S0022-328X(00)82469-9.

(50) Brandão, P.; Philippou, A.; Rocha, J.; Anderson, M. W. Dehydration of Alcohols by Microporous Niobium Silicate AM-11. Catal. Letters 2002, 80 (3-4), 99-102. https://doi.org/10.1023/A:1015444005961.

(51) Philippou, A.; Brandão, P.; Ghanbari-Siahkali, A.; Dwyer, J.; Rocha, J.; Anderson, M. W. Catalytic Studies of the Novel Microporous Niobium Silicate AM-11. Appl. Catal. A Gen. 2001, 207 (1-2), 229-238. https://doi.org/10.1016/S0926-860X(00)00623-2. 
Styskalik Debecker - Stability of hybrid metallosilicate - pre... (7.21 MiB) view on ChemRxiv • download file 


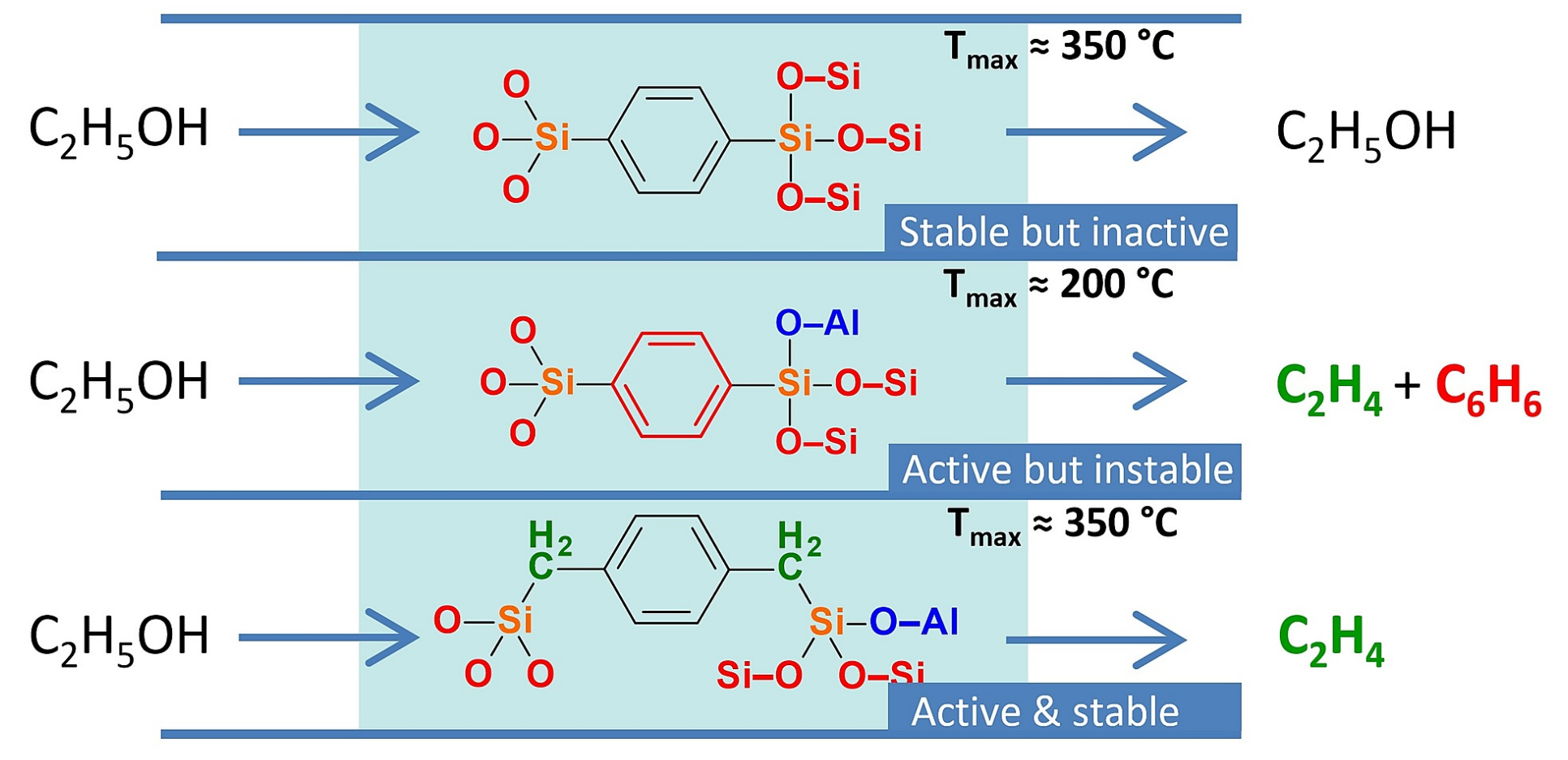




\section{Highly porous hybrid metallosilicate materials prepared by non-hydrolytic sol-gel: hydrothermal stability and catalytic properties in ethanol dehydration}

Ales Styskalik, a,b,c Imene Kordoghli, ${ }^{a}$ Claude Poleunis, ${ }^{a}$ Arnaud Delcorte, ${ }^{a}$ Carmela Aprile, ${ }^{d}$ Luca Fusaro, ${ }^{d}$ Damien P. Debecker*a

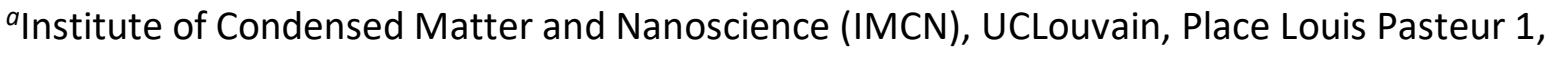
1348 Louvain-La-Neuve, Belgium

${ }^{b}$ Masaryk University, Department of Chemistry, Kotlarska 2, CZ-61137 Brno, Czech Republic

'Masaryk University, CEITEC MU, Kamenice 5, CZ-62500 Brno, Czech Republic

${ }^{d}$ Department of Chemistry, Unit of Nanomaterials Chemistry, University of Namur, 5000 Namur, Belgium

*Corresponding author (damien.debecker@uclouvain.be). 


\section{ABSTRACT}

Herein, we present novel phenylene- and xylylene-bridged silica and metallosilicate materials prepared by non-hydrolytic sol-gel. The hybrid silica are highly porous, chemically similar to periodic mesoporous organosilica (PMO), but amorphous. Analogous hybrid metallosilicates are obtained by directly incorporating $\mathrm{Al}, \mathrm{Nb}$, or $\mathrm{Sn}$ in the hybrid silica framework. Exhibiting open texture, surface acidity and tunable hydrophobicity, these materials are excellent candidates for catalytic alcohol dehydration reactions. The gas-phase hydrothermal and thermal stability of these materials is examined. While the hybrid silica is expectedly stable, a stark decrease in stability is observed for phenylene bridged silsesquioxanes upon metal introduction. The extent of the hydrolytic $\mathrm{Si}-\mathrm{C}\left(\mathrm{sp}^{2}\right)$ bond cleavage is quantitatively followed by ${ }^{29} \mathrm{Si} \mathrm{MAS} \mathrm{NMR,} \mathrm{TG}$ analysis, and GC-FID analysis of effluent coming from samples exposed to water vapor. Two important features affecting the hydrothermal and thermal stability are identified: (i) the homogeneity of metal dispersion within the silica matrix, and (ii) the electronegativity of the incorporated metal. The stability of hybrid metallosilicates is significantly improved by replacing the phenylene bridges with xylylene bridges, due to the presence of more stable $\mathrm{Si}-\mathrm{C}\left(\mathrm{sp}^{3}\right)$ bonds. Interestingly, the latter hybrid metallosilicate proves to be an active catalyst for the dehydration of ethanol to ethylene. Unlike the other hybrid materials presented here, it reaches high ethylene yields without undergoing degradation and deactivation.

Keywords: non-hydrolytic sol-gel, hybrid metallosilicate; hydrothermal stability; heterogeneous catalysis; ethanol dehydration 


\section{Introduction}

Hybrid organic-inorganic materials based on silica have recently attracted considerable attention because of their possible application in catalysis, adsorption, gas sensing, etc. ${ }^{1}$ The thermal stability of these materials depends on the nature of the organic group which is incorporated, e.g. ethylene bridges $\left(-\mathrm{CH}_{2} \mathrm{CH}_{2}-\right)$ are stable up to $300{ }^{\circ} \mathrm{C}$, methylene bridges $\left(-\mathrm{CH}_{2}-\right)$ up to $400{ }^{\circ} \mathrm{C}$, and phenylene bridges $\left(-\mathrm{C}_{6} \mathrm{H}_{4}-\right)$ up to $550{ }^{\circ} \mathrm{C}^{2-4}$ Hydrothermal $(\mathrm{HT})$ stability was tested thoroughly in batch (boiling water, various $\mathrm{pH}, \ldots$ ). ${ }^{5} \mathrm{HT}$ stability of periodic mesoporous organosilica networks (PMO) is generally evaluated by boiling the samples in water for up to several days and monitoring the mesostructural order by X-ray diffraction and is reported to be higher than for plain inorganic silica materials. ${ }^{5}$ Dral et al. suggested, that the improved hydrothermal stability of silica with organic bridges is caused by the higher connectivity of Si precursors and by the relaxation of strained siloxane bonds (due to the incorporation of flexible bridges) rather than by increased hydrophobicity. ${ }^{5}$

Hydrothermal stability tests in flow (gas phase) were reported only scarcely. It was shown that both methylene and phenylene bridged silica start to decompose at $400{ }^{\circ} \mathrm{C}$ in a flow of humid air. ${ }^{3,6}$ The degradation was observed by ${ }^{13} \mathrm{C}$ and ${ }^{29} \mathrm{Si}$ MAS NMR: methylene and phenylene bridges transformed to terminal methyl and phenyl groups, respectively, and Q signals of silicon appeared at the expense of T signals in ${ }^{29} \mathrm{Si} \mathrm{NMR} \mathrm{spectra.} \mathrm{It} \mathrm{was} \mathrm{concluded} \mathrm{that} \mathrm{the} \mathrm{hydrolysis} \mathrm{of} \mathrm{Si}-\mathrm{C}$ bonds is responsible for the degradation. ${ }^{3,6}$

The catalytic activity is brought to hybrid silica materials in most cases by grafting or cocondensation of organosilanes with reactive organic groups (e.g. benzene sulphonic acid, propyl sulphonic acid, propyl amine, metal porphyrin complexes, etc.). ${ }^{7-10}$ These materials were shown to be very promising catalysts in many liquid phase reactions performed in batch (e.g. transesterification of fatty acids, condensation of aldehydes with alcohols, alkylation of phenols, etc.). Hydrophobic catalysts exhibited improved performance, when bulky organic molecules need to be transformed, while water should be repelled. ${ }^{7,8}$ As a rare example of catalysis in gas phase, Rác et al. performed the alkylation of phenol by isopropyl alcohol over sulfonated phenylene bridged silica at $150{ }^{\circ} \mathrm{C}$; the studied materials were stable under these conditions. ${ }^{11}$ 
The incorporation of a catalytically active metal into the structure of hybrid silica-based materials is less common. On the first hand, a recent field of research is focused on hybrid zeolites. ${ }^{12,13}$ These materials require elaborate procedures and precise conditions and are relatively unstable, possibly owing to the rapid hydrolysis of $\mathrm{Si}-\mathrm{C}$ bonds by water molecules trapped in the pores of zeolites. ${ }^{14}$ On the second hand, amorphous hybrid metallosilicate are also attracting a lot of attention. $\mathrm{Al}, \mathrm{Ti}, \mathrm{V}$, and $\mathrm{Zr}$ were successfully incorporated in ethylene-bridged silica. ${ }^{15-22}$ Remarkably, these hybrid metallosilicates showed high hydrothermal stability in boiling water, even higher than corresponding metal-free mesoporous organosilica. Phenylene-bridged silicas with $\mathrm{Al}$ and $\mathrm{Zr}$ were also prepared and their stability in boiling water was again improved in comparison to plain hybrid silica. ${ }^{23,24}$ The generally accepted explanation of this phenomenon is based on a lower amount of $\mathrm{Si}-\mathrm{O}-\mathrm{Si}$ bonds (unstable in hot liquid water); these bridges are substituted by $\mathrm{Si}-\mathrm{O}-\mathrm{M}$ and $\mathrm{Si}-\mathrm{C}-\mathrm{Si}$ linkages in hybrid metallosilicates. ${ }^{25}$ Catalytic applications included epoxidation of cyclooctene, alkylation of 2,4-di-tert-butylphenol, methanolysis of palm oil, etc. ${ }^{17,19,21,23}$ However, to the best of our knowledge, the gas phase stability and catalytic performance of hybrid metallosilicates have not been assessed yet.

Here, our intention was to apply hybrid metallosilicates ( $\mathrm{Al}, \mathrm{Nb})$ in the gas phase dehydration of (bio)ethanol to (bio)ethylene - an important reaction in the perspective of integrated biorefineries ${ }^{26}$ - and to study the effect of hydrophobicity on catalytic performance. To do so, highly porous hybrid metallosilicate catalysts were prepared by non-hydrolytic sol-gel chemistry (NHSG). ${ }^{27-29}$ The introduction of organic groups and of the metal took place directly during the polycondensation reactions, using either the acetamide elimination route or the alkyl halide elimination route. Phenylene bridged materials were selected because of the well-known high thermal stability of this organic moiety. However after performing some preliminary catalytic experiments, it appeared that the (hydro)thermal stability of these materials was very low in comparison to reported data on hybrid silica without metal. ${ }^{3}$ Therefore we conducted a systematic study on the stability of hybrid metallosilicates. Using XPS and ToF-SIMS, we show here that the homogeneity of active metal sites distribution is the key property which dictates both the catalytic activity and the (hydro)thermal stability of these hybrid catalysts. We also propose a strategy to obtain more stable hybrid catalysts, active in ethanol dehydration. 


\section{Experimental}

General. All manipulations were performed under high vacuum or dry $\mathrm{N}_{2}$ atmospheres using Schlenk techniques or in a dry box with $\mathrm{H}_{2} \mathrm{O}$ and $\mathrm{O}_{2}$ levels below $1 \mathrm{ppm}$. Diisopropylether and benzene- $\mathrm{d}_{6}$ were dried over $\mathrm{Na}$ metal. $\mathrm{CH}_{2} \mathrm{Cl}_{2}$ was dried with $\mathrm{P}_{4} \mathrm{O}_{10}$. All solvents were distilled, and stored in a glovebox over molecular sieves. Aluminum chloride ( $\mathrm{ABCR}, \mathrm{AlCl} 3,99.999 \%$ ), niobium(V) chloride $\left(\mathrm{ABCR}, \mathrm{NbCl}_{5}, 99.99 \%\right)$, tris(dimethylamido)aluminum (Aldrich, $\left.\mathrm{Al}\left(\mathrm{NMe}_{2}\right)_{3}\right)$, niobium(V) ethoxide $\left(A B C R, \mathrm{Nb}(\mathrm{OEt})_{5}, 99.9 \% \text { ), tetrakis(diethylamido)tin (ABCR, Sn(Net }\right)_{4}, 99.99$ $\%)$, and 1,4-bis(triethoxysilyl)benzene (ABCR, $95 \%)$ were stored in a glovebox and used as received. Ethanol absolute (AnalaR NORMAPUR, $99.95 \%$ ), acetic acid anhydride (Acros, $99 \%$ ), $\alpha$, a'-dichloro-p-xylene ( $\mathrm{TCl} 98.0 \%$ ), tripropylamine ( $\mathrm{TCl}, 98 \%$ ), thionyl chloride (Roth, $98 \%$ ), and trichlorosilane (Sigma, 99 \%) were used as received. 1,4-Bis(trichlorosilyl)benzene was prepared from 1,4-bis(triethoxysilyl)benzene according to a patent. ${ }^{30}$ 1,4-Bis(trichlorosilylmethyl)benzene was prepared from trichlorosilane and $\alpha, \alpha^{\prime}$-dichloro-p-xylene according to literature. ${ }^{31} 1,4$ Bis(triacetoxysilyl)benzene and 1,4-bis(triacetoxysilylmethyl)benzene were prepared from their corresponding trichlorosilyl- derivatives by an action of acetic acid anhydride. ${ }^{32,33}$ Silica-alumina catalyst support (grade 135, SSA $=600 \mathrm{~m}^{2} \mathrm{~g}^{-1}, \mathrm{~V}_{\mathrm{P}}=0.76 \mathrm{~cm}^{3} \mathrm{~g}^{-1}, \mathrm{Si} / \mathrm{Al}$ ratio $\sim$ ) was purchased from Sigma-Aldrich.

Characterization. Transmission IR spectra $\left(4000-400 \mathrm{~cm}^{-1}\right)$ were recorded on a Bruker Equinox 55 spectrometer from $\mathrm{KBr}$ pellets or on a Bruker Alpha-Platinum ATR system. Thermal analysis (TG/DSC) was performed on a Mettler Toledo TGA/DSC 3+ apparatus in the stream of air $\left(100 \mathrm{~cm}^{3}\right.$ $\mathrm{min}^{-1}$ ) with a temperature ramp of $5^{\circ} \mathrm{C} \mathrm{min}^{-1}$ to $1000^{\circ} \mathrm{C}$, in an alumina crucible. Surface areas (SA) and pore volumes were determined by nitrogen adsorption at $77.4 \mathrm{~K}$ by volumetric techniques $^{34,35}$ on a Tristar 3000 instrument (Micromeritics, USA). Prior to measurement, the samples were degassed at $150{ }^{\circ} \mathrm{C}$ for at least $8 \mathrm{~h}$. The specific surface area was determined by the multipoint BET method with at least five data points with relative pressures between 0.05 and 0.30. Aluminum and silicon contents were determined on an ICP optical emission spectrometer iCAP 6500 Duo (Thermo, UK) equipped with a solid-state generator with a frequency of 27.12 $\mathrm{MHz}$ and a maximum power input of $1350 \mathrm{~W}$. The measurements of Al were performed at 167.0, 
308.2, and $309.2 \mathrm{~nm}$. For Si analysis, wavelengths 212.4 and $251.6 \mathrm{~nm}$ were used. Solution NMR spectra were recorded on a Bruker $300 \mathrm{MHz}$ NMR spectrometer at frequencies $299.8 \mathrm{MHz}$ for proton and $75.4 \mathrm{MHz}$ for carbon with deuterated solvents as the external lock. The proton and carbon NMR spectra were referenced to the residual proton signals or carbon resonances of benzene- $d_{6}$ (7.15 and $128.0 \mathrm{ppm}$, respectively). Solid-state ${ }^{27} \mathrm{Al},{ }^{29} \mathrm{Si}$, and ${ }^{13} \mathrm{C}$ solid state MAS NMR spectra were acquired on Bruker Avance-500 NMR spectrometer with a $4 \mathrm{~mm}$ CP-MAS Bruker probe at frequencies 99.4 MHz for silicon, 130.3 MHz for aluminum, and $125.8 \mathrm{MHz}$ for carbon. Magic angle spinning rates were $8 \mathrm{kHz}$ for ${ }^{29} \mathrm{Si}$ and ${ }^{13} \mathrm{C}(\mathrm{CP}) \mathrm{MAS}$ and $10 \mathrm{kHz}$ for ${ }^{27} \mathrm{Al} \mathrm{MAS}$ spectra. Quantitative ${ }^{29} \mathrm{Si}$ MAS spectra were recorded using a 300 s relaxation delay, a $3 \mu \mathrm{s}\left(90^{\circ}\right)$ excitation pulse, and a $52 \mathrm{~ms}$ acquisition time. Chemical shifts were referenced externally to ${ }^{29} \mathrm{Si} \delta[3-$ (trimethylsilyl)-1-propanesulfonic acid sodium salt (DSS)]: $1.53 \mathrm{ppm} ;{ }^{13} \mathrm{C} \delta[$ adamantane] 38.68 ppm; ${ }^{27} \mathrm{Al} \delta\left[\left[\mathrm{Al}\left(\mathrm{H}_{2} \mathrm{O}\right)_{6}\right]{ }^{3+}\right.$ (aq. solution)]: $0.0 \mathrm{ppm}$. The quantitative analysis of ${ }^{29} \mathrm{Si}$ MAS NMR spectra (exponential line broadening value $=0$ ) was performed as follows: (i) phase correction; (ii) baseline correction using least squares method; (iii) deconvolution of signals to $\mathrm{T}^{1}, \mathrm{~T}^{2}, \mathrm{~T}^{3}, \mathrm{Q}^{2}$, $\mathrm{Q}^{3}$, and $\mathrm{Q}^{4}$ peaks with $100 \%$ Gaussian shape until RMS deviation characterizing the fit between calculated and measured data was below 0.05; (iv) integration. The relative integrated areas of mentioned peaks were used to calculate the percentage of $\mathrm{T}$ sites and degree of condensation (sum of weighed ratios of peak areas vs. total peak area). X-Ray photoelectron spectroscopy (XPS) measurements were carried out on a SSI X probe spectrometer (model SSI 100, Surface Science Laboratories, Mountain View, CA) equipped with a monochromatized Al-Ka radiation (1486 eV). The sample powders, pressed in small stainless troughs of $4 \mathrm{~mm}$ diameter, were placed on an insulating home-made ceramic carousel. The pressure in the analysis chamber was around $10^{-6}$ Pa. The analyzed area was approximately $1.4 \mathrm{~mm}^{2}$ and the pass energy was set at $150 \mathrm{eV}$. The C1s peak of carbon has been fixed to $284.8 \mathrm{eV}$ to set the binding energy scale. ${ }^{36}$ Data treatment was performed with the CasaXPS program (Casa Software Ltd, UK) and spectra were decomposed with the least squares fitting routine provided by the software with a Gaussian/Lorentzian (85/15) product function and after baseline was subtracted. Time of flight secondary ion mass spectrometry (ToF-SIMS) analyses were carried out by using a TOF.SIMS ${ }^{5}$ instrument (IONTOF $\mathrm{GmbH}$, Münster, Germany). A pulsed $\mathrm{Bi}_{5}{ }^{+}$metal ion source was used to produce a primary beam 
using an acceleration voltage of $30 \mathrm{kV}$. An AC target current of $0.07 \mathrm{pA}$ with a bunched pulse width lower than 1 ns was used. Both positive and negative secondary ion species were analysed. For spectra, a raster of $128 \times 128$ data points over an area of $250 \times 250 \mu \mathrm{m}^{2}$ was used. The total primary ion beam dose for each analysed area was always kept below $5 \cdot 10^{10}$ ions $\mathrm{cm}^{-2}$, ensuring static conditions. Lateral resolution of $\sim 3 \mu \mathrm{m}$ and mass resolution $\mathrm{m} / \Delta \mathrm{m}>4000$ at $29 \mathrm{~m} / \mathrm{z}$ were maintained for positive and negative spectra acquisition. Charge compensation was done by interlaced electron flood gun $\left(E_{k}=20 \mathrm{eV}\right)$. All data analyses were carried out using the software supplied by the instrument manufacturer, SurfaceLab (version 6.5). Sample powders were pressed onto adhesive part of Post-it ${ }^{\circledR}$ papers.

Xerogel synthesis - acetamide elimination route. $4.565 \mathrm{~g}$ (9.383 mmol) 1,4bis(triacetoxysilyl)benzene was loaded in an autoclave in a glove box and dissolved in $25 \mathrm{~cm}^{3}$ $\mathrm{CH}_{2} \mathrm{Cl}_{2}$. In a separate vial, a $\mathrm{CH}_{2} \mathrm{Cl}_{2}$ solution $\left(5 \mathrm{~cm}^{3}\right)$ of $0.1931 \mathrm{~g}(1.213 \mathrm{mmol}) \mathrm{Al}\left(\mathrm{NMe}_{2}\right)_{3}$ was prepared and stirred at RT for $5 \mathrm{~min}$. The solution of $\mathrm{Al}\left(\mathrm{NMe}_{2}\right)_{3}$ was then added to the solution of the 1,4-bis(triacetoxysilyl)benzene with vigorous stirring (5 $\mathrm{min})$. The autoclave was sealed and kept in an oven at $130{ }^{\circ} \mathrm{C}$ for $72 \mathrm{hrs}$. During this time, gelation occurred. After cooling down, the autoclave was put back into the glovebox, opened and the gel was transferred into a Schlenk vessel. The gel was then dried under vacuum at $60^{\circ} \mathrm{C}$ overnight in order to remove the solvent and volatile condensation products ( $N, N^{\prime}$-dimethylacetamide and acetic acid anhydride). The resulting powder was annealed in flow of dry nitrogen at $250^{\circ} \mathrm{C}\left(1{ }^{\circ} \mathrm{C} \mathrm{min}-1,6 \mathrm{hrs}\right)$ yielding a pale brown xerogel sample (Al-8SiPhSi-Ac), where 8 is the molar ratio between the silicon precursor and the aluminum precursor (nominal $\mathrm{Si} / \mathrm{Al}$ ratio $=16$ ), "Ph" stands for the phenyl bridges and "Ac" stands for "acetamide elimination route". Samples Nb-8SiPhSi-Ac and Sn-8SiPhSi-Ac, were prepared using the same procedure, but with $\mathrm{Nb}(\mathrm{OEt})_{5}$ or $\mathrm{Sn}\left(\mathrm{NMe}_{2}\right)_{4}$ respectively as the metal precursors. As a benchmark, SiPhSi-Ac (plain, no metal) was prepared without addition of metal precursor. Also, one xylylene bridged sample was prepared with bis(triacetoxysilylmethyl)benzene instead of bis(triacetoxysilyl)benzene (Al-8SiXySi-Ac) (Table 1). Higher temperatures $\left(160-190^{\circ} \mathrm{C}\right)$ were needed for SiPhSi-Ac, Sn-8SiPhSi-Ac, and Al-8SiXySi-Ac in order to obtain gels. 
Table 1: Synthesis (amount on precursors introduced in the preparation) and characterization of phenylene bridged metallosilicate catalysts by XPS, and ICP-OES.

\begin{tabular}{lcccc}
\hline Sample & $\begin{array}{c}\mathrm{n}_{\mathrm{Si}} \\
(\mathrm{mmol})\end{array}$ & $\begin{array}{c}\mathrm{n}_{\mathrm{M}} \\
(\mathrm{mmol})\end{array}$ & $\begin{array}{c}\mathrm{n}_{\text {DIPE }} \\
(\mathrm{mmol})\end{array}$ & $\begin{array}{c}\text { Si/M ratio (-) } \\
\text { Theor }^{\mathrm{a}} / \mathrm{ICP} / \mathrm{XPS}\end{array}$ \\
\hline SiPhSi-Ac & 8.910 & - & - & $-/-/-$ \\
Al-8SiPhSi-Ac & 9.383 & 1.213 & - & $15.5 / 16.4 / 15.3$ \\
Al-8SiPhSi-Et & 9.386 & 1.170 & 30.00 & $16.0 / 15.6 / 18.3$ \\
Nb-8SiPhSi-Ac & 9.392 & 1.171 & - & $16.0 / 15.2 / 19.3$ \\
Nb-8SiPhSi-Et & 9.670 & 1.223 & 32.51 & $15.8 / 16.8 / 42.9$
\end{tabular}

aThe nominal $\mathrm{Si} / \mathrm{M}$ ratio is 16 ; the theoretical value presented in the table is the value calculated from the precise masses of reactants introduced during the synthesis $\left(n_{S i}, n_{M}, n_{D I P E}\right)$.

Xerogel synthesis - alkylhalide elimination (ether) route. 3.238 g (9.386 mmol) 1,4bis(trichlorosilyl)benzene was loaded in an autoclave in a glove box and dissolved in $25 \mathrm{~cm}^{3}$ $\mathrm{CH}_{2} \mathrm{Cl}_{2}$. In a separate vial, a $\mathrm{CH}_{2} \mathrm{Cl}_{2}$ solution $\left(5 \mathrm{~cm}^{3}\right)$ of $0.1560 \mathrm{~g}(1.170 \mathrm{mmol}) \mathrm{AlCl}_{3}$ and 3.065 (30.00 mmol) diisopropylether (DIPE) was prepared and stirred at RT for $15 \mathrm{~min}$. This solution was then added to the solution of the 1,4-bis(trichlorosilyl)benzene with vigorous stirring (5 $\mathrm{min}$ ). The autoclave was sealed and kept in an oven at $130{ }^{\circ} \mathrm{C}$ for $72 \mathrm{hrs}$ for gelation. After cooling down, the autoclave was put back into the glovebox, opened and the gel was transferred into a Schlenk vessel. The gel was then dried under vacuum at $60{ }^{\circ} \mathrm{C}$ overnight in order to remove the solvent and volatile condensation product (isopropylchloride). The resulting powder was annealed in flow of dry nitrogen at $250{ }^{\circ} \mathrm{C}\left(1{ }^{\circ} \mathrm{C} \mathrm{min}-1,6 \mathrm{hrs}\right)$ yielding a pale yellow xerogel (Al-8SiPhSi-Et, Et stands for ether route). Sample $\mathbf{N b - 8 S i P h S i - E t ~ w a s ~ p r e p a r e d ~ i n ~ t h e ~ s a m e ~ w a y ~ w i t h ~} \mathrm{NbCl}_{5}$ as the metal precursor. Pure inorganic benchmarking catalyst with the same Si/Al nominal ratio was prepared in the same way utilising $\mathrm{SiCl}_{4}$ and silicon precursor (Al-16Si-Et).

Spectroscopic characterization data (IR and NMR). Complete summary can be found in the supporting material to this manuscript (ESI). These may be accessed via journal website.

Hydrothermal stability test - dynamic. The xerogel samples (0.192 g, 0.20-0.40 mm particle size) were diluted with glass beads $(0.5-1 \mathrm{~mm})$ in order to keep the volume of the catalyst bed constant. 
The void space of the reactor was filled with silica beads. Stability testing was carried out by feeding $0.216 \mathrm{~g} \mathrm{~h}^{-1}$ of liquid $\mathrm{H}_{2} \mathrm{O}$ by means of $\mathrm{NE}-300$ syringe pump in $40 \mathrm{~cm}^{3} \mathrm{~min}^{-1}$ of $\mathrm{N}_{2}$ (10 mol\% of water in $\mathrm{N}_{2}$ ). The tests were carried out at atmospheric pressure, WHSV $=1.1 \mathrm{~h}^{-1}$. Temperature was varied stepwise in the range from 205 to $415^{\circ} \mathrm{C}$ by steps of $35^{\circ} \mathrm{C}$. One step consisted of (i) heating ramp and stabilization at the temperature $(21 \mathrm{~min})$ and (ii) steady temperature state (35 min). The analysis of effluent gas containing products of hydrolysis was carried out by VARIAN 3800 Gas Chromatograph (5 injections at each temperature) equipped with a flame ionization detector (FID) and a Cydex B column $(25 \mathrm{~m}$ long, internal diameter $0.22 \mathrm{~mm}$, film thickness $0.25 \mu \mathrm{m})$.

Hydrothermal stability test - static. The fixed bed reactor was prepared in the same way as for the dynamic test. $0.216 \mathrm{~g} \mathrm{~h}^{-1}$ of $\mathrm{H}_{2} \mathrm{O}$ in $40 \mathrm{~cm}^{3} \mathrm{~N}_{2}$ was fed for $24 \mathrm{~h}$, temperature of the bed was kept at $240^{\circ} \mathrm{C}$. Sample was collected after cooling down and analyzed by TGA, MAS NMR, and $\mathrm{N}_{2}$ physisorption.

Thermal stability was assessed simply by calcination of the xerogel at $400{ }^{\circ} \mathrm{C}$ in a flow of dry air (flow ca. $40 \mathrm{~cm}^{3} \mathrm{~min}^{-1}$, fixed bed, ramp $1^{\circ} \mathrm{C} \mathrm{min}^{-1}, 4 \mathrm{hrs}$ ) followed by analysis of calcined sample.

Catalytic dehydration of ethanol. The fixed bed reactor was prepared in the same way as for hydrothermal stability tests. $0.192 \mathrm{~g}$ of phenylene bridged samples was used; the mass of catalyst was normalized based on inorganic part in the case of samples with significantly different mass fraction of organic groups (Al-16Si-Et and Al-8SiXySi-Ac) so that the amount of metal is the same in all experiments. Catalytic testing was carried out by feeding $0.212 \mathrm{~g} \mathrm{~h}^{-1}$ of absolute ethanol by means of NE-300 syringe pump in a $\mathrm{N}_{2}$ flow of $40 \mathrm{~cm}^{3} \mathrm{~min}^{-1}\left(4.4 \mathrm{~mol} \%\right.$ of ethanol in $\left.\mathrm{N}_{2}\right)$. The tests were carried out at atmospheric pressure, WHSV $=1.1 \mathrm{~h}^{-1}$. Temperature was varied stepwise in the range from 205 to $415{ }^{\circ} \mathrm{C}$ by steps of $35^{\circ} \mathrm{C}$. One step consisted of (i) heating ramp and stabilization at the temperature $(21 \mathrm{~min})$ and (ii) steady temperature state (56 $\mathrm{min})$. The analysis of reactants and products in the effluent gas was carried out by VARIAN 3800 Gas Chromatograph (8 injections at each temperature) equipped with a flame ionization detector (FID) and a Cydex B column ( $25 \mathrm{~m}$ long, internal diameter $0.22 \mathrm{~mm}$, film thickness $0.25 \mu \mathrm{m}$ ). 


\section{Results and discussion}

\section{Phenylene bridged silsesquioxane (no metal) - synthesis, characterisation, and stability}

Sample without any metal (SiPhSi-Ac) was synthesized by NHSG as a benchmark (eq. 1) and annealed in flow of dry $\mathrm{N}_{2}\left(250^{\circ} \mathrm{C}\right)$. This material exhibited very similar structural properties to previously reported hybrid silica with phenylene bridges prepared by conventional hydrolytic solgel methods. ${ }^{39} \mathrm{Si}$ and ${ }^{13} \mathrm{C}$ CPMAS NMR spectra of the as prepared sample (annealed in $\mathrm{N}_{2}$ at $250^{\circ} \mathrm{C}$ ) confirmed presence of intact phenylene bridges (Fig. 1 and 1 S), only signals in the T region $\left(\mathrm{CSiO}_{3}\right)$ were observed for ${ }^{29} \mathrm{Si}$ species. These signals originate from the presence of 3 overlapping contributions centered at $-62,-72$, and $-78 \mathrm{ppm}$ which can be attributed respectively to $\mathrm{CSi}(\mathrm{OSi})(\mathrm{OH})_{2}(\mathrm{~T} 1), \mathrm{CSi}(\mathrm{OSi})_{2}(\mathrm{OH})(\mathrm{T} 2)$, and $\mathrm{CSi}(\mathrm{OSi})_{3}(\mathrm{~T} 3)$ species, where $\mathrm{C}$ stands for an aromatic carbon of a phenylene group bound to silicon. ${ }^{3}$ The absence of $Q^{n}$ signals (i.e. $\mathrm{Si}(\mathrm{OSi})_{n}(\mathrm{OH})_{4-n}$ species) in region comprised between -90 and -110 ppm is a clear indication of the good performance of our synthesis strategy. ${ }^{3}$ Thus we can state that sample SiPhSi-Ac indeed was a phenylene bridged silsesquioxane with no traces of $\mathrm{SiO}_{2}$. XPS further attested the presence of aromatic moieties: the intensity of C1s peak was very high and accompanied by a shake-up satellite peak characteristic for aromatic groups (Fig. 2S). Furthermore Si $2 p$ peak was shifted by $1 \mathrm{eV}$ from $\mathrm{SiO}_{2}{ }^{37}$ and NHSG-prepared purely inorganic sample (Fig. 3S) supporting the fact that the close $\mathrm{Si}$ environment can be described as $\mathrm{CSiO}_{3}$. Finally, surface area and pore volume reach $260 \mathrm{~m}^{2} \mathrm{~g}^{-1}$ and $0.079 \mathrm{~cm}^{3} \mathrm{~g}^{-1}$ respectively (Table 3), which is lower than previously reported phenylene bridged PMOs. ${ }^{2}$

Importantly TGA showed high thermal stability of SiPhSi-Ac (up to $500^{\circ} \mathrm{C}$ ) similar to reported data (Fig. 2). ${ }^{3}$ The mass loss due to the burning of phenylene bridges $\left(500-725^{\circ} \mathrm{C}\right)$ accounted for $38 \%$ of the mass which is in a good agreement with the theoretical value (33 \%, Fig. 2). This mass loss is slightly higher than expected presumably due to the presence of some unreacted acetoxygroups, which burn at the same temperature range as phenylene bridges. For the sample calcined at $400{ }^{\circ} \mathrm{C}$ in dry air, the mass loss was virtually the same (35\%), showing that the organic species survived the calcination step. However, a partial cleavage of $\mathrm{Si}-\mathrm{C}$ bonds was observed by ${ }^{29} \mathrm{Si}$ MAS NMR spectroscopy, as evidenced by the presence of a combination of $Q^{2}, Q^{3}$, and $Q^{4}$ sites at -93 , -100 , and -109 ppm, respectively, with an overall proportion of Q sites equal to $25 \%$ (Fig. 1, Table 
2). Since the mass loss did not change after calcination, it can be concluded, that the predominant reaction is a conversion of bridging phenylene moieties to terminal phenyl groups (eq. 2). This transformation has been already reported ${ }^{3}$ and is here reflected in the ${ }^{13} \mathrm{C} C P$ MAS spectrum where a shoulder of the main peak (134 ppm) characteristic for a terminal phenyl group emerged at $128 \mathrm{ppm}$ (Fig. 1S). ${ }^{3}$ Water necessary for this hydrolytic reaction (eq. 2 ) is either adsorbed in the pores or comes from the oxidation of residual organic groups. Thus, the data presented above confirm that NHSG preparation led to phenylene bridged silsesquioxane materials exhibiting similar thermal stability as conventional hydrolytic sol-gel technique. ${ }^{3}$

$$
(\mathrm{AcO})_{3} \mathrm{Si}-\mathrm{C}_{6} \mathrm{H}_{4}-\mathrm{Si}(\mathrm{OAC})_{3} \rightarrow \mathrm{O}_{1.5} \mathrm{Si}_{-} \mathrm{C}_{6} \mathrm{H}_{4}-\mathrm{SiO}_{1.5}+3 \mathrm{AcOAC}
$$

Table 2: Evaluation of thermal and hydrothermal stability by TGA and ${ }^{29} \mathrm{Si}$ MAS NMR.

\begin{tabular}{|c|c|c|c|c|c|c|}
\hline \multirow[t]{2}{*}{ Sample } & \multicolumn{2}{|c|}{$\begin{array}{l}\text { As-prepared (annealed } \\
\text { at } 250{ }^{\circ} \mathrm{C}, \text { dry N} \mathrm{N}_{2} \text { ) }\end{array}$} & \multicolumn{2}{|c|}{$\begin{array}{c}\text { Calcined at } 400{ }^{\circ} \mathrm{C} \text {, dry } \\
\text { air }\end{array}$} & \multicolumn{2}{|c|}{$\begin{array}{c}\text { After static HT stability } \\
\text { test }\end{array}$} \\
\hline & $\mathrm{ML}(\%)^{\mathrm{a}}$ & $\begin{array}{l}\text { Proportion of } \\
\text { T sites }(\%)^{b}\end{array}$ & $\mathrm{ML}(\%)^{\mathrm{a}}$ & $\begin{array}{l}\text { Proportion of } \\
\text { T sites }(\%)^{b}\end{array}$ & $\mathrm{ML}(\%)^{\mathrm{a}}$ & $\begin{array}{l}\text { Proportion of } \\
\text { T sites }(\%)^{b}\end{array}$ \\
\hline SiPhSi-Ac & 38 & $100^{c}$ & 35 & 75 & 36 & 100 \\
\hline Al-8SiPhSi-Ac & 42 & 79 & 22 & 0 & 28 & 22 \\
\hline Al-8SiPhSi-Et & 34 & 40 & 19 & 0 & 31 & 12 \\
\hline $\mathrm{Nb}-8 \mathrm{SiPhSi}-\mathrm{Ac}$ & 38 & 73 & 15 & 10 & 30 & 45 \\
\hline Nb-8SiPhSi-Et & 33 & 78 & 21 & 21 & 28 & 58 \\
\hline
\end{tabular}

Table 3: Surface area evolution with different sample treatment

\begin{tabular}{|l|c|c|c|}
\hline Sample & $\begin{array}{c}\text { As-prepared (annealed } \\
\left.\text { at } 250{ }^{\circ} \mathrm{C}, \mathrm{dry} \mathrm{N}_{2}\right)\end{array}$ & Calcined at $400^{\circ} \mathrm{C}$, dry air & After static HT stability test \\
\hline
\end{tabular}




\begin{tabular}{|l|c|c|c|c|c|c|c|c|c|}
\hline & $\begin{array}{c}\mathrm{SA}_{\text {BET }} \\
\left(\mathrm{m}^{2} \mathrm{~g}^{-1}\right)\end{array}$ & $\begin{array}{c}\mathrm{V}_{\text {total }} \\
\left(\mathrm{cm}^{3} \mathrm{~g}^{-1}\right)\end{array}$ & $\begin{array}{c}\mathrm{D} \\
(\mathrm{nm})\end{array}$ & $\begin{array}{c}\mathrm{SA}_{\mathrm{BET}} \\
\left(\mathrm{m}^{2} \mathrm{~g}^{-1}\right)\end{array}$ & $\begin{array}{c}\mathrm{V}_{\text {total }} \\
\left(\mathrm{cm}^{3} \mathrm{~g}^{-1}\right)\end{array}$ & $\begin{array}{c}\mathrm{D} \\
(\mathrm{nm})\end{array}$ & $\begin{array}{c}\mathrm{SA}_{\mathrm{BET}} \\
\left(\mathrm{m}^{2} \mathrm{~g}^{-1}\right)\end{array}$ & $\begin{array}{c}\mathrm{V}_{\text {total }} \\
\left(\mathrm{cm}^{3} \mathrm{~g}^{-1}\right)\end{array}$ & $\begin{array}{c}\mathrm{D} \\
(\mathrm{nm})\end{array}$ \\
\hline SiPhSi-Ac & 260 & 0.079 & 1.2 & $<10$ & - & - & 156 & 0.066 & 1.7 \\
\hline Al-8SiPhSi-Ac & 54 & 0.015 & 1.1 & 380 & 0.12 & 1.3 & $<10$ & - & - \\
\hline Al-8SiPhSi-Et & 460 & 1.0 & 9.8 & 430 & 1.27 & 12 & 320 & 0.47 & 8.3 \\
\hline Nb-8SiPhSi-Ac & 380 & 0.14 & 1.5 & 130 & 0.036 & 1.1 & $<10$ & - & - \\
\hline Nb-8SiPhSi-Et & 880 & 1.40 & 7.4 & 650 & 0.49 & 6.2 & 710 & 0.76 & 6.7 \\
\hline
\end{tabular}

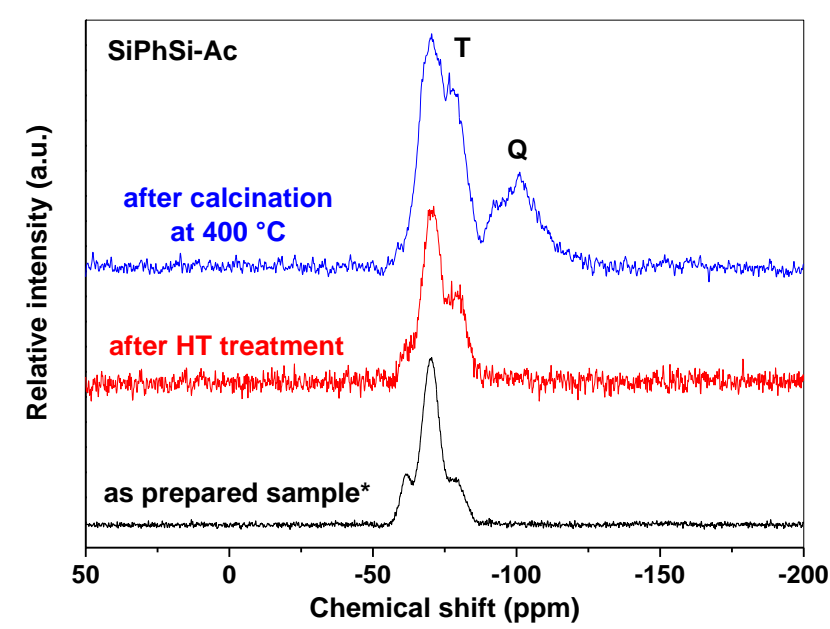

Fig. 1: ${ }^{29} \mathrm{Si}(\mathrm{CP}) \mathrm{MAS}$ NMR spectra of SiPhSi-Ac after various treatment, *denotes CPMAS spectrum.

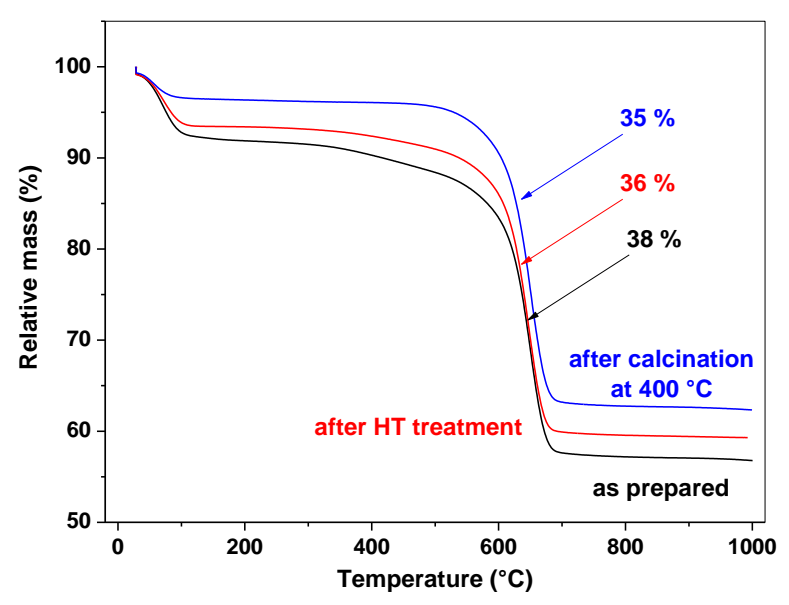

Fig. 2: TG curves of SiPhSi-Ac after various treatment.

$$
\begin{aligned}
& \mathrm{O}_{1.5} \mathrm{Si}-\mathrm{C}_{6} \mathrm{H}_{4}-\mathrm{SiO}_{1.5}+\mathrm{H}_{2} \mathrm{O} \rightarrow \mathrm{O}_{1.5} \mathrm{Si}-\mathrm{C}_{6} \mathrm{H}_{5}+\mathrm{HO}-\mathrm{SiO}_{1.5} \\
& 0_{1.5} \mathrm{Si}-\mathrm{C}_{6} \mathrm{H}_{5}+\mathrm{H}_{2} \mathrm{O} \rightarrow \mathrm{O}_{1.5} \mathrm{Si}-\mathrm{OH}+\mathrm{C}_{6} \mathrm{H}_{6}
\end{aligned}
$$

Since water is unavoidably one of the products of ethanol dehydration, we aimed for studying the gas phase hydrothermal stability of prepared materials in more detail. Two types of tests were performed. In the first test (dynamic), the sample was exposed to a wet $\mathrm{N}_{2}$ flow (10 mol\% of water) in a fixed bed reactor, the temperature was raised from 205 to $415^{\circ} \mathrm{C}$ in steps of $35^{\circ} \mathrm{C}$. The product of the hydrolysis (benzene; coming from the hydrolysis of both $\mathrm{Si}-\mathrm{C}$ bonds of phenylene bridges in hybrid silica as presented in eq. 2 and 3) was observed and quantified by GC-FID (Fig. 3). Thus, we were able to identify the temperature at which the hydrolysis starts to occur. The second hydrothermal stability test (static) was performed to probe the long term 
stability. The samples were placed in the same humid flow at $240{ }^{\circ} \mathrm{C}$ (typical reaction temperature for EtOH dehydration) for $24 \mathrm{hrs}$. The treated catalyst was then characterized.

Sample SiPhSi-Ac showed high hydrothermal stability. It started to release benzene only from $345^{\circ} \mathrm{C}$ during the dynamic $\mathrm{HT}$ treatment (Fig. 3). Note, however, that this temperature is much lower than the first signs of degradation observed in dry air (see TGA results in Fig. 2). Long-term stability at $240{ }^{\circ} \mathrm{C}$ in humid atmosphere was excellent: the ${ }^{29} \mathrm{Si}$ MAS NMR spectrum did not exhibit any hint of $Q$ signals and mass loss remained virtually same as compared to the fresh catalyst (Fig 1 and 2).

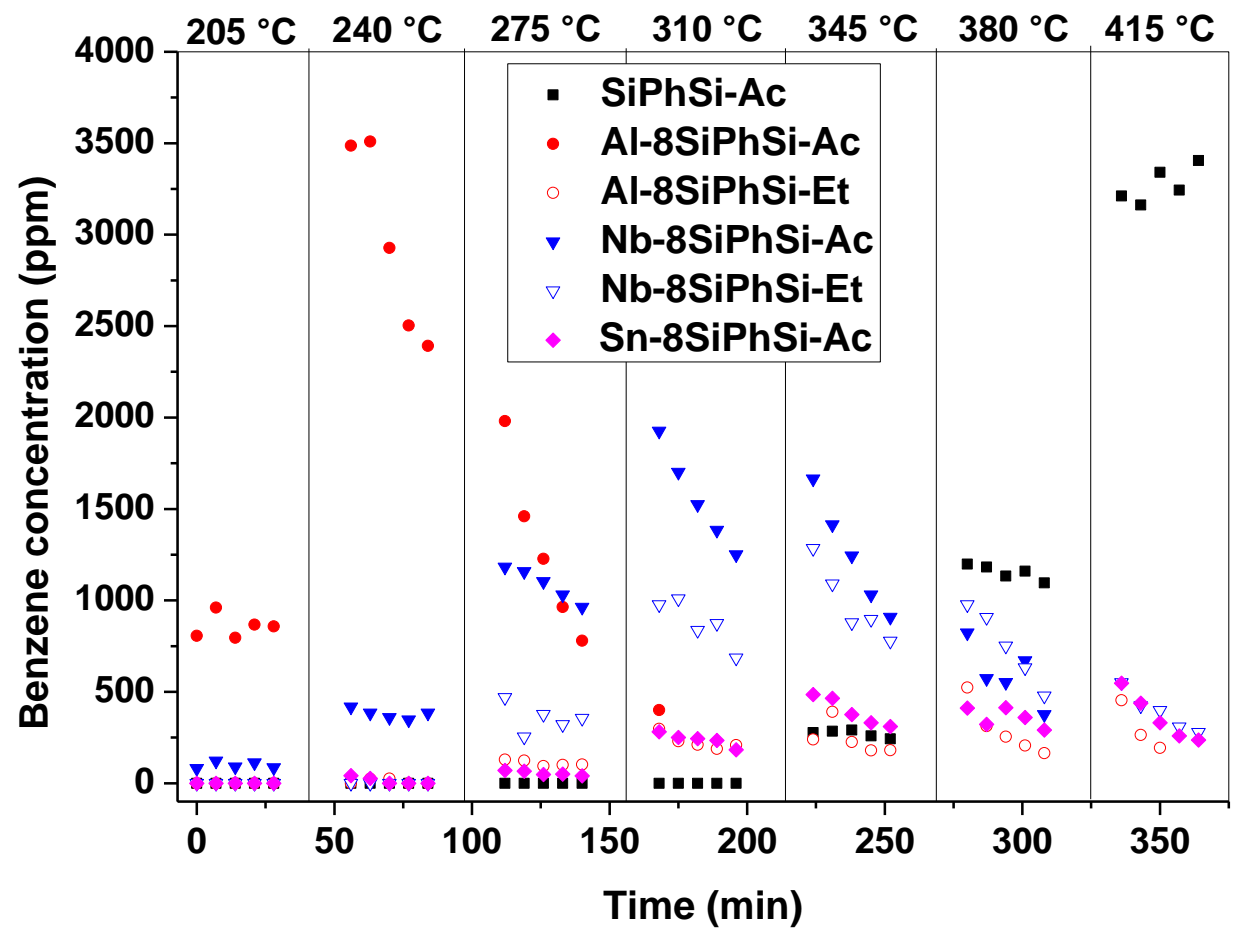

Fig. 3: Benzene release from phenylene bridged metallosilicate catalysts during dynamic HT stability test.

\section{Phenylene bridged metallosilicates - synthesis, characterization, and stability}

Hybrid metallosilicates were prepared by NHSG. This technique is known to yield highly porous mixed metal oxides. ${ }^{33,38-40}$ Another advantage is that the kinetics of condensation of different metal precursors are levelled off in NHSG (as compared to classical hydrolytic sol-gel) and therefore it allows for a good control over the homogeneity of the formed mixed metal oxide. ${ }^{27-}$ 29 Here, two NHSG pathways were applied: the acetamide elimination route ${ }^{38,41}$ and the 
alkylhalide elimination (ether) route ${ }^{39,40}$ (eq. 4 and 5). Reactions were performed at $130{ }^{\circ} \mathrm{C}$ in autoclaves in order to get high condensation degrees and obtain gels. This was necessary mainly in the case of acetamide elimination route, where homocondesation of two acetoxy- groups resulting in acetic acid anhydride and $\equiv \mathrm{Si}-\mathrm{O}-\mathrm{Si} \equiv$ bridge formation (eq. 4 ) was reported to occur slowly at lower temperatures. ${ }^{42,43}$

IR (ESI), ${ }^{13} \mathrm{C}$ (Fig. 4S) and ${ }^{29}$ Si NMR (Fig. 4) spectra and XPS (Fig. 3S and 5S) confirmed presence of phenylene bridges in the hybrid metallosicate materials, similar to SiPhSi-Ac. In XP spectra phenylene bridged metallosilicates exhibited very intense $C$ 1s peak with a shake-up satellite peak characteristic for aromatic groups (Fig. 5S). The position of Si $2 \mathrm{p}$ peak was shifted again by $1 \mathrm{eV}$ from $\mathrm{SiO}_{2}$ and NHSG-prepared purely inorganic benchmark. ${ }^{37}$ However in this case some Si-C bond cleavage already occurred in the as-prepared samples as reflected by the larger peak width (higher FWHM) of Si 2p peak in XP spectra (Fig. 3S). Quantification of this cleavage was performed by ${ }^{29} \mathrm{Si}$ MAS NMR and discussed in detail (see below).

Textural properties (Table 3 ) of prepared materials strongly depended on the chosen synthetic route. While materials prepared by the acetamide elimination route were microporous with surface areas, pore volumes and average pore diameters up to $380 \mathrm{~m}^{2} \mathrm{~g}^{-1}, 0.14 \mathrm{~cm}^{3} \mathrm{~g}^{-1}$, and $1.5 \mathrm{~nm}$, respectively, materials synthesized by the ether route were mesoporous and reached higher surface areas and pore volumes (up to $880 \mathrm{~m}^{2} \mathrm{~g}^{-1}$ and $1.4 \mathrm{~cm}^{3} \mathrm{~g}^{-1}$, respectively). All samples were XRD amorphous.

$$
\mathrm{Al}\left(\mathrm{NMe}_{2}\right)_{3}+8(\mathrm{AcO})_{3} \mathrm{Si}-\mathrm{C}_{6} \mathrm{H}_{4}-\mathrm{Si}(\mathrm{OAc})_{3} \rightarrow \frac{1}{2} \mathrm{Al}_{2} \mathrm{O}_{3} \cdot 8 \mathrm{O}_{1.5} \mathrm{Si}-\mathrm{C}_{6} \mathrm{H}_{4}-\mathrm{SiO}_{1.5}+3 \mathrm{AcNMe}_{2}+22.5 \mathrm{AcOAc}
$$

$$
\mathrm{AlCl}_{3}+8 \mathrm{Cl}_{3} \mathrm{Si}-\mathrm{C}_{6} \mathrm{H}_{4}-\mathrm{SiCl}_{3}+25.5^{i} \mathrm{PrO}{ }^{i} \mathrm{Pr} \rightarrow \frac{1 / 2}{2} \mathrm{Al}_{2} \mathrm{O}_{3} \cdot 8 \mathrm{O}_{1.5} \mathrm{Si}-\mathrm{C}_{6} \mathrm{H}_{4}-\mathrm{SiO}_{1.5}+51^{i} \mathrm{PrCl}
$$

The stability of phenylene bridges was found to be markedly affected by metal introduction. As prepared Al-8SiPhSi-Ac (annealed at $250^{\circ} \mathrm{C}$ in dry $\mathrm{N}_{2}$ ) already displayed an extensive cleavage of Si-C bonds (T site proportion was only $79 \%$, compare to $100 \%$ for SiPhSi-Ac, Fig. 4). It is worth noting that mass loss of as prepared Al-8SiPhSi-Ac was higher than the expected value (42\% vs. $32 \%)$. It can be explained by the presence of residual acetoxy-groups, which is clearly reflected 
in IR and NMR spectra (bands representing asymmetric valence COO vibration in IR spectra at 1535 and $1710 \mathrm{~cm}^{-1}$, signals of methyl and carboxyl groups in ${ }^{13} \mathrm{C}$ CPMAS NMR spectra at 21, and 169-177 ppm, respectively; Fig. 4S). The presence of broad signals in ${ }^{13} \mathrm{C}$ CPMAS NMR spectra in the chemical shift range comprised between 169 and 177 ppm suggests that some of the acetoxygroups are in the bidentate form. ${ }^{44}$ This assumption can be further supported by the observation of two sets of bands originating from symmetrical and asymmetrical vibrations of $\mathrm{COO}$ groups in IR spectra (ESI). ${ }^{45,46}$ The bidentate acetoxy-groups are coordinated to the aluminum atoms and make them predominantly six-coordinated. ${ }^{27} \mathrm{AI}$ MAS NMR spectra corroborate this hypothesis; a major contribution comes from $\mathrm{AlO}_{6}$ species in as-prepared sample, while signal for $\mathrm{AlO}_{4}$ moieties becomes the most intense peak after calcination at $400{ }^{\circ} \mathrm{C}$ (when most of the acetoxy-groups is burned, Fig. 6S.). As another consequence, these bidentate acetoxy-groups are very stable and lower the catalytic activity of Al-8SiPhSi-Ac (see below).

TG analysis showed that thermal decomposition of Al-8SiPhSi-Ac started already at ca. $400{ }^{\circ} \mathrm{C}$ in dry air (Fig. 5), ca. $100{ }^{\circ} \mathrm{C}$ earlier than for metal-free SiPhSi-Ac. ${ }^{29}$ Si MAS NMR analysis confirmed that the damage to the material was deeply progressing with thermal treatment: no T signal was observed after calcination at $400{ }^{\circ} \mathrm{C}$ (only $\mathrm{Q}$ signal coming from $\mathrm{SiO}_{4}$ species between -90 and -120 ppm, Fig. 4). Yet, the mass loss of calcined sample during TGA was still relatively high (22 \%, Fig. 5, Table 2). The possible contribution to high mass loss is coke formation by carbonization of phenylene bridges and residual acetoxy-groups; sample after calcination at $400{ }^{\circ} \mathrm{C}$ is black.

The dynamic HT stability test allowed to highlight an important release of benzene already at 205 ${ }^{\circ} \mathrm{C}$ for sample Al-8SiPhSi-Ac (Fig. 3). ${ }^{29} \mathrm{Si}$ MAS NMR spectra further evidenced the very low hydrothermal stability of Al-8SiPhSi-Ac: T sites proportion after static HT stability test was only $22 \%$. (Table 2, Fig. 4). Moreover the amount of organic groups after static HT treatment decreased significantly in comparison to as-prepared sample as can be deduced from TG analyses (Fig. 5, Table 2). Similar to what is observed with the calcined sample, the mass loss after static HT stability test was higher than expected on the basis of ${ }^{29} \mathrm{Si} \mathrm{MAS} \mathrm{NMR} \mathrm{spectra.} \mathrm{It} \mathrm{is} \mathrm{probably}$ caused by carbonization of organic groups. Finally, the poor HT stability was observed also by a loss of porosity: the solid was nonporous after static HT treatment (Table 3). 


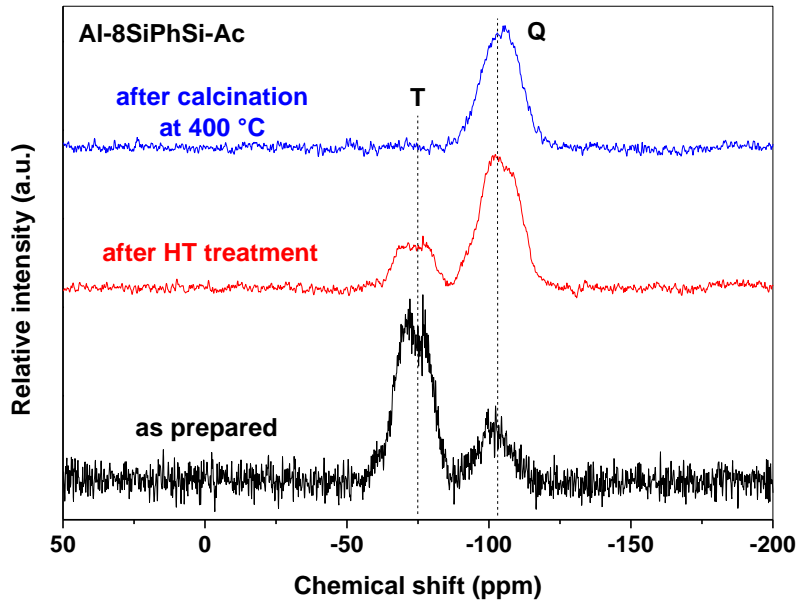

Fig. 4: ${ }^{29}$ Si MAS NMR spectra of Al-8SiPhSi-Ac after various treatment.

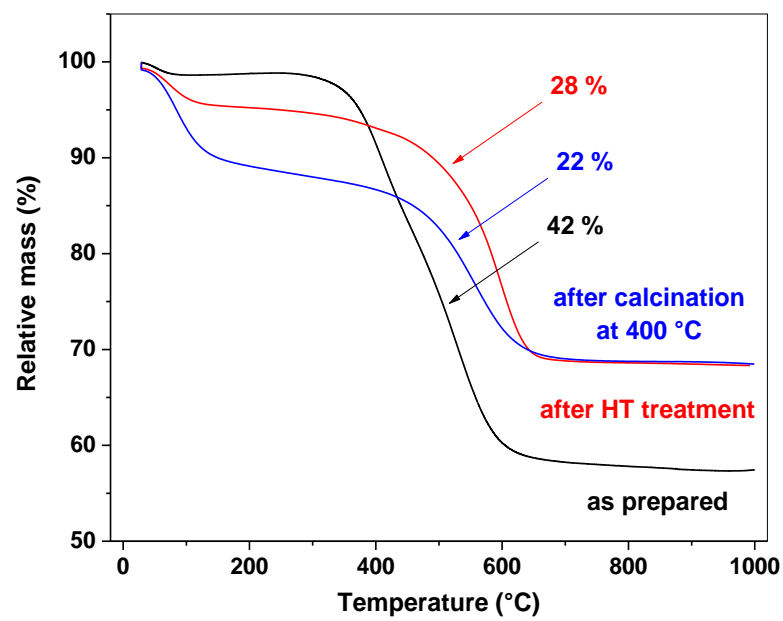

Fig. 5: TG curves of Al-8SiPhSi-Ac after various treatment.

The sample with identical composition prepared by the ether route (Al-8SiPhSi-Et) displayed also a significant stability drop. Similar to Al-8SiPhSi-Ac the as-prepared sample Al-SiPhSi-Et (annealed at $250{ }^{\circ} \mathrm{C}$ in dry $\mathrm{N}_{2}$ ) exhibited considerable $\mathrm{Si}-\mathrm{C}$ bond cleavage based on ${ }^{29} \mathrm{Si}$ MAS NMR spectra, $\mathrm{T}$ site proportion was $40 \%$ (Fig. 6, Table 2). However most of the organic groups were preserved within Al-SiPhSi-Et - not as phenylene bridges, but as terminal phenyl moieties - these were observed as a very intense peak in ${ }^{13} \mathrm{C}$ NMR spectrum (Fig. 4S). Moreover the TGA mass loss was close to the theoretical value ( $34 \%$ vs. $32 \%$, Fig. 7) and the as-prepared sample was only slightly yellowish indicating the absence of coke coming from carbonization of organic groups.

Thermal stability of Al-SiPhSi-Et was very poor: no T signal was observed in ${ }^{29} \mathrm{Si}$ MAS NMR spectra after calcination at $400^{\circ} \mathrm{C}$ (only Q signal, Fig. 6). Mass loss exhibited by calcined sample (19 \%) can be thus ascribed to coke formed by carbonization of phenylene and phenyl groups (sample after calcination at $400^{\circ} \mathrm{C}$ is black, Fig. 7, Table 2).

Interestingly, Al-8SiPhSi-Et displayed somewhat higher stability during dynamic HT treatment in comparison to Al-8SiPhSi-Ac. While the sample from acetamide elimination route (Al-8SiPhSi-Ac) released benzene already at $205{ }^{\circ} \mathrm{C}$, the sample from ether route (Al-8SiPhSi-Et) showed first hints of benzene at $275{ }^{\circ} \mathrm{C}$ (Fig. 3). Sample Al-SiPhSi-Et showed similar extensive Si-C bond cleavage to Al-8SiPhSi-Ac after static hydrothermal stability test at $240{ }^{\circ} \mathrm{C}$; $\mathrm{T}$ site proportion in ${ }^{29} \mathrm{Si}$ MAS NMR spectra dropped to $12 \%$ (Table 2). Textural properties were deteriorated after 
static HT treatment, surface area and pore volume dropped by 29 and $54 \%$, respectively (Table 3). Unlike Al-8SiPhSi-Ac, sample Al-SiPhSi-Et retained some porosity again pointing at its somewhat higher HT stability.

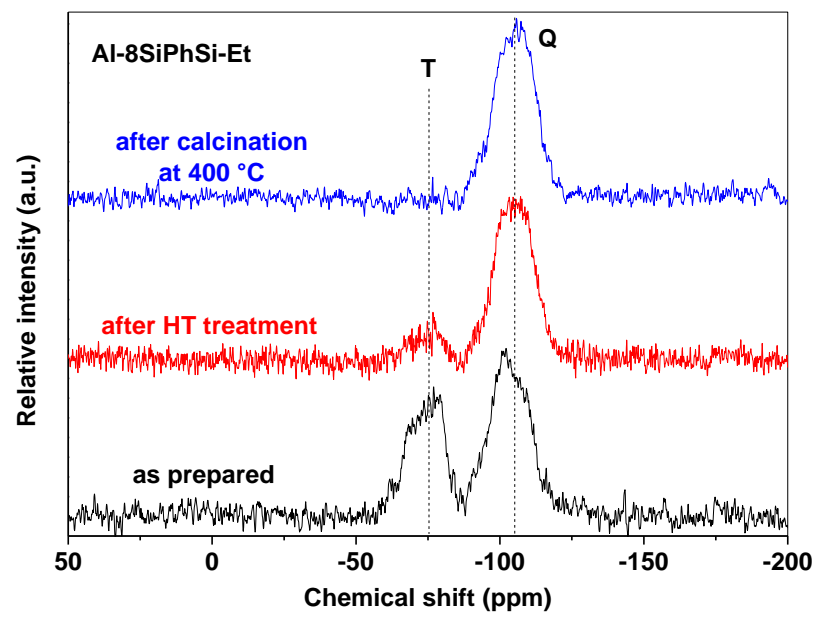

Fig. 6: ${ }^{29}$ Si MAS NMR spectra of Al-8SiPhSi-Et after various treatment.

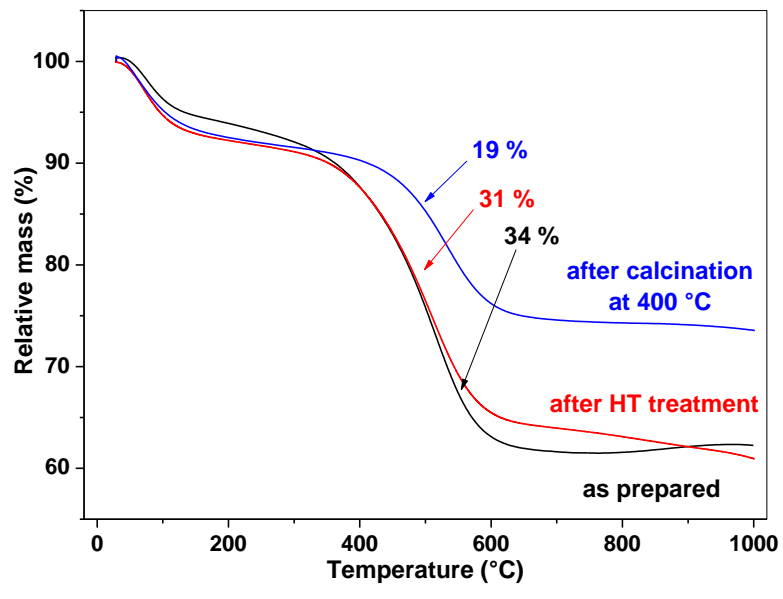

Fig. 7: TG curves of Al-8SiPhSi-Et after various treatment.

In order to better understand the observed hydrolytic reactions and release of benzene from phenylene bridged metallosilicates, $\mathrm{Nb}$ containing samples were prepared in the same manner by acetamide elimination and ether route. The obtained results closely resemble those obtained for samples containing Al. Both as-prepared samples exhibited already some Si-C bond cleavage; T site proportions were 73 and $78 \%$ for $\mathbf{N b - 8 S i P h S i - A c}$ and $\mathbf{N b}-8$ SiPhSi-Et, respectively (Fig. 8 and 9, Table 2). Thermal stability was much lower for both samples than in the case of metal free SiPhSi-Ac (Table 2). ${ }^{29}$ Si MAS NMR spectra after static HT stability test revealed that the Si-C bond hydrolysis was considerably progressing, T site proportions decreased to 45 and $58 \%$ for $\mathbf{~} \mathbf{b}$ 8SiPhSi-Ac and Nb-8SiPhSi-Et, respectively (Fig. 8 and 9, Table 2). All these data were in a good agreement with TG analyses (Fig. 7S and 8S). Static HT stability test also provoked a porosity loss. Similar to Al samples $\mathbf{N b - 8 S i P h S i - A c}$ was completely nonporous after static $\mathrm{HT}$ treatment. $\mathbf{N b}$ 8SiPhSi-Et kept some surface area and pore volume (80 and $54 \%$, respectively, as compared to the as-prepared sample, Table 3). Finally benzene release was observed at $205^{\circ} \mathrm{C}$ for sample $\mathbf{~ N b}$ 8SiPhSi-Ac; sample from ether route (Nb-8SiPhSi-Et) started to release benzene at $275^{\circ} \mathrm{C} \mathrm{(Fig.} \mathrm{3).}$ It is noteworthy that the sample prepared by acetamide elimination route displays more 
extensive Si-C bond cleavage after all types of treatment (as-prepared, calcination, static HT treatment). Moreover it starts to release benzene at lower temperature than $\mathbf{N b - 8 S i P h S i - E t . ~}$ Finally, after static HT stability test, the textural properties of $\mathbf{N b}-\mathbf{8 S i P h S i - A c}$ are affected more deeply than for $\mathbf{N b}-\mathbf{8 S i P h S i - E t}$. Thus $\mathbf{N b - 8 S i P h S i - A c}$ clearly appears less stable than the corresponding hybrid material prepared by the ether route.

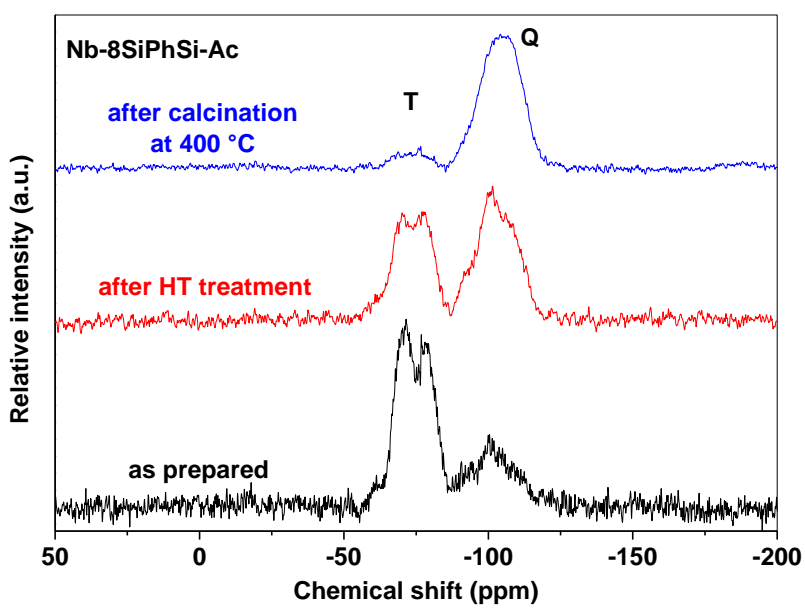

Fig. $8:{ }^{29}$ Si MAS NMR spectra of Nb-8SiPhSi-Ac after various treatment.

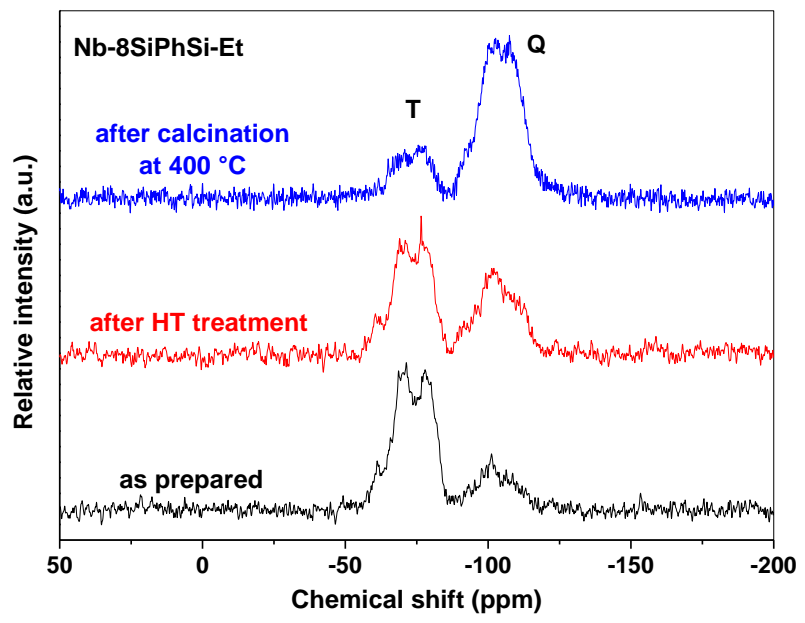

Fig. 9: ${ }^{29}$ Si MAS NMR spectra of Nb-8SiPhSi-Et after various treatment.

\section{Identification of stability drop cause - homogeneity of M/Si mixing and electronegativity}

To identify the possible reasons for the different stability of samples prepared by ether and acetamide elimination route, we inspected their properties as revealed by a variety of characterization techniques. Al-8SiPhSi-Et and Al-8SiPhSi-Ac both had similar Si:Al ratios and they both contained comparable amount of phenyl and/or phenylene groups. The degree of condensation was also very similar based on ${ }^{29}$ Si MAS NMR spectra (Table 1S). The less stable Al8SiPhSi-Ac had a lower surface area than more stable Al-8SiPhSi-Et (Table 3). Thus, higher surface area as a cause for lower hydrothermal stability can be ruled out. Both samples could in principle exhibit different amounts of Brønsted acid sites $\left(\mathrm{H}^{+}\right.$could promote $\mathrm{Si}-\mathrm{C}$ bond scission by an electrophilic aromatic substitution) ${ }^{47}$. A possible role of acidic protons on the instability of the hybrids was however excluded by a specific experiment: Al-8SiPhSi-Ac and Al-8SiPhSi-Et were 
exposed to a mixture of EtOH and 2,6-ditertbutyl pyridine (a strong base known to interact selectively with $\mathrm{H}^{+}$due to its steric constraints) ${ }^{48}$ and compared to a catalytic run with EtOH only. For both catalysts, while activity in ethanol dehydration decreased (i.e. Brønsted acid sites were selectively poisoned), the production of benzene remained unaffected (Fig. 9S).

The homogeneity of these hybrid Si-Al materials (which can be viewed as the degree of dispersion of $\mathrm{Al}$ in the hybrid silica matrix) was clearly different, depending on the synthesis route. For Al8SiPhSi-Ac the surface molar Si:Al ratio determined by XPS fitted almost perfectly with the bulk molar Si:Al ratio determined by ICP-OES, indicating a high homogeneity for this material. For Al8SiPhSi-Et, the amount of Al detected at the surface layer was slightly lower, hinting at its lower homogeneity (Table 1).

The homogeneity of Al mixing within silica matrices was further studied using ToF-SIMS. Peaks of $\left(\mathrm{AlSiO}_{3}\right)^{-},\left(\mathrm{AlSi}_{2} \mathrm{O}_{5}\right)^{-},\left(\mathrm{Al}_{2} \mathrm{O}_{4}\right)^{-}$, and $\left(\mathrm{AlO}_{2}\right)^{-}$were followed at $\mathrm{m} / \mathrm{z}=102.94,162.92,117.95$, and 58.967, respectively (relevant parts of mass spectra Fig. 10S). These signals were well resolved, without any overlap, and undoubtedly assigned. The peak area for the first two masses is taken as an indication of the presence of homogeneously dispersed Al in silica. The peak area of the third mass is taken as an indication of the presence of alumina clusters (poorly dispersed Al oxide species). Finally the peak area of the last mass is a function of Al concentration in the surface layer. Reporting the peak areas of the Al-Si moieties vs. alumina clusters it appears that the sample prepared by acetamide elimination route (Al-8SiPhSi-Ac) shows relatively more mixed AlSi clusters than the sample prepared by the ether route (Al-8SiPhSi-Et) (Fig. 10a and b). In a very good agreement, the peak area ratio of $\left(\mathrm{Al}_{2} \mathrm{O}_{4}\right)^{-}$vs. $\left(\mathrm{AlO}_{2}\right)^{-}$shows a higher proportion of alumina clusters per aluminum atoms in surface layer for Al-8SiPhSi-Et in comparison to Al-8SiPhSi-Ac (Fig. 10c). Therefore we suggest that Al dispersion in hybrid silica in sample Al-8SiPhSi-Ac is better than in Al-8SiPhSi-Et. Thus, it seems that the homogeneity of Si-Al mixing has a direct influence on $\mathrm{Si}-\mathrm{C}$ bond hydrolytic stability. We propose that the more homogeneous distribution of $\mathrm{Al}$ in phenylene silsequioxane matrices, the less stable these materials are. Our hypothesis works with the fact that a homogeneous Al dispersion implies higher amount of Si-O-Al bridges, which introduce instability into hybrid metallosilicates similar to pure inorganic metallosilicates and zeolites under gas-phase hydrothermal conditions. ${ }^{25}$ Unlike inorganic materials, where the highly 
polar $\mathrm{Al}-\mathrm{O}$ bond is reported to have the lowest stability (leading in turn to dealumination), ${ }^{25}$ we observe the most striking difference in $\mathrm{Si}-\mathrm{C}$ bond stability upon $\mathrm{Al}$ introduction in hybrid metallosilicates.
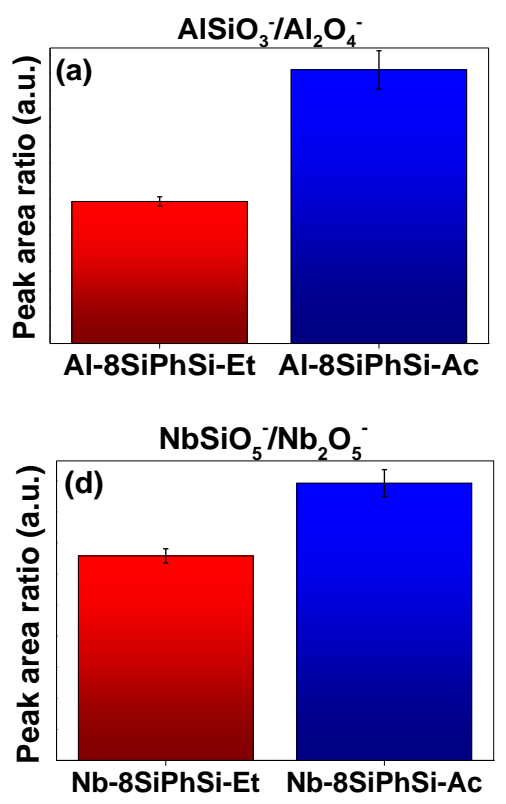
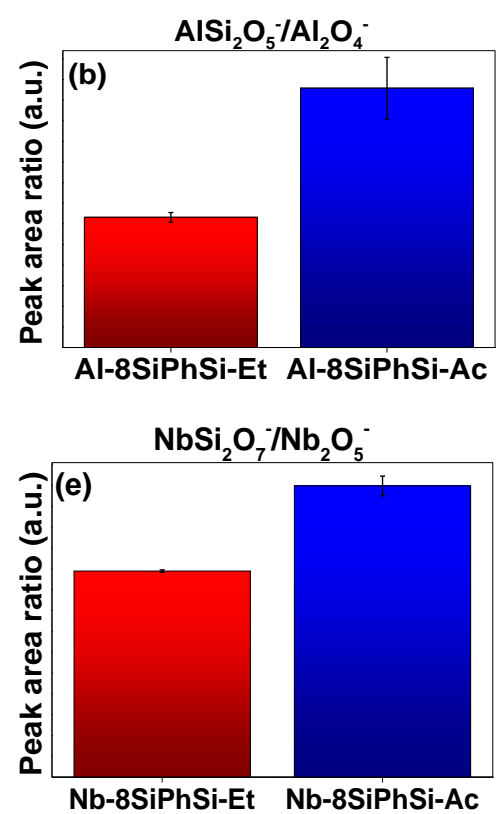

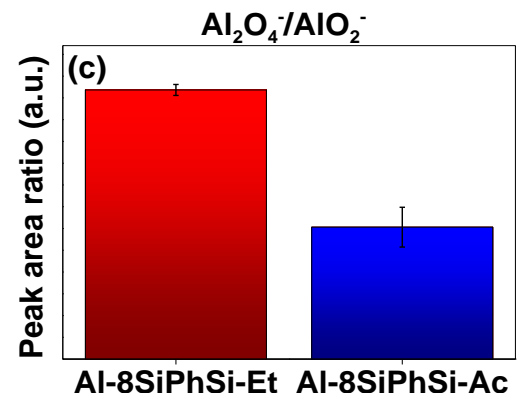

Al-8SiPhSi-Et Al-8SiPhSi-Ac

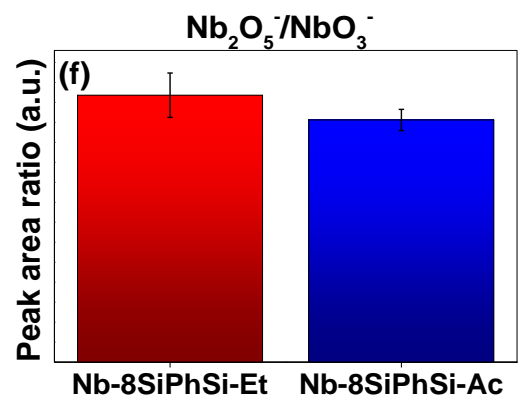

Fig. 10: Comparison of samples prepared by acetamide elimination (blue) and ether route (red) in terms of peak area ratios of various masses in mass spectra obtained by ToF-SIMS. Plots $a, b$, and $c$ refer to Al containing samples, plots $\mathrm{d}, \mathrm{e}$, and $\mathrm{f}$ to $\mathrm{Nb}$ containing samples.

The possible reasons for different hydrothermal and thermal stabilities of $\mathbf{N b}-\mathbf{8 S i P h S i - A c ~ v s . ~} \mathbf{N b}-$ 8SiPhSi-Et were also analyzed. On the one hand, influence of degree of condensation (which is similar for both samples according to ${ }^{29} \mathrm{Si}$ MAS NMR, Table 1S) and surface area (which is lower for less stable material) was ruled out, similar to Al containing samples. On the other hand, striking difference in $\mathrm{Nb}$ dispersion within hybrid silica matrices was again observed. $\mathrm{Nb}$ content in the surface layer was much lower than in bulk material in the sample prepared by ether route, while well corresponding values were observed for the sample prepared by acetamide elimination route (XPS, ICP-OES, Table 1). Moreover ToF-SIMS revealed that $\mathbf{N b - 8 S i P h S i - E t ~ c o n t a i n e d ~ l e s s ~}$ mixed $\mathrm{Nb}$-Si moieties $\left(\mathrm{NbSiO}_{5}{ }^{-}\right.$and $\mathrm{NbSi}_{2} \mathrm{O}_{7}{ }^{-}, \mathrm{m} / \mathrm{z}=200.89$ and 260.86 , respectively) and more niobia clusters $\left(\mathrm{Nb}_{2} \mathrm{O}_{5}{ }^{-}, \mathrm{m} / \mathrm{z}=265.81\right)$ per $\mathrm{Nb}$ atoms in surface layer $\left(\mathrm{NbO}_{3}{ }^{-}, \mathrm{m} / \mathrm{z}=140.90\right)$ in comparison to $\mathbf{N b - 8 S i P h S i - A c ~ ( F i g . ~ 1 0 d , ~ e , ~ a n d ~ f ) . ~ T h u s ~ i t ~ i s ~ p o s s i b l e ~ t o ~ s u g g e s t ~ a g a i n ~ t h a t ~ t h e ~}$ 
degree of homogeneity plays a significant role in hydrothermal and thermal stability of hybrid metallosilicates (based on the results for both $\mathrm{Al}$ and $\mathrm{Nb}$ containing samples).

It is noteworthy, that the abrupt decrease of gas phase HT stability of phenylene bridged silsesquioxane matrices upon metal introduction is in striking contrast to what was observed in boiling water, where an improvement of HT stability was observed upon metal insertion (based on BET and XRD analyses). ${ }^{23,24}$ Moreover the bonds reported to cleave in boiling water are Si-OSi bridges, while in our case we observe the hydrolysis to occur at the expense of $\mathrm{Si}-\mathrm{C}$ bonds. However it is useful to realize that gas phase and liquid phase hydrothermal stabilities of zeolites are also two completely different cases with Al-O bonds being cleaved in the former, while the latter causes the $\mathrm{Si}-\mathrm{O}-\mathrm{Si}$ or $\mathrm{Si}-\mathrm{O}-\mathrm{M}$ bridges to hydrolyze (depending on $\mathrm{pH}$ ). ${ }^{25}$

At this point we intend to identify the cause of such an abrupt decrease of (hydro)thermal stability upon introduction of metals into the silsesquioxane matrices. While Al and $\mathrm{Nb}$ have very similar electronegativities (1.61 and 1.60 according to Pauling, respectively), Si exhibits different electronegativity value (1.90). The differences in electron withdrawing properties between Si and guest elements $(\mathrm{Al}, \mathrm{Nb})$ can introduce partial charges into the silsesquioxane matrices making them prone to attack by polar water molecules. This is in a good agreement with our hypothesis that the higher content of polar $\mathrm{Si}-\mathrm{O}-\mathrm{Al} / \mathrm{Nb}$ bridges in materials with better metal dispersion causes their lower stability.

To prove the effect of electronegativity phenylene bridged silsesquioxane with tin was synthesized by acetamide elimination route (Sn-8SiPhSi-Ac; details on synthesis and characterization in ESI). Tin has an electronegativity value close to silicon (1.96). Indeed, sample Sn-8SiPhSi-Ac was more stable than its corresponding $\mathrm{Al}$ and $\mathrm{Nb}$ derivatives. The as-prepared sample contained intact phenylene bridges as deduced from ${ }^{29} \mathrm{Si}$ MAS NMR spectra where only signals of T sites were observed (compare with T site proportion ranging from 44 to $85 \%$ for $\mathrm{Al}$ and $\mathrm{Nb}$ containing samples, Fig. 11). Calcination at $400{ }^{\circ} \mathrm{C}$ only led to a mild $\mathrm{Si}-\mathrm{C}$ bond cleavage in comparison to Al-8SiPhSi-Ac and Nb-8SiPhSi-Ac (T site proportion $41 \%$, Fig. 11). Finally, Sn8SiPhSi-Ac started to release low amounts of benzene at $275^{\circ} \mathrm{C}$ (Fig. 3) during dynamic $\mathrm{HT}$ treatment (compared to substantial evolution of benzene from Al-8SiPhSi-Ac and Nb-8SiPhSi-Ac already at $205^{\circ} \mathrm{C}$ ). In a good agreement, lower amount of Si-C bonds was cleaved after static HT 
stability test in comparison to Al-8SiPhSi-Ac and $\mathbf{N b - 8 S i P h S i - A c ~ ( T ~ s i t e ~ p r o p o r t i o n ~} 77 \%$ according to ${ }^{29} \mathrm{Si}$ MAS NMR spectra, Fig. 11). Electronegativity of inserted metal was thus identified to be a second important parameter (after homogeneity of $\mathrm{M} / \mathrm{Si}$ dispersion) influencing stability of hybrid metallosilicates.

\section{Increasing stability of hybrid metallosilicates - xylylene bridged material}

It is known that $\mathrm{Si}-\mathrm{C}\left(\mathrm{sp}^{3}\right)$ bonds are more resistant towards both electrophilic and nucleophilic substitution than $\mathrm{Si}-\mathrm{C}\left(\mathrm{sp}^{2}\right)$ bonds. ${ }^{47,49}$ In order to increase the stability of our materials, but retain hydrophobic aromatic groups, aluminum-containing p-xylylene $\left(-\mathrm{CH}_{2}-\mathrm{C}_{6} \mathrm{H}_{4}-\mathrm{CH}_{2}-\right)$ bridged silsesquioxane was prepared by acetamide elimination route (Al-8SiXySi-Ac; details on synthesis and characterization in ESI). SS NMR unambiguously proved the presence of $\mathrm{Si}-\mathrm{CH}_{2}-\mathrm{C}_{6} \mathrm{H}_{4}-\mathrm{CH}_{2}-\mathrm{Si}$ moieties in the as-prepared sample, new intense signal ascribed to methylene species was observed at $22 \mathrm{ppm}$ in ${ }^{13} \mathrm{C}$ CP MAS NMR spectra. $\mathrm{N}_{2}$ physisorption measurements indicated presence of both micro- and mesopores in contrary to phenylene bridged samples prepared by acetamide elimination route, which were completely microporous. Surface area reached $520 \mathrm{~m}^{2}$ $\mathrm{g}^{-1}$, pore volume $0.33 \mathrm{~cm}^{3} \mathrm{~g}^{-1}$, and average pore diameter $2.5 \mathrm{~nm}$ for Al-8SiXySi-Ac. According to t-plot analysis $46 \%$ of pore volume was microporous. Varying bridging groups (length and flexibility) has been already reported as a way to change textural properties in hybrid materials made via NHSG. ${ }^{33}$ Finally, similar to Al-SiPhSi-Ac two sets of signals of acetoxy-groups were observed in IR spectra and COO peak was broadened towards lower field in ${ }^{13} \mathrm{C}$ NMR spectra indicating the presence of bidentate acetoxy- moieties. Again, these groups coordinated to Al atoms, made them predominantly six-coordinated ( ${ }^{27} \mathrm{AI}$ MAS NMR spectra Fig. $\left.6 \mathrm{~S}\right)$, and impaired catalytic activity of Al-8SiXySi-Ac (see below).

The as-prepared sample contained solely well preserved xylylene bridges (no $\mathrm{SiO}_{4} \mathrm{moieties,}$ compare with T site proportion of $79 \%$ for Al-SiPhSi-Ac, Fig. 12). On the contrary, Si-C bonds in the sample calcined at $400{ }^{\circ} \mathrm{C}$ were almost completely cleaved (Fig. 12). Importantly, the first hints of xylene (product of hydrolysis of $\mathrm{Si}-\mathrm{C}$ bonds) were observed at $345^{\circ} \mathrm{C}$ only during the dynamic HT stability test (not shown); moreover no Si-C bond hydrolysis was observed after 24 hrs at 240 ${ }^{\circ} \mathrm{C}$ on stream (static HT treatment, Fig. 12). Based on these results it can be concluded that the 
hydrothermal stability of Al-8SiXySi-Ac was significantly improved in comparison to phenylene bridged metallosilicates and was close to SiPhSi-Ac (metal free phenylene bridged sample). The hydrothermal as well as thermal stability limit temperature is ca. $345{ }^{\circ} \mathrm{C}$ for xylylene bridged hybrid metallosilicates. It is worth noting that this value is close to the temperature $\left(400{ }^{\circ} \mathrm{C}\right)$, at which a transformation of bridging methylene moieties to terminal methyl groups was observed in metal free hybrid silica samples. ${ }^{6}$ At the same time, it is above the thermal stability limit $\left(300{ }^{\circ} \mathrm{C}\right)$ of ethylene bridged silsesquioxanes (no metal). ${ }^{2}$

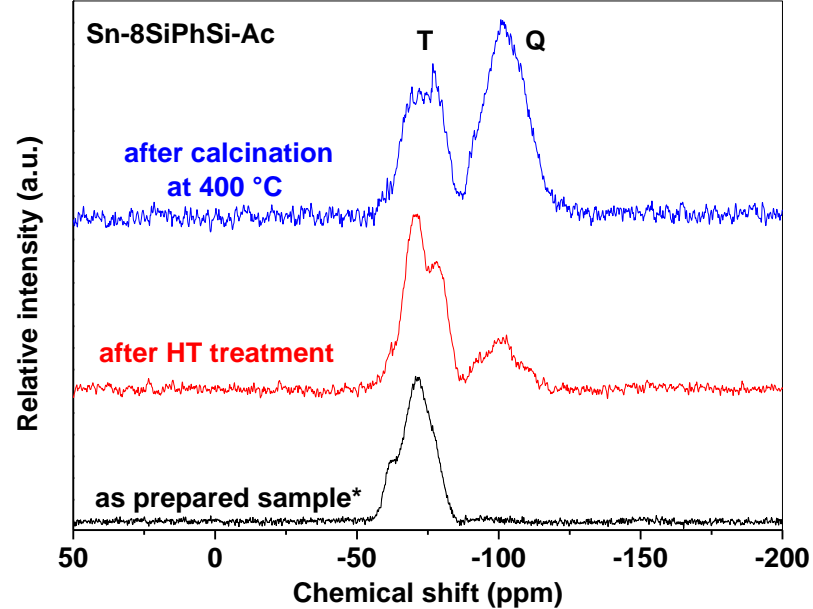

Fig. $11:{ }^{29} \mathrm{Si}(\mathrm{CP}) \mathrm{MAS}$ NMR spectra of Sn-8SiPhSiAc after various treatment, * denotes CPMAS spectrum.

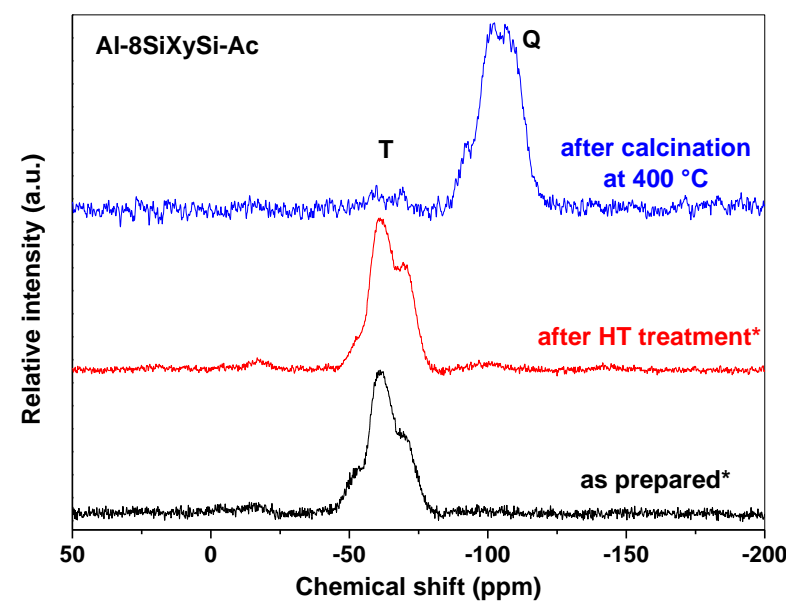

Fig. $12:{ }^{29} \mathrm{Si}(\mathrm{CP}) \mathrm{MAS}$ NMR spectra of Al-8SiXySiAc after various treatment, *denotes CPMAS spectra.

\section{Catalysis}

As-prepared materials were tested as catalysts for the gas-phase ethanol dehydration in the temperature range between 205 and $400{ }^{\circ} \mathrm{C}$. The major products of catalytic reaction were ethylene and diethylether with carbon balances 95-100\%, other observed products in very low amounts were acetaldehyde, butenes, and butadiene (mainly at higher temperatures). Ethylene selectivity was high and similar for all samples prepared by NHSG (80-100\%) and was substantially higher than for commercial benchmarking catalyst (Silica alumina catalyst support grade 135), which was the only sample producing vast amounts of diethylether.

The activity of hybrid Al samples was as follows: Al-8SiPhSi-Et $>$ Al-8SiPhSi-Ac > Al-8SiXySi-Ac (Fig. 13). While higher activity was expected for samples prepared by acetamide elimination route (since they display high homogeneity of Si-Al mixing, and therefore putatively a high density of 
active sites for dehydration), one factor strongly impaired their performance: the strong binding of acetoxy- groups to aluminum causing high amounts of six-coordinated Al atoms (Fig. 6S).

Hybrid Al-containing samples were compared to pure inorganic catalyst prepared by the ether route (Al-16Si-Et). Similar high catalytic activity and ethylene yields were observed for hybrid Al8SiPhSi-Et and pure inorganic Al-16Si-Et. The commercial benchmarking silica-alumina exhibited slightly lower ethanol conversion than the best NHSG catalysts (Al-8SiPhSi-Et and Al-16Si-Et), however due to its low ethylene selectivity the ethylene yields were much lower.

Niobium samples exhibited lower catalytic activity than their Al analogues, as expected, due to generally lower acid strength of niobium silicates in comparison to aluminosilicates. ${ }^{50,51}$ In this case, more homogeneous sample (Nb-8SiPhSi-Ac) was more active than the less homogeneous catalyst (Nb-8SiPhSi-Et). The amount of acetoxy-groups in as-prepared $\mathbf{N b - 8 S i P h S i - A c ~ w a s ~ m u c h ~}$ lower than in Al-8SiPhSi-Ac meaning that the affinity of acetoxy-groups to $\mathrm{Nb}$ atoms is not as high as it is in the case of aluminum.

It is important to make a connection between the HT stability and catalytic activity. Al-8SiXySi-Ac (xylylene bridged material) was the only hybrid catalyst which was able to reach high ethanol conversion without any observation of hydrolytic products (xylene); substantial release of benzene was observed for all phenylene bridged metallosilicates during catalytic experiments. The improved hydrothermal stability of xylylene bridges makes Al-8SiXySi-Ac promising as a starting point for further studies (e.g. lower loading of hydrophobic organic groups, etc.). 

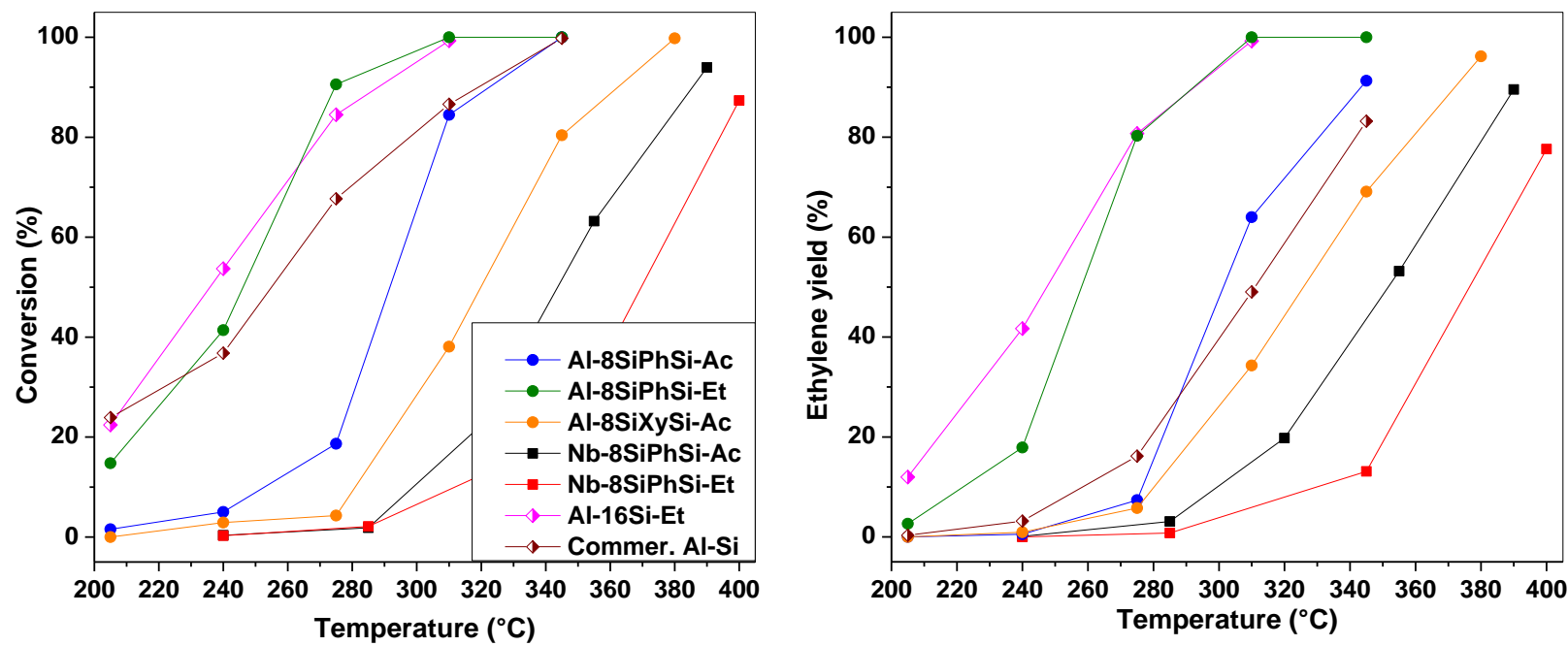

Fig. 13: Ethanol conversion and ethylene yield at different temperatures over hybrid metallosilicate catalysts.

\section{Conclusions}

In this paper we have shown that the hydrothermal gas-phase and thermal stability of hybrid phenylene bridged silica materials abruptly decrease upon metal introduction ( $M=A l, N b, S n)$. The degradation of hybrid materials was reflected mainly in the hydrolysis of $\mathrm{Si}-\mathrm{C}$ bonds, which was followed by analysis of the effluent during HT stability test (amount of benzene evolved), by TGA, and by ${ }^{29} \mathrm{Si}$ MAS NMR. While the first hint of $\mathrm{Si}-\mathrm{C}$ bonds cleavage was observed at $345^{\circ} \mathrm{C}$ for metal free silica, extensive hydrolysis took place between 205 and $275{ }^{\circ} \mathrm{C}$ for hybrid metallosilicates. These results are complementary to previously reported data on hydrothermal stability of Al and Zr containing PMOs in boiling water where an improvement of stability was observed upon metal insertion. ${ }^{23,24}$ The gas phase HT stability of hybrid metallosilicates with aromatic groups was improved by the introduction of xylylene instead of phenylene bridges due to better stability of $\mathrm{Si}-\mathrm{C}\left(\mathrm{sp}^{2}\right)$ bonds.

Among the phenylene bridged metallosilicates studied, Sn-containing sample was the most stable. It was concluded that this is due to its electronegativity value, close to that of $\mathrm{Si}$. Al and $\mathrm{Nb}$ differ more in electronegativity from $\mathrm{Si}$, thus introducing higher partial charges into the silsesquioxane networks and making them prone to attack by polar water molecules. Homogeneity of metal dispersion in hybrid silica (and consequently the number of Si-O-M 
bridges) was identified as the other key factor influencing stability. Influence of surface area, degree of condensation, and Brønsted acid sites was discarded.

In the gas-phase ethanol dehydration reaction, the most active hybrid catalysts made by NHSG markedly outperformed a commercial silica-alumina benchmark catalyst, mainly owing to a much higher ethene selectivity. Yet, a similar catalytic activity was also achieved with a purely inorganic catalyst prepared in the same way. Also, in terms of stability, we show that all phenylene bridged metallosilicates hydrolyzed in the course of the reaction and released benzene. The only stable hybrid metallosilicate able to achieve high ethanol conversion under reaction conditions was the xylylene bridged aluminosilicate. It is suggested that this functionality should be investigated further - possibly with a lower degree of organic groups content - in a search for higher performance in ethanol dehydration.

\section{Acknowledgements}

A.S. acknowledges funding from the European Union's Horizon 2020 research and innovation programme under the Marie Skłodowska-Curie grant agreement No 751774. F.R.S.-F.N.R.S. is thanked for the acquisition of the physi-chemisorption equipment used here (project "EQP U.N030.18"). Authors acknowledge the 'Communauté française de Belgique' for the financial support through the ARC programme (15/20-069). This research used resources of the "Plateforme Technologique Physico-Chemical Characterization" - PC ${ }^{2}$, the SIAM platform (Synthesis, Irradiation \& Analysis of Materials) and the MORPH-IM platform (Morphology \& Imaging) located at the University of Namur. Authors thank L. Simonikova for performing ICP-OES analyses. 


\section{References}

(1) Faustini, M.; Nicole, L.; Ruiz-Hitzky, E.; Sanchez, C. History of Organic-Inorganic Hybrid Materials: Prehistory, Art, Science, and Advanced Applications. Adv. Funct. Mater. 2018, 28 (27), 1704158. https://doi.org/10.1002/adfm.201704158.

(2) Esquivel, D.; Jiménez-Sanchidrián, C.; Romero-Salguero, F. J. Comparison of the Thermal and Hydrothermal Stabilities of Ethylene, Ethylidene, Phenylene and Biphenylene Bridged Periodic Mesoporous Organosilicas. Mater. Lett. 2011, 65 (10), 1460-1462.

https://doi.org/10.1016/J.MATLET.2011.02.037.

(3) Esquivel, D.; Jiménez-Sanchidrián, C.; Romero-Salguero, F. J. Thermal Behaviour, Sulfonation and Catalytic Activity of Phenylene-Bridged Periodic Mesoporous Organosilicas. J. Mater. Chem. 2011, 21 (3), 724-733. https://doi.org/10.1039/C0JM02980G.

(4) Van Der Voort, P.; Esquivel, D.; De Canck, E.; Goethals, F.; Van Driessche, I.; Romero-Salguero, F. J. Periodic Mesoporous Organosilicas: From Simple to Complex Bridges; a Comprehensive Overview of Functions, Morphologies and Applications. Chem. Soc. Rev. 2013, 42 (9), 3913-3955. https://doi.org/10.1039/C2CS35222B.

(5) Dral, A. P.; Lievens, C.; Ten Elshof, J. E. Influence of Monomer Connectivity, Network Flexibility, and Hydrophobicity on the Hydrothermal Stability of Organosilicas. Langmuir 2017, 33 (22), 5527-5536. https://doi.org/10.1021/acs.langmuir.7b00971.

(6) Asefa, T.; MacLachlan, M. J.; Grondey, H.; Coombs, N.; Ozin, G. A. Metamorphic Channels in Periodic Mesoporous Methylenesilica. Angew. Chemie - Int. Ed. 2000, 39 (10), 1808-1811. https://doi.org/10.1002/(SICI)1521-3773(20000515)39:10<1808::AID-ANIE1808>3.0.CO;2-G.

(7) Bispo, C.; Ferreira, P.; Trouvé, A.; Batonneau-Gener, I.; Liu, F.; Jérôme, F.; Bion, N. Role of Acidity and Hydrophobicity in the Remarkable Catalytic Activity in Water of Sulfonic Acid-Functionalized Phenyl-PMO Materials. Catal. Today 2013, 218-219, 85-92. https://doi.org/10.1016/j.cattod.2013.06.004.

(8) An, S.; Sun, Y.; Song, D.; Zhang, Q.; Guo, Y.; Shang, Q. Arenesulfonic Acid-Functionalized AlkylBridged Organosilica Hollow Nanospheres for Selective Esterification of Glycerol with Lauric Acid to Glycerol Mono- and Dilaurate. J. Catal. 2016, 342, 40-54.

https://doi.org/10.1016/j.jcat.2016.07.004.

(9) Melero, J. A.; van Grieken, R.; Morales, G. Advances in the Synthesis and Catalytic Applications of Organosulfonic-Functionalized Mesostructured Materials. Chem. Rev. 2006, 106 (9), 3790-3812. https://doi.org/10.1021/cr050994h.

(10) Manayil, J.; Lee, A.; Wilson, K. Functionalized Periodic Mesoporous Organosilicas: Tunable Hydrophobic Solid Acids for Biomass Conversion. Molecules 2019, 24 (2), 239. https://doi.org/10.3390/molecules24020239.

(11) Rác, B.; Hegyes, P.; Forgo, P.; Molnár, Á. Sulfonic Acid-Functionalized Phenylene-Bridged Periodic Mesoporous Organosilicas as Catalyst Materials. Appl. Catal. A Gen. 2006, 299 (1-2), 193-201. https://doi.org/10.1016/j.apcata.2005.10.026.

(12) Corma, A.; Díaz, U.; García, T.; Sastre, G.; Velty, A. Multifunctional Hybrid Organic-Inorganic Catalytic Materials with a Hierarchical System of Well-Defined Micro- and Mesopores. J. Am. Chem. Soc. 2010, 132 (42), 15011-15021. https://doi.org/10.1021/ja106272z.

(13) Millini, R.; Bellussi, G. Hybrid Organic-Inorganic Zeolites: Status and Perspectives. Catal. Sci. 
Technol. 2016, 6 (8), 2502-2527. https://doi.org/10.1039/c5cy02057c.

(14) Zanardi, S.; Parker, W. O.; Carati, A.; Botti, G.; Montanari, E. On the Thermal Behaviour of the Crystalline Hybrid Organic-Inorganic Aluminosilicate ECS-3. Microporous Mesoporous Mater. 2013, 172, 200-205. https://doi.org/10.1016/J.MICROMESO.2013.01.029.

(15) Xia, Y.; Wang, W.; Mokaya, R. Bifunctional Hybrid Mesoporous Organoaluminosilicates with Molecularly Ordered Ethylene Groups. J. Am. Chem. Soc. 2005, 127 (2), 790-798. https://doi.org/10.1021/ja0453230.

(16) Hughes, B. J.; Guilbaud, J.-B.; Allix, M.; Khimyak, Y. Z. Synthesis of Periodic Mesoporous Organosilicas with Incorporated Aluminium. J. Mater. Chem. 2005, 15 (44), 4728. https://doi.org/10.1039/b510700h.

(17) Melero, J. A.; Iglesias, J.; Arsuaga, J. M.; Sainz-Pardo, J.; de Frutos, P.; Blazquez, S. Synthesis and Catalytic Activity of Organic-Inorganic Hybrid Ti-SBA-15 Materials. J. Mater. Chem. 2007, 17 (4), 377-385. https://doi.org/10.1039/B610868G.

(18) Shylesh, S.; Samuel, P. P.; Singh, A. P. Synthesis of Hydrothermally Stable Aluminium-Containing Ethane-Silica Hybrid Mesoporous Materials Using Different Aluminium Sources. Microporous Mesoporous Mater. 2007, 100 (1-3), 250-258. https://doi.org/10.1016/J.MICROMESO.2006.11.010.

(19) Shylesh, S.; Samuel, P. P.; Singh, A. P. Cyclooctene Epoxidation over Mesoporous Organo Vanadosilicates Having - $\mathrm{CH} 2-\mathrm{CH} 2-$ Groups in the Frame Wall Positions. Catal. Commun. 2007, 8 (6), 894-898. https://doi.org/10.1016/J.CATCOM.2006.08.038.

(20) Guo, W.; Zhao, X. S. Room-Temperature Synthesis of Hydrothermally Stable Aluminum-Rich Periodic Mesoporous Organosilicas with Wormlike Pore Channels. Microporous Mesoporous Mater. 2005, 85 (1-2), 32-38. https://doi.org/10.1016/J.MICROMESO.2005.06.004.

(21) Yang, Q.; Li, Y.; Zhang, L.; Yang, J.; Liu, J.; Li, C. Hydrothermal Stability and Catalytic Activity of Aluminum-Containing Mesoporous Ethane-Silicas. J. Phys. Chem. B 2004, 108 (23), 7934-7937. https://doi.org/10.1021/jp040124o.

(22) Zhai, S.-R.; Park, S. S.; Park, M.; Ullah, M. H.; Ha, C.-S. Direct Synthesis of Zr-Containing Hybrid Periodic Mesoporous Organosilicas with Tunable Zirconium Content. Eur. J. Inorg. Chem. 2007, 2007 (35), 5480-5488. https://doi.org/10.1002/ejic.200700775.

(23) Sánchez-Vázquez, R.; Pirez, C.; Iglesias, J.; Wilson, K.; Lee, A. F.; Melero, J. A. Zr-Containing Hybrid Organic-Inorganic Mesoporous Materials: Hydrophobic Acid Catalysts for Biodiesel Production. ChemCatChem 2013, 5 (4), 994-1001. https://doi.org/10.1002/cctc.201200527.

(24) Yang, Q.; Yang, J.; Feng, Z.; Li, Y. Aluminium-Containing Mesoporous Benzene-Silicas with Crystallike Pore Wall Structure. J. Mater. Chem. 2005, 15 (39), 4268. https://doi.org/10.1039/b507437a.

(25) Gounder, R. Hydrophobic Microporous and Mesoporous Oxides as Brønsted and Lewis Acid Catalysts for Biomass Conversion in Liquid Water. Catal. Sci. Technol. 2014, 4 (9), 2877-2886. https://doi.org/10.1039/c4cy00712c.

(26) Angelici, C.; Weckhuysen, B. M.; Bruijnincx, P. C. A. Chemocatalytic Conversion of Ethanol into Butadiene and Other Bulk Chemicals. ChemSusChem 2013, 6 (9), 1595-1614. https://doi.org/10.1002/cssc.201300214.

(27) Styskalik, A.; Skoda, D.; Barnes, C. E.; Pinkas, J. The Power of Non-Hydrolytic Sol-Gel Chemistry: A Review. Catalysts 2017, 7 (6), 168. https://doi.org/10.3390/catal7060168. 
(28) Debecker, D. P.; Hulea, V.; Mutin, P. H. Mesoporous Mixed Oxide Catalysts via Non-Hydrolytic Sol-Gel: A Review. Appl. Catal. A Gen. 2013, 451, 192-206.

https://doi.org/10.1016/j.apcata.2012.11.002.

(29) Debecker, D. P.; Mutin, P. H. Non-Hydrolytic Sol-Gel Routes to Heterogeneous Catalysts. Chem. Soc. Rev. 2012, 41 (9), 3624-3650. https://doi.org/10.1039/C2CS15330K.

(30) Katsoulis, D. E.; Kenney, M. E.; Vassilaras, P. E. Alternative Methods for the Synthesis of Organosilicon Compounds. WO2013137904A1, September 20, 2013.

(31) Motevalli, M.; Ou, D. L.; Sullivan, A. C. Synthesis and Characterization of Bis(Trichlorosilylmethyl)Benzenes. J. Organomet. Chem. 1993, 445 (1-2), 35-38. https://doi.org/10.1016/0022-328X(93)80183-C.

(32) Balthis, J. H.; Rochow, E. G.; White, D. G. Silicon Tetraacetate. In Inorganic Syntheses; Jr, J. C. B., Ed.; John Wiley \& Sons, Inc., 2007; pp 45-47.

(33) Styskalik, A.; Skoda, D.; Moravec, Z.; Babiak, M.; Barnes, C. E.; Pinkas, J. Control of Micro/Mesoporosity in Non-Hydrolytic Hybrid Silicophosphate Xerogels. J. Mater. Chem. A 2015, 3 (14), 7477-7487. https://doi.org/10.1039/c4ta06823h.

(34) Rouquerol, J.; Rouquerol, F.; Sing, K. S. W. Adsorption by Powders and Porous Solids; Academic Press, 1998.

(35) Lowell, S. Characterization of Porous Solids and Powders: Surface Area, Pore Size and Density; Springer, 2004.

(36) Shirley, D. A. High-Resolution X-Ray Photoemission Spectrum of the Valence Bands of Gold. Phys. Rev. B 1972, 5 (12), 4709-4714. https://doi.org/10.1103/PhysRevB.5.4709.

(37) Wagner, C. D.; Naumkin, A. V; Kraut-Vass, A.; Allison, J. W.; Powell, C. J.; Rumble Jr, J. R. NIST Standard Reference Database 20, Version 3.4 (Web Version). Natl. Inst. Stand. Technol. Gaithersburg, MD 2003, 20899.

(38) Skoda, D.; Styskalik, A.; Moravec, Z.; Bezdicka, P.; Babiak, M.; Klementova, M.; Barnes, C. E.; Pinkas, J. Novel Non-Hydrolytic Templated Sol-Gel Synthesis of Mesoporous Aluminosilicates and Their Use as Aminolysis Catalysts. RSC Adv. 2016, 6 (29). https://doi.org/10.1039/c5ra24563j.

(39) Lafond, V.; Mutin, P. H.; Vioux, A. Control of the Texture of Titania-Silica Mixed Oxides Prepared by Nonhydrolytic Sol-Gel. Chem. Mater. 2004, 16 (25), 5380-5386.

https://doi.org/10.1021/cm0490569.

(40) Debecker, D. P.; Bouchmella, K.; Stoyanova, M.; Rodemerck, U.; Gaigneaux, E. M.; Hubert Mutin, P. A Non-Hydrolytic Sol-Gel Route to Highly Active $\mathrm{MoO}_{3}-\mathrm{SiO}_{2}-\mathrm{Al}_{2} \mathrm{O}_{3}$ Metathesis Catalysts. Catal. Sci. Technol. 2012, 2 (6), 1157. https://doi.org/10.1039/c2cy00475e.

(41) Styskalik, A.; Skoda, D.; Pinkas, J.; Mathur, S. Non-Hydrolytic Synthesis of Titanosilicate Xerogels by Acetamide Elimination and Their Use as Epoxidation Catalysts. J. Sol-Gel Sci. Technol. 2012, 63 (3), 463-472. https://doi.org/10.1007/s10971-012-2808-5.

(42) Skoda, D.; Styskalik, A.; Moravec, Z.; Bezdicka, P.; Bursik, J.; Mutin, P. H.; Pinkas, J. Mesoporous $\mathrm{SnO}_{2}-\mathrm{SiO}_{2}$ and $\mathrm{Sn}-\mathrm{Silica}-\mathrm{Carbon}$ Nanocomposites by Novel Non-Hydrolytic Templated Sol-Gel Synthesis. RSC Adv. 2016, 6 (73), 68739-68747. https://doi.org/10.1039/C6RA16556G.

(43) Skoda, D.; Styskalik, A.; Moravec, Z.; Bezdicka, P.; Pinkas, J. Templated Non-Hydrolytic Synthesis of Mesoporous Zirconium Silicates and Their Catalytic Properties. J. Mater. Sci. 2015, 50 (9), 3371- 
3382. https://doi.org/10.1007/s10853-015-8888-1.

(44) Styskalik, A.; Skoda, D.; Moravec, Z.; Abbott, J. G.; Barnes, C. E.; Pinkas, J. Synthesis of Homogeneous Silicophosphate Xerogels by Non-Hydrolytic Condensation Reactions. Microporous Mesoporous Mater. 2014, 197, 204-212.

(45) Deacon, G. B.; Phillips, R. J. Relationships between the Carbon-Oxygen Stretching Frequencies of Carboxylato Complexes and the Type of Carboxylate Coordination. Coord. Chem. Rev. 1980, 33 (3), 227-250. https://doi.org/10.1016/S0010-8545(00)80455-5.

(46) Nara, M.; Torii, H.; Tasumi, M. Correlation between the Vibrational Frequencies of the Carboxylate Group and the Types of Its Coordination to a Metal Ion: An Ab Initio Molecular Orbital Study. J. Phys. Chem. 1996, 100 (51), 19812-19817. https://doi.org/10.1021/jp9615924.

(47) Eaborn, C. Cleavages of Aryl-Silicon and Related Bonds by Electrophiles. J. Organomet. Chem. 1975, 100 (1), 43-57. https://doi.org/10.1016/S0022-328X(00)88933-0.

(48) Carr, R. T.; Neurock, M.; Iglesia, E. Catalytic Consequences of Acid Strength in the Conversion of Methanol to Dimethyl Ether. J. Catal. 2011, 278 (1), 78-93.

https://doi.org/10.1016/j.jcat.2010.11.017.

(49) Eaborn, C.; Stamper, J. G.; Seconi, G. Calculations of the Deprotonation Energies of MonoSubstituted Benzenes, and Their Significance for the Mechanisms of Base-Catalysed Cleavages of Aryl-Silicon and Aryl-Tin Bonds and Hydrogen-Exchange in Substituted Benzenes. J. Organomet. Chem. 1981, 204 (1), 27-45. https://doi.org/10.1016/S0022-328X(00)82469-9.

(50) Brandão, P.; Philippou, A.; Rocha, J.; Anderson, M. W. Dehydration of Alcohols by Microporous Niobium Silicate AM-11. Catal. Letters 2002, 80 (3-4), 99-102. https://doi.org/10.1023/A:1015444005961.

(51) Philippou, A.; Brandão, P.; Ghanbari-Siahkali, A.; Dwyer, J.; Rocha, J.; Anderson, M. W. Catalytic Studies of the Novel Microporous Niobium Silicate AM-11. Appl. Catal. A Gen. 2001, 207 (1-2), 229-238. https://doi.org/10.1016/S0926-860X(00)00623-2. 
Styskalik Debecker - Stability of hybrid metallosilicate - pre... (1.54 MiB) view on ChemRxiv • download file 


\section{Highly porous hybrid metallosilicate materials prepared by non-hydrolytic sol-gel: hydrothermal stability and catalytic properties in ethanol dehydration}

Ales Styskalik, ${ }^{a, b, c}$ Imene Kordoghli, ${ }^{a}$ Claude Poleunis, ${ }^{a}$ Arnaud Delcorte, ${ }^{a}$ Carmela Aprile, ${ }^{d}$ Luca Fusaro, ${ }^{\mathrm{d}}$ Damien P. Debecker*a

Institute of Condensed Matter and Nanoscience (IMCN), UCLouvain, Place Louis Pasteur 1, 1348 Louvain-La-Neuve, Belgium

${ }^{b}$ Masaryk University, Department of Chemistry, Kotlarska 2, CZ-61137 Brno, Czech Republic 'Masaryk University, CEITEC MU, Kamenice 5, CZ-62500 Brno, Czech Republic

${ }^{d}$ Department of Chemistry, Unit of Nanomaterials Chemistry, University of Namur, 5000 Namur, Belgium

${ }^{*}$ Corresponding author (damien.debecker@uclouvain.be). 
Synthesis of Sn-8SiPhSi-Ac was performed in the same way as Al-8SiPhSi-Ac and Nb-8SiPhSiAc. Precursor loadings: $3.925 \mathrm{mmol}$ 1,4-bis(triacetoxysilyl)benzene; $0.506 \mathrm{mmol}$ tetrakis(diethylamido)tin.

Synthesis of Al-8SiXySi-Ac was performed in the same way as Al-8SiPhSi-Ac and Nb-8SiPhSiAc. Precursor loadings: 9.400 mmol 1,4-bis(triacetoxysilylmethyl)benzene; $1.180 \mathrm{mmol}$ tris(dimethylamido)aluminum.

\section{Spectroscopic characterization data.}

SiPhSi: IR $\left(\mathrm{KBr}, \mathrm{cm}^{-1}\right)$ v : $518 \mathrm{~s}(\rho \mathrm{Si}-\mathrm{O}-\mathrm{Si}), 633 \mathrm{vw}, 668 \mathrm{w}, 701 \mathrm{w}$ ( $\delta \mathrm{C}-\mathrm{C}$ out of plane aromatic ring bend), $743 \mathrm{vw}\left(\delta \mathrm{C}_{\mathrm{ar}}-\mathrm{H}\right.$ out of plane), $779 \mathrm{~m}$ ( $\left.\mathrm{v}_{\mathrm{s}} \mathrm{Si}-\mathrm{O}-\mathrm{Si}\right), 810 \mathrm{~m}(\delta \mathrm{Si}-\mathrm{C}), 910 \mathrm{~s}(\mathrm{v} \mathrm{Si}-\mathrm{OH})$, $1014 \mathrm{vs}, 1033 \mathrm{vs}(\mathrm{v} \mathrm{Si}-\mathrm{O}-\mathrm{Si}), 1152 \mathrm{~s}\left(\mathrm{v} \mathrm{Si}-\mathrm{C}_{\mathrm{ar}}\right), 1204 \mathrm{vw}, 1263 \mathrm{vw}, 1381 \mathrm{w}\left(\delta_{\mathrm{as}} \mathrm{CH}_{3}\right), 1432 \mathrm{vw}(\mathrm{v}$ $\mathrm{C}-\mathrm{C}), 1624 \mathrm{~m}(\delta \mathrm{OH}), 2961 \mathrm{vw}\left(\mathrm{v}_{\mathrm{as}} \mathrm{CH}_{3}\right), 3014 \mathrm{vw}\left(\mathrm{v}_{\mathrm{s}} \mathrm{CH}_{\mathrm{ar}}\right), 3061 \mathrm{w}\left(\mathrm{v}_{\mathrm{as}} \mathrm{CH}_{\mathrm{ar}}\right), 3300 \mathrm{~m}$-broad ( $\mathrm{OH})$.

${ }^{13} \mathrm{C}$ CPMAS NMR (ppm) $\delta: 20\left(\mathrm{CH}_{3} \mathrm{COO}\right.$ unident), $134\left(\mathrm{Si}-\mathrm{C}_{6} \mathrm{H}_{4}-\mathrm{Si}\right.$, both types of carbon atoms).

${ }^{29} \mathrm{Si}$ MAS NMR (ppm) $\delta$ : $-62\left(\mathrm{C}_{\mathrm{ar}} \mathrm{Si}(\mathrm{OSi})(\mathrm{OH})_{2}\right),-70\left(\mathrm{C}_{\mathrm{ar}} \mathrm{Si}(\mathrm{OSi})_{2}(\mathrm{OH})\right),-78\left(\mathrm{C}_{\mathrm{ar}} \mathrm{Si}(\mathrm{OSi})_{3}\right)$.

Al-8SiPhSi-Ac: IR (KBr, cm $\left.{ }^{-1}\right)$ v : $520 \mathrm{~s}(\rho \mathrm{Si}-\mathrm{O}-\mathrm{Si}), 631 \mathrm{vw}, 667 \mathrm{w}, 701 \mathrm{w}$ ( $\delta \mathrm{C}-\mathrm{C}$ out of plane aromatic ring bend), $746 \mathrm{w}$ ( $\delta \mathrm{C}_{\mathrm{ar}}-\mathrm{H}$ out of plane), $781 \mathrm{w}\left(\mathrm{v}_{\mathrm{s}} \mathrm{Si}-\mathrm{O}-\mathrm{Si}\right), 811 \mathrm{~m}(\delta \mathrm{Si}-\mathrm{C}), 905 \mathrm{~s}(\mathrm{v}$ $\mathrm{Si}-\mathrm{OH}), 1018 \mathrm{vs}, 1037 \mathrm{vs}(\mathrm{v} \mathrm{Si}-\mathrm{O}-\mathrm{Si} / \mathrm{Al}), 1152 \mathrm{~s}\left(\mathrm{v} \mathrm{Si}-\mathrm{C}_{\mathrm{ar}}\right.$ ), $1263 \mathrm{vw}, 1380 \mathrm{w}\left(\delta_{\mathrm{as}} \mathrm{CH}_{3}\right), 1430 \mathrm{w}$ ( $\mathrm{v}$ $\mathrm{C}-\mathrm{C}), 1471 \mathrm{w}, 1535 \mathrm{w}$ ( $\left.\mathrm{v}_{\text {as }} \mathrm{COO}\right), 1593 \mathrm{w}$ (v C $\left.-\mathrm{C}\right), 1621 \mathrm{~m}(\delta \mathrm{OH}), 1710 \mathrm{w}$ ( $\left.\mathrm{v}_{\text {as }} \mathrm{COO}\right), 2959 \mathrm{vw}$ $\left(\mathrm{v}_{\mathrm{as}} \mathrm{CH}_{3}\right), 3011 \mathrm{vw}\left(\mathrm{v}_{\mathrm{s}} \mathrm{CH}_{\mathrm{ar}}\right), 3062 \mathrm{w}\left(\mathrm{v}_{\mathrm{as}} \mathrm{CH}_{\mathrm{ar}}\right), 3300 \mathrm{~m}$-broad $(\mathrm{v} \mathrm{OH})$.

${ }^{13} \mathrm{C}$ CPMAS NMR (ppm) $\delta: 21\left(\mathrm{CH}_{3} \mathrm{COO}\right.$ unident), $22\left(\mathrm{CH}_{3} \mathrm{COO}\right.$ bident), $129\left(\mathrm{Si}-\mathrm{C}_{6} \mathrm{H}_{5}\right), 134$ ( $\left.\mathrm{Si}-\mathrm{C}_{6} \mathrm{H}_{4}-\mathrm{Si}\right), 169$ ( $\mathrm{CH}_{3} \mathrm{COO}$ bident), 177 ( $\mathrm{CH}_{3} \mathrm{COO}$ unident).

${ }^{29} \mathrm{Si}$ MAS NMR (ppm) $\delta:-61\left(\mathrm{C}_{\mathrm{ar}} \mathrm{Si}(\mathrm{OSi})(\mathrm{OH} / \mathrm{Al})_{2}\right),-71\left(\mathrm{C}_{\mathrm{ar}} \mathrm{Si}(\mathrm{OSi})_{2}(\mathrm{OH} / \mathrm{Al})\right),-77\left(\mathrm{C}_{\mathrm{ar}} \mathrm{Si}(\mathrm{OSi})_{3}\right)$, $-100\left(\mathrm{SiO}_{4}\right)$.

${ }^{27} \mathrm{Al} \mathrm{MAS} \mathrm{NMR}(\mathrm{ppm}) \delta: 0\left(\mathrm{AlO}_{6}\right), 26\left(\mathrm{AlO}_{5}\right), 52\left(\mathrm{AlO}_{4}\right)$.

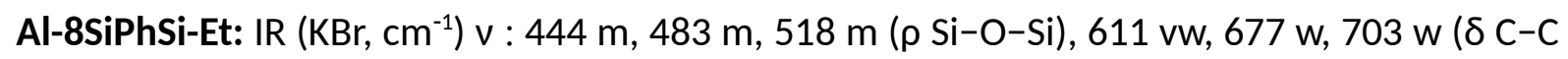
out of plane aromatic ring bend), $746 \mathrm{w}\left(\delta \mathrm{C}_{\mathrm{ar}}-\mathrm{H}\right.$ out of plane), $786 \mathrm{w}\left(\mathrm{v}_{\mathrm{s}} \mathrm{Si}-\mathrm{O}-\mathrm{Si}\right), 812 \mathrm{w}(\delta$ $\mathrm{Si}-\mathrm{C}), 934 \mathrm{~s}(\mathrm{v} \mathrm{Si}-\mathrm{OH}), 1021 \mathrm{vs}, 1045 \mathrm{vs}(\mathrm{v} \mathrm{Si}-\mathrm{O}-\mathrm{Si} / \mathrm{Al}), 1132 \mathrm{~s}\left(\mathrm{v} \mathrm{Si}-\mathrm{C}_{\mathrm{ar}}\right), 1384 \mathrm{w}\left(\mathrm{\delta}_{\mathrm{as}} \mathrm{CH}_{3}\right), 1434$ w (v C-C), $1491 \mathrm{w}, 1596 \mathrm{w}$ (v C-C), $1628 \mathrm{~m}(\delta \mathrm{OH}), 2979 \mathrm{vw}\left(\mathrm{v}_{\mathrm{as}} \mathrm{CH}_{3}\right), 3016 \mathrm{vw}\left(\mathrm{v}_{\mathrm{s}} \mathrm{CH}_{\mathrm{ar}}\right), 3059$ $\mathrm{w}\left(\mathrm{v}_{\mathrm{as}} \mathrm{CH}_{\mathrm{ar}}\right.$ ), $3300 \mathrm{~m}$-broad ( $\left.\mathrm{v} \mathrm{OH}\right)$.

${ }^{13} \mathrm{C}$ CPMAS NMR (ppm) $\delta: 23 \quad\left(\left(\mathrm{CH}_{3}\right)_{2} \mathrm{CHO}\right), 59 \quad\left(\left(\mathrm{CH}_{3}\right)_{2} \mathrm{CHO}\right), \quad 128 \quad\left(\mathrm{Si}-\mathrm{C}_{6} \mathrm{H}_{5}\right), 133$ $\left(\mathrm{Si}-\mathrm{C}_{6} \mathrm{H}_{5} / \mathrm{Si}-\mathrm{C}_{6} \mathrm{H}_{4}-\mathrm{Si}\right)$.

${ }^{29} \mathrm{Si}$ MAS NMR (ppm) $\delta:-62\left(\mathrm{C}_{\mathrm{ar}} \mathrm{Si}(\mathrm{OSi})(\mathrm{OH} / \mathrm{Al})_{2}\right),-70\left(\mathrm{C}_{\mathrm{ar}} \mathrm{Si}(\mathrm{SiO})_{2}(\mathrm{OH} / \mathrm{Al})\right),-77\left(\mathrm{C}_{\mathrm{ar}} \mathrm{Si}(\mathrm{OSi})_{3}\right)$, $-100\left(\mathrm{SiO}_{4}\right)$.

${ }^{27} \mathrm{Al}$ MAS NMR (ppm) $\delta: 0\left(\mathrm{AlO}_{6}\right), 54\left(\mathrm{AlO}_{4}\right)$.

Nb-8SiPhSi-Ac: IR (KBr, cm ${ }^{-1}$ ) v : $520 \mathrm{~s}$ ( $\left.\rho \mathrm{Si}-\mathrm{O}-\mathrm{Si}\right), 633 \mathrm{vw}, 656 \mathrm{w}, 699 \mathrm{w}$ ( $\delta \mathrm{C}-\mathrm{C}$ out of plane aromatic ring bend), $746 \mathrm{w}$ ( $\delta \mathrm{C}_{\mathrm{ar}}-\mathrm{H}$ out of plane), $781 \mathrm{w}\left(\mathrm{v}_{\mathrm{s}} \mathrm{Si}-\mathrm{O}-\mathrm{Si}\right), 810 \mathrm{~m}(\delta \mathrm{Si}-\mathrm{C}), 917 \mathrm{~s}(\mathrm{v}$ $\mathrm{Si}-\mathrm{OH} / \mathrm{Si}-\mathrm{O}-\mathrm{Nb}$ ), $1018 \mathrm{vs}, 1033$ vs (v Si-O-Si), $1150 \mathrm{~s}$ (v Si-Car $), 1269 \mathrm{vw}, 1378 \mathrm{w}\left(\delta_{\mathrm{as}} \mathrm{CH}_{3}\right)$, $1432 \mathrm{w}(\mathrm{v} C-\mathrm{C}), 1471 \mathrm{w}, 1502 \mathrm{w}$ ( $\left.\mathrm{v}_{\text {as }} \mathrm{COO}\right), 1598 \mathrm{w}$ ( $\left.\mathrm{v} \mathrm{C}-\mathrm{C}\right), 1625 \mathrm{~m}(\mathrm{O} \mathrm{OH}), 1707 \mathrm{w}$ ( $\left.\mathrm{v}_{\text {as }} \mathrm{COO}\right)$, $2946 \mathrm{vw}\left(\mathrm{v}_{\mathrm{as}} \mathrm{CH}_{3}\right), 3016 \mathrm{vw}\left(\mathrm{v}_{\mathrm{s}} \mathrm{CH}_{\mathrm{ar}}\right), 3059 \mathrm{w}\left(\mathrm{v}_{\mathrm{as}} \mathrm{CH}_{\mathrm{ar}}\right), 3300 \mathrm{~m}$-broad ( $\left.\mathrm{v} \mathrm{OH}\right)$. 
${ }^{13} \mathrm{C}$ CPMAS NMR (ppm) $\delta: 20\left(\mathrm{CH}_{3} \mathrm{COO}\right.$ unident), $129\left(\mathrm{Si}-\mathrm{C}_{6} \mathrm{H}_{5}\right), 134\left(\mathrm{Si}-\mathrm{C}_{6} \mathrm{H}_{5} / \mathrm{Si}-\mathrm{C}_{6} \mathrm{H}_{4}-\mathrm{Si}\right), 178$ ( $\mathrm{CH}_{3} \mathrm{COO}$ unident).

${ }^{29} \mathrm{Si}$ MAS NMR (ppm) $\delta$ : $-62\left(\mathrm{C}_{\mathrm{ar}} \mathrm{Si}(\mathrm{OSi})(\mathrm{OH} / \mathrm{Nb})_{2}\right),-70\left(\mathrm{C}_{\mathrm{ar}} \mathrm{Si}(\mathrm{OSi})_{2}(\mathrm{OH} / \mathrm{Nb})\right),-78\left(\mathrm{C}_{\mathrm{ar}} \mathrm{Si}(\mathrm{OSi})_{3}\right)$, $-101\left(\mathrm{SiO}_{4}\right)$.

Nb-8SiPhSi-Et: IR (KBr, $\left.\mathrm{cm}^{-1}\right)$ v : $522 \mathrm{~s}(\rho \mathrm{Si}-\mathrm{O}-\mathrm{Si}), 629 \mathrm{vw}, 667 \mathrm{w}, 701 \mathrm{w}(\delta \mathrm{C}-\mathrm{C}$ out of plane aromatic ring bend), $740 \mathrm{w}$ ( $\delta \mathrm{C}_{\mathrm{ar}}-\mathrm{H}$ out of plane), $786 \mathrm{w}\left(\mathrm{v}_{\mathrm{s}} \mathrm{Si}-\mathrm{O}-\mathrm{Si}\right), 812 \mathrm{~m}(\delta \mathrm{Si}-\mathrm{C}), 921 \mathrm{~s}(\mathrm{v}$ $\mathrm{Si}-\mathrm{OH} / \mathrm{Si}-\mathrm{O}-\mathrm{Nb}$ ), $1024 \mathrm{vs}, 1053$ vs ( $\mathrm{v} \mathrm{Si}-\mathrm{O}-\mathrm{Si}), 1150 \mathrm{~s}$ ( $\left.\mathrm{v} \mathrm{Si}-\mathrm{C}_{\mathrm{ar}}\right), 1380 \mathrm{w}\left(\delta_{\mathrm{as}} \mathrm{CH}_{3}\right), 1432 \mathrm{w}(\mathrm{v}$ $\mathrm{C}-\mathrm{C}), 1491 \mathrm{w}, 1596 \mathrm{w}(\mathrm{v} \mathrm{C}-\mathrm{C}), 1628 \mathrm{~m}(\delta \mathrm{OH}), 2975 \mathrm{vw}\left(\mathrm{v}_{\mathrm{as}} \mathrm{CH}_{3}\right), 3016 \mathrm{vw}\left(\mathrm{v}_{\mathrm{s}} \mathrm{CH}_{\mathrm{ar}}\right), 3063 \mathrm{w}\left(\mathrm{v}_{\mathrm{as}}\right.$ $\mathrm{CH}_{\mathrm{ar}}$ ), $3300 \mathrm{~m}$-broad ( $\left.v \mathrm{OH}\right)$.

${ }^{13} \mathrm{C}$ CPMAS NMR (ppm) $\delta: 23\left(\left(\mathrm{CH}_{3}\right)_{2} \mathrm{CHO}\right), 128\left(\mathrm{Si}-\mathrm{C}_{6} \mathrm{H}_{5}\right), 134\left(\mathrm{Si}-\mathrm{C}_{6} \mathrm{H}_{5} / \mathrm{Si}-\mathrm{C}_{6} \mathrm{H}_{4}-\mathrm{Si}\right)$.

${ }^{29} \mathrm{Si}$ MAS NMR (ppm) $\delta$ : $-61\left(\mathrm{C}_{\mathrm{ar}} \mathrm{Si}(\mathrm{OSi})(\mathrm{OH} / \mathrm{Nb})_{2}\right),-71\left(\mathrm{C}_{\mathrm{ar}} \mathrm{Si}(\mathrm{OSi})_{2}(\mathrm{OH} / \mathrm{Nb})\right),-78\left(\mathrm{C}_{\mathrm{ar}} \mathrm{Si}(\mathrm{SiO})_{3}\right)$, $-100\left(\mathrm{SiO}_{4}\right)$.

Sn-8SiPhSi-Ac: IR (KBr, cm ${ }^{-1}$ ) v : 518 s ( $\rho$ Si-O-Si), 633 vw, 667 w, 701 w ( $\delta$ C-C out of plane aromatic ring bend), $746 \mathrm{w}\left(\delta \mathrm{C}_{\mathrm{ar}}-\mathrm{H}\right.$ out of plane), $779 \mathrm{w}\left(\mathrm{v}_{\mathrm{s}} \mathrm{Si}-\mathrm{O}-\mathrm{Si}\right), 812 \mathrm{~m}(\delta \mathrm{Si}-\mathrm{C}), 891 \mathrm{~s}(\mathrm{v}$ $\mathrm{Si}-\mathrm{OH} / \mathrm{Si}-\mathrm{O}-\mathrm{Sn}$ ), 1014 vs, 1037 vs (v Si-O-Si), $1152 \mathrm{~s}$ (v Si-C $\left.\mathrm{C}_{\mathrm{ar}}\right), 1265 \mathrm{~m}, 1384 \mathrm{~m}\left(\delta_{\mathrm{as}} \mathrm{CH}_{3}\right)$, $1430 \mathrm{w}(\mathrm{v} C-\mathrm{C}), 1471 \mathrm{w}, 1537 \mathrm{w}$ ( $\left.\mathrm{v}_{\text {as }} \mathrm{COO}\right), 1568 \mathrm{w}$ ( $\left.\mathrm{v} \mathrm{C}-\mathrm{C}\right), 1621$ shoulder $(\delta \mathrm{OH}), 1707 \mathrm{~s}$ ( $\mathrm{v}_{\text {as }}$ $\mathrm{COO}), 2965 \mathrm{vw}\left(\mathrm{v}_{\mathrm{as}} \mathrm{CH}_{3}\right), 3012 \mathrm{w}\left(\mathrm{v}_{\mathrm{s}} \mathrm{CH}_{\mathrm{ar}}\right), 3061 \mathrm{w}\left(\mathrm{v}_{\mathrm{as}} \mathrm{CH}_{\mathrm{ar}}\right.$ ), $3300 \mathrm{~m}$-broad ( $\mathrm{v} \mathrm{OH}$ ).

${ }^{29} \mathrm{Si}$ MAS NMR (ppm) $\delta$ : $-62\left(\mathrm{C}_{\mathrm{ar}} \mathrm{Si}(\mathrm{OSi})(\mathrm{OH} / \mathrm{Sn})_{2}\right),-72\left(\mathrm{C}_{\mathrm{ar}} \mathrm{Si}(\mathrm{OSi})_{2}(\mathrm{OH} / \mathrm{Sn})\right),-78\left(\mathrm{C}_{\mathrm{ar}} \mathrm{Si}(\mathrm{OSi})_{3}\right)$,

Al-8SiCH ${ }_{2}$ PhCH $_{2} \mathrm{Si}-\mathrm{Ac}:$ IR ( $\mathrm{KBr}, \mathrm{cm}^{-1}$ ) v : $426 \mathrm{w}, 471 \mathrm{w}, 526 \mathrm{w}$ ( $\left.\rho \mathrm{Si}-\mathrm{O}-\mathrm{Si}\right), 561 \mathrm{vw}, 629 \mathrm{vw}, 693 \mathrm{w}$ ( $\delta \mathrm{C}-\mathrm{C}$ out of plane aromatic ring bend), $747 \mathrm{w}\left(\delta \mathrm{C}_{\mathrm{ar}}-\mathrm{H}\right.$ out of plane), $806 \mathrm{~m}\left(\mathrm{v}_{\mathrm{s}} \mathrm{Si}-\mathrm{O}-\mathrm{Si}\right), 837$ m ( $\delta \mathrm{Si}-\mathrm{C}), 907 \mathrm{~s}(\mathrm{v} \mathrm{Si}-\mathrm{OH}), 1010 \mathrm{vs}(\mathrm{v} \mathrm{Si}-\mathrm{O}-\mathrm{Si} / \mathrm{Al}), 1176 \mathrm{~m}, 1226 \mathrm{~m}$ (v Si-C), $1261 \mathrm{w}, 1399 \mathrm{vw}$ $\left(\delta_{\text {as }} \mathrm{CH}_{3}\right), 1421 \mathrm{~m}(\mathrm{v} \mathrm{C}-\mathrm{C}), 1471 \mathrm{~m}, 1514 \mathrm{~m}$ ( $\left.\mathrm{v}_{\mathrm{as}} \mathrm{COO}\right), 1593 \mathrm{~m}(\mathrm{v} \mathrm{C}-\mathrm{C}), 1621$ shoulder $(\delta \mathrm{OH})$, $1711 \mathrm{~m}\left(\mathrm{v}_{\mathrm{as}} \mathrm{COO}\right), 2895 \mathrm{w}\left(\mathrm{v}_{\mathrm{as}} \mathrm{CH}_{2}\right), 2980 \mathrm{vw}\left(\mathrm{v}_{\mathrm{as}} \mathrm{CH}_{3}\right), 3015 \mathrm{w}\left(\mathrm{v}_{\mathrm{s}} \mathrm{CH}_{\mathrm{ar}}\right), 3053 \mathrm{w}\left(\mathrm{vas}_{\mathrm{as}} \mathrm{CH}_{\mathrm{ar}}\right), 3300$ m-broad ( $v \mathrm{OH})$.

${ }^{13} \mathrm{C}$ CPMAS NMR (ppm) $\delta: 22 \quad\left(\mathrm{Si}-\mathrm{CH}_{2}-\mathrm{C}_{6} \mathrm{H}_{4}-\mathrm{CH}_{2}-\mathrm{Si} / \mathrm{CH}_{3} \mathrm{COO}\right.$ unident), 129 ( $\mathrm{Si}-\mathrm{CH}_{2}-\mathrm{C}_{6} \mathrm{H}_{4}-\mathrm{CH}_{2}-\mathrm{Si}$ ), 169 ( $\mathrm{CH}_{3} \mathrm{COO}$ bident), 179 ( $\mathrm{CH}_{3} \mathrm{COO}$ unident).

${ }^{29} \mathrm{Si}$ MAS NMR $(\mathrm{ppm}) \delta$ : $-52\left(\mathrm{CH}_{2} \mathrm{Si}(\mathrm{OSi})(\mathrm{OH} / \mathrm{Al})_{2}\right),-61\left(\mathrm{CH}_{2} \mathrm{Si}(\mathrm{OSi})_{2}(\mathrm{OH} / \mathrm{Al})\right),-70\left(\mathrm{CH}_{2} \mathrm{Si}(\mathrm{SiO})_{3}\right)$.

${ }^{27} \mathrm{Al}$ MAS NMR (ppm) $\delta: 0\left(\mathrm{AlO}_{6}\right), 31\left(\mathrm{AlO}_{5}\right), 51\left(\mathrm{AlO}_{4}\right)$. 


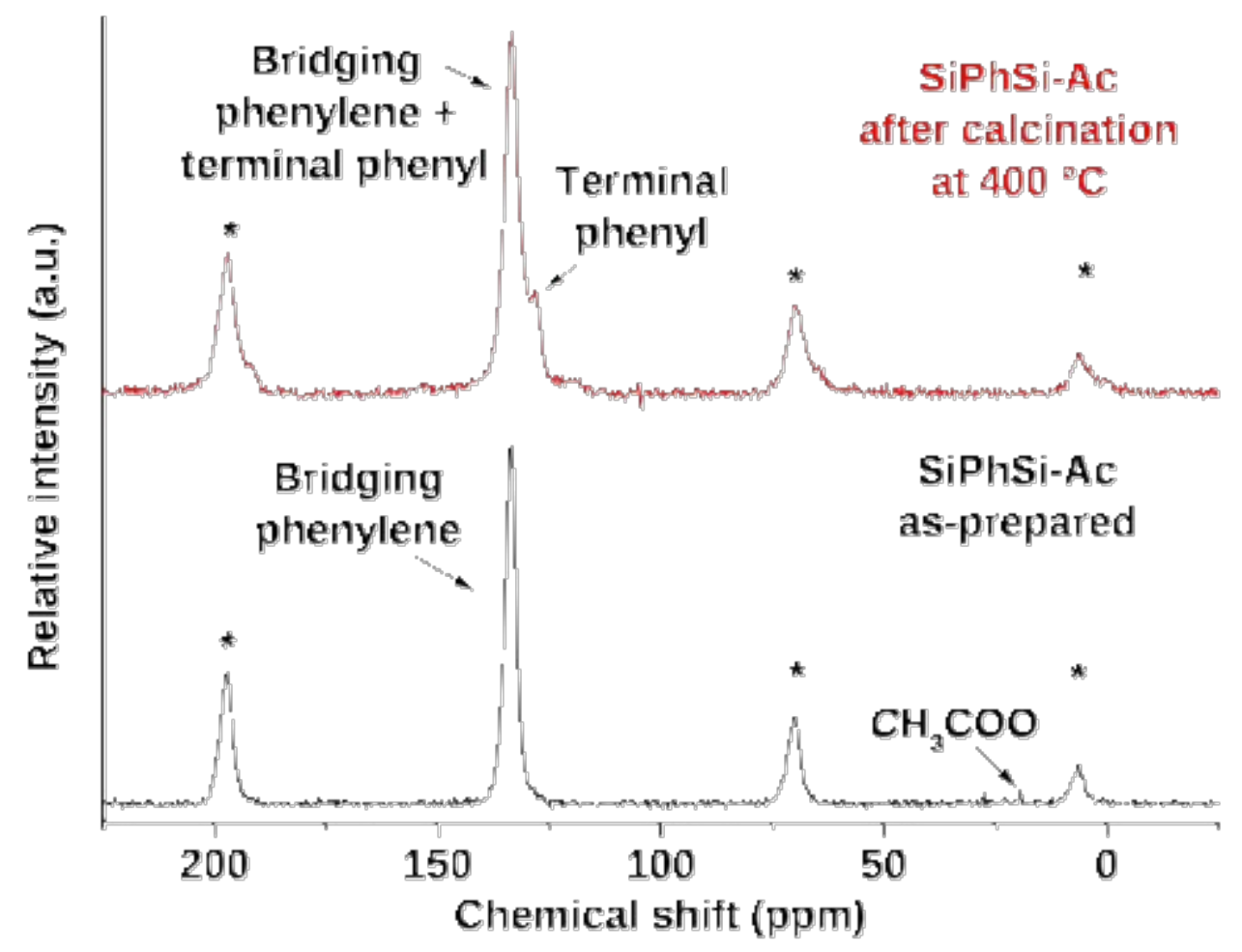

Fig. 1S: ${ }^{13} \mathrm{C}$ CPMAS NMR spectra of sample SiPhSi-Ac (as-prepared in black, calcined at $400^{\circ} \mathrm{C}$ in red). 


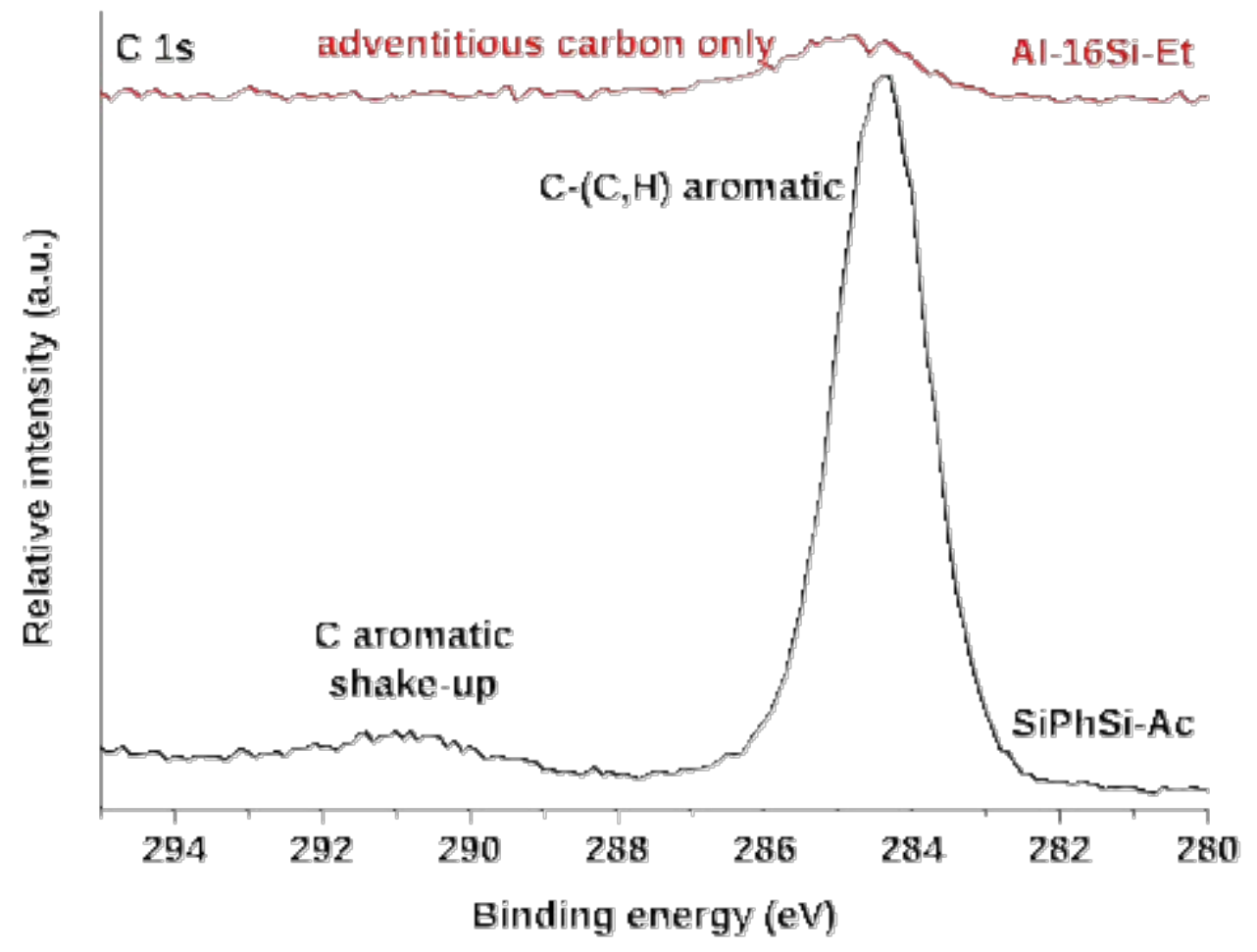

Fig. 2S: C 1s XP spectra of hybrid material SiPhSi-Ac and pure inorganic Al-16Si-Et. 


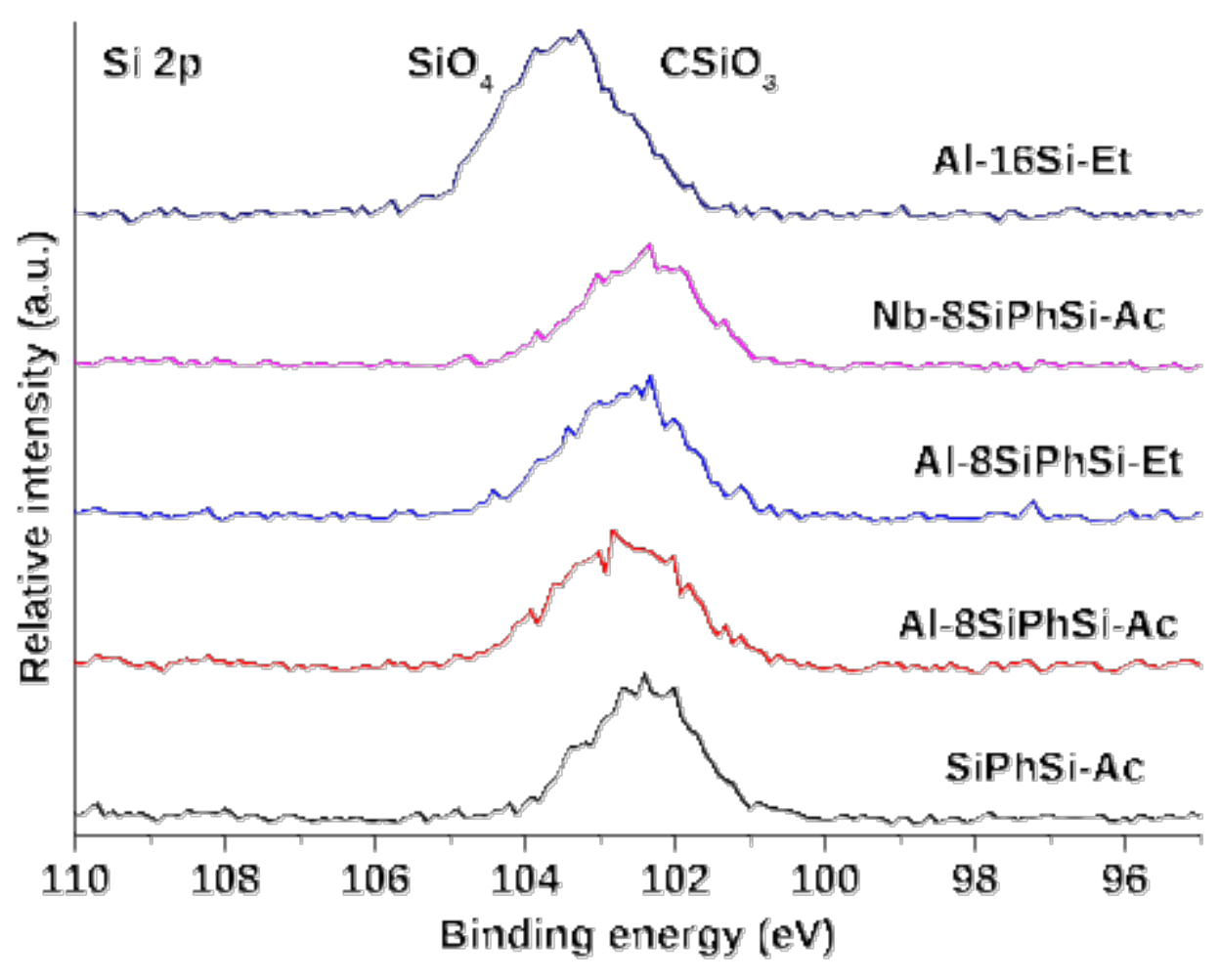

Fig. 3S: Si 2p XP spectra of NHSG-prepared samples.

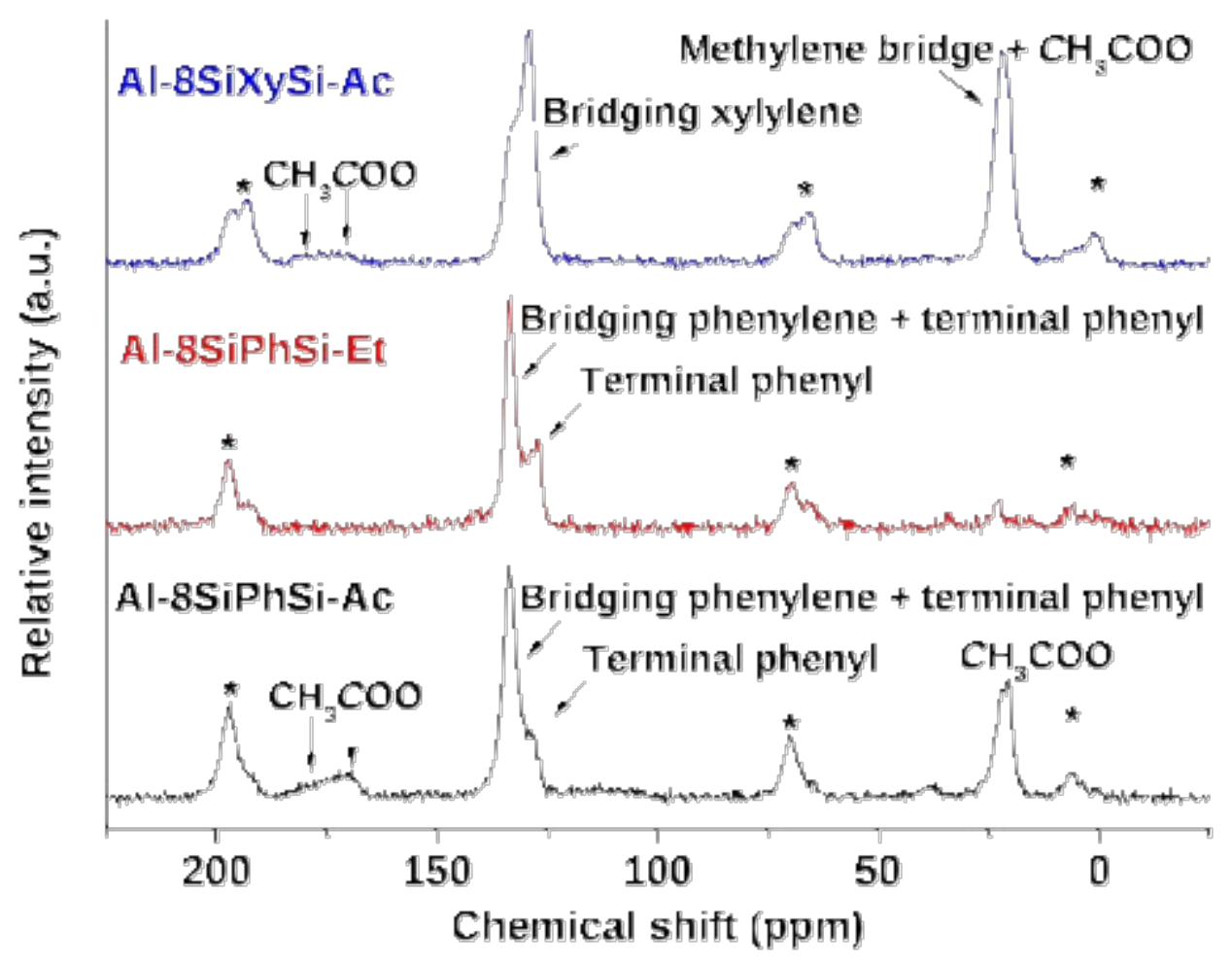

Fig. 4S: ${ }^{13} \mathrm{C}$ CPMAS NMR spectra of aluminum containing samples (as-prepared). 


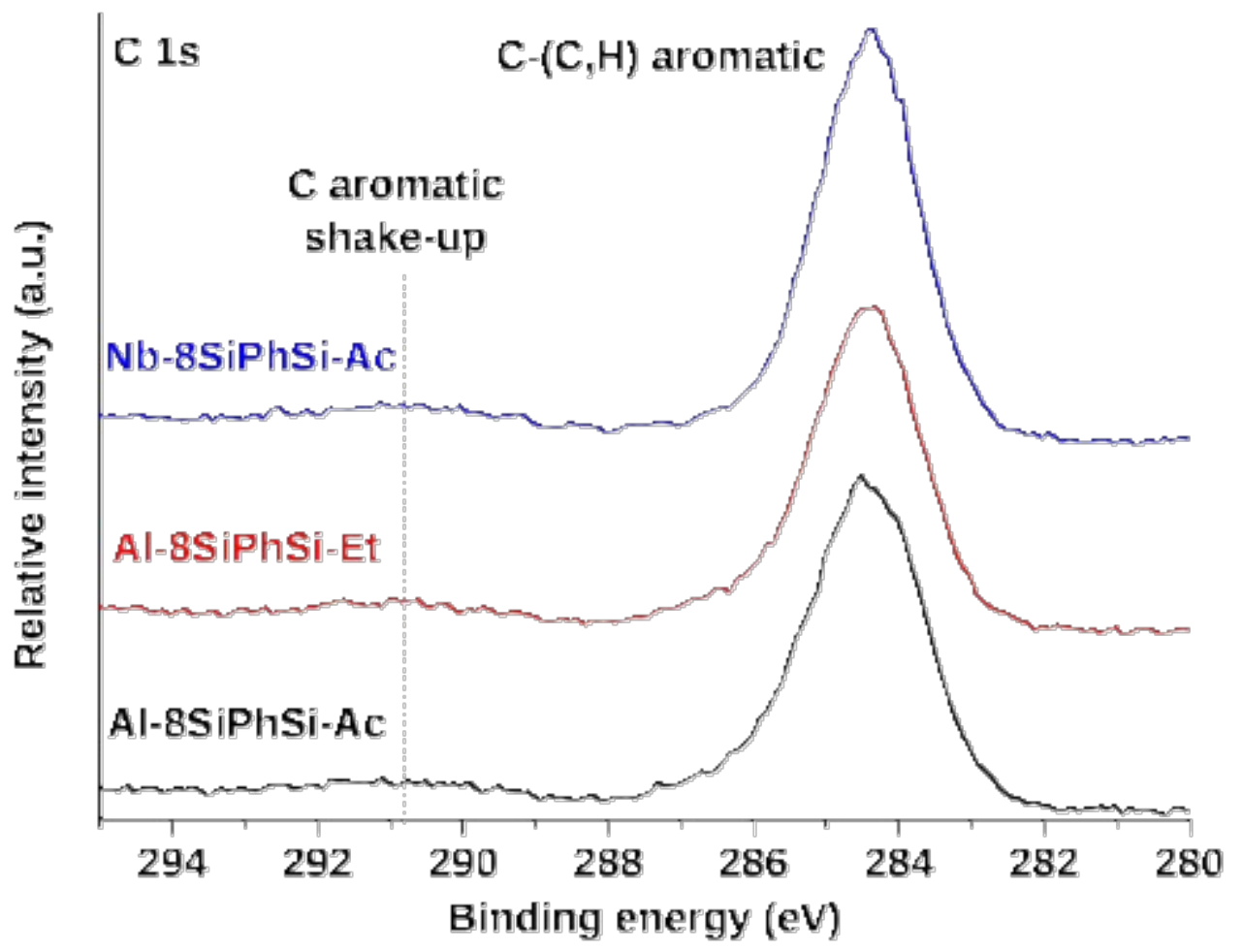

Fig. 5S: C 1s XP spectra of phenylene bridged metallosilicates.

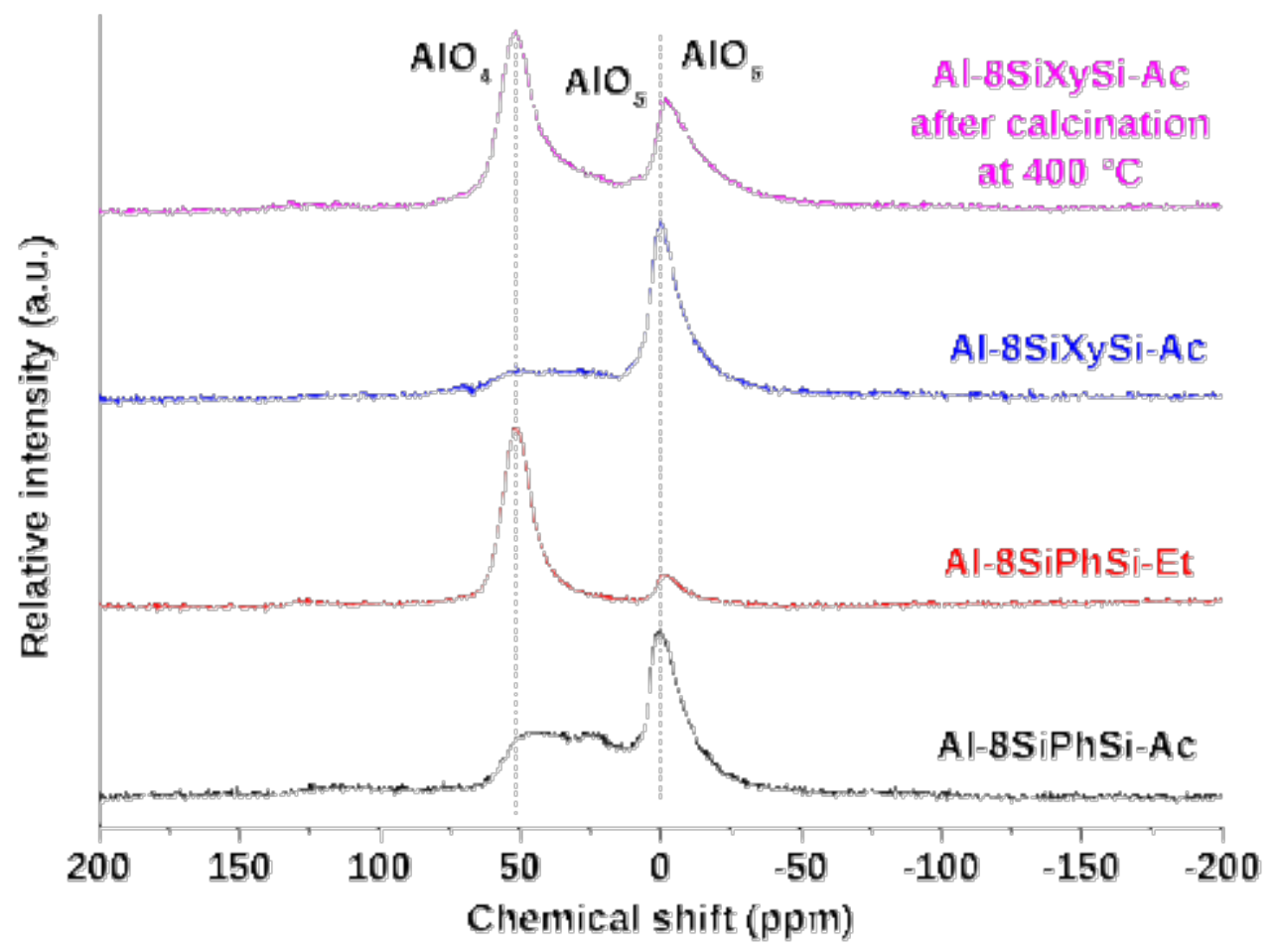

Fig. 6S: ${ }^{27} \mathrm{Al}$ MAS NMR spectra of Al containing hybrid metallosilicates. 


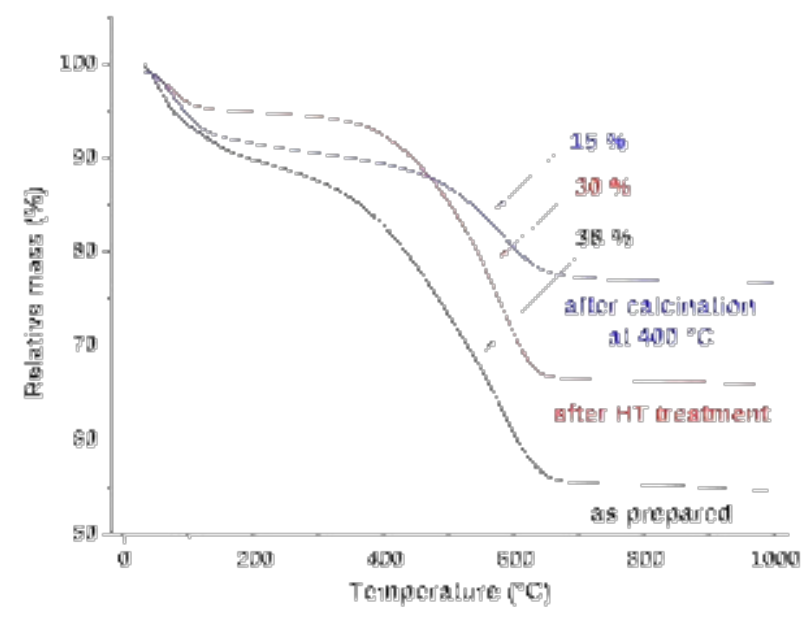

Fig. 7S: TG curves of sample Nb-8SiPhSi-Ac after various treatments.

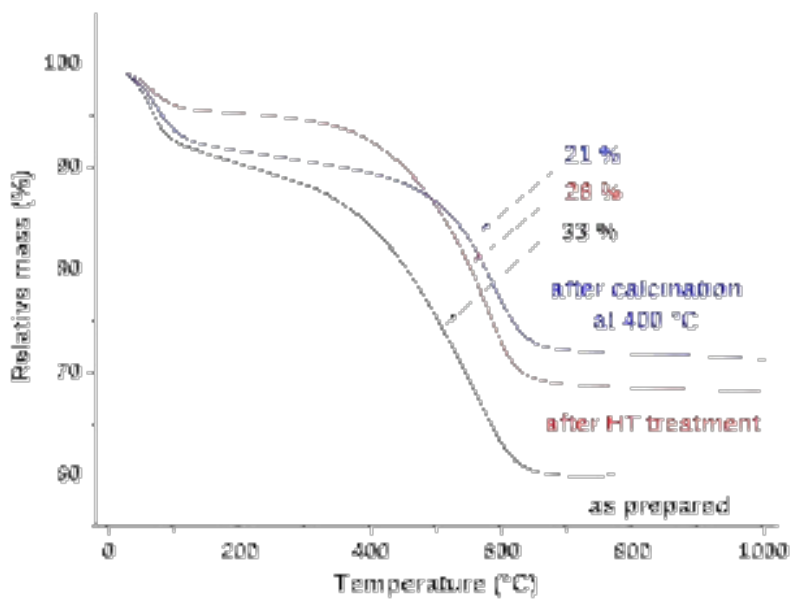

Fig. 8S: TG curves of sample Nb-8SiPhSi-Et after various treatments.

Table 1S: Areas of deconvoluted peaks in ${ }^{29} \mathrm{Si}$ MAS NMR spectra and degrees of condensation based on their weighed ratios.

\begin{tabular}{|c|c|c|c|c|c|c|c|}
\hline Sample & T1 $^{\mathbf{a}}$ & T2 $^{\mathbf{a}}$ & T3 $^{\mathbf{a}}$ & $\mathbf{Q}^{\mathbf{a}}$ & Q3 $^{\mathbf{a}}$ & Q4 $^{\text {a }}$ & DC (\%) $^{\mathbf{b}}$ \\
\hline Al-8SiPhSi-Ac & 60.674 & 143.609 & 163.969 & 72.697 & 277.206 & 198.917 & $\mathbf{7 8 . 8}$ \\
\hline Al-8SiPhSi-Et & 21.081 & 365.449 & 282.411 & 21.773 & 160.629 & 27.793 & $\mathbf{7 8 . 7}$ \\
\hline Nb-8SiPhSi-Ac & 47.881 & 244.263 & 299.109 & 16.542 & 89.197 & 61.454 & $\mathbf{8 1 . 0}$ \\
\hline Nb-8SiPhSi-Et & 53.152 & 228.583 & 260.253 & 27.818 & 110.316 & 52.964 & $\mathbf{7 9 . 1}$ \\
\hline
\end{tabular}

${ }^{\mathrm{a}}$ Relative integrated area of deconvoluted peak (a.u.); ${ }^{\mathrm{b}}$ Degree of condensation. 

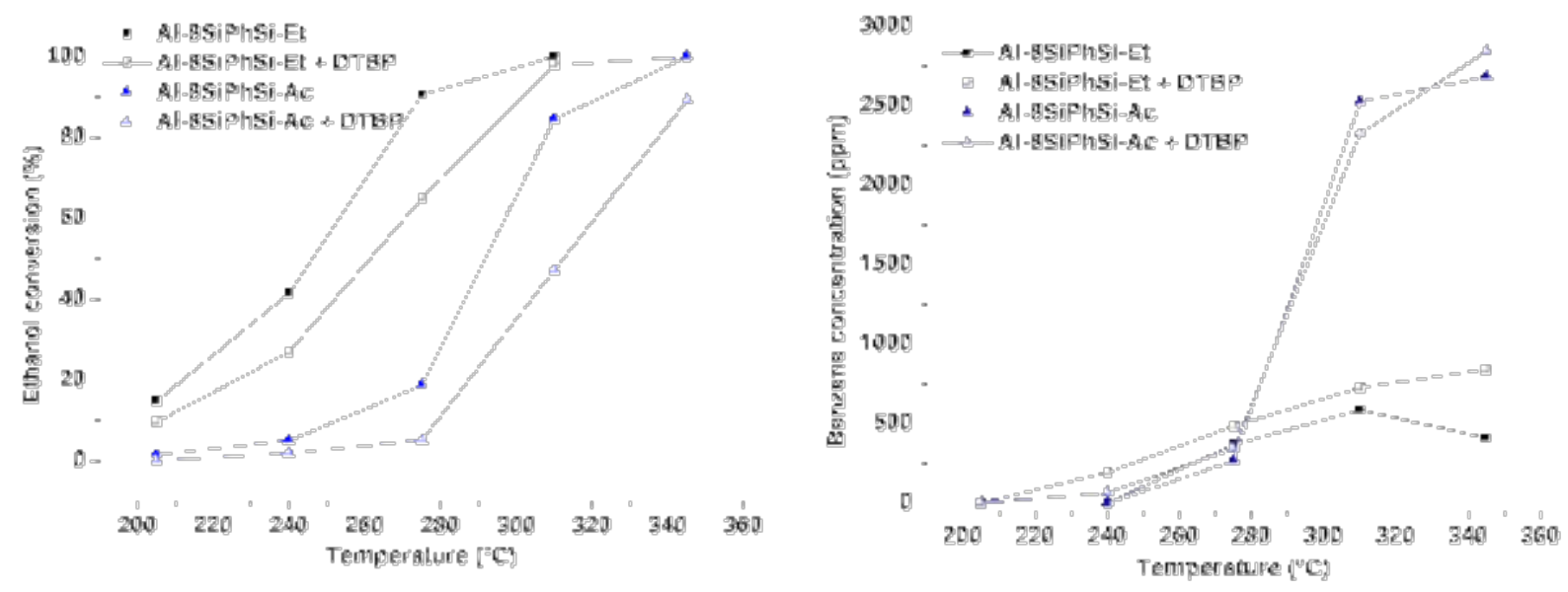

Fig. 9S: Ethanol conversion (left) and benzene concentration in effluent (right) during catalytic runs over Al containing phenylene bridged catalysts, acidic protons selectively poisoned with 2,6-ditertbutylpyridine.
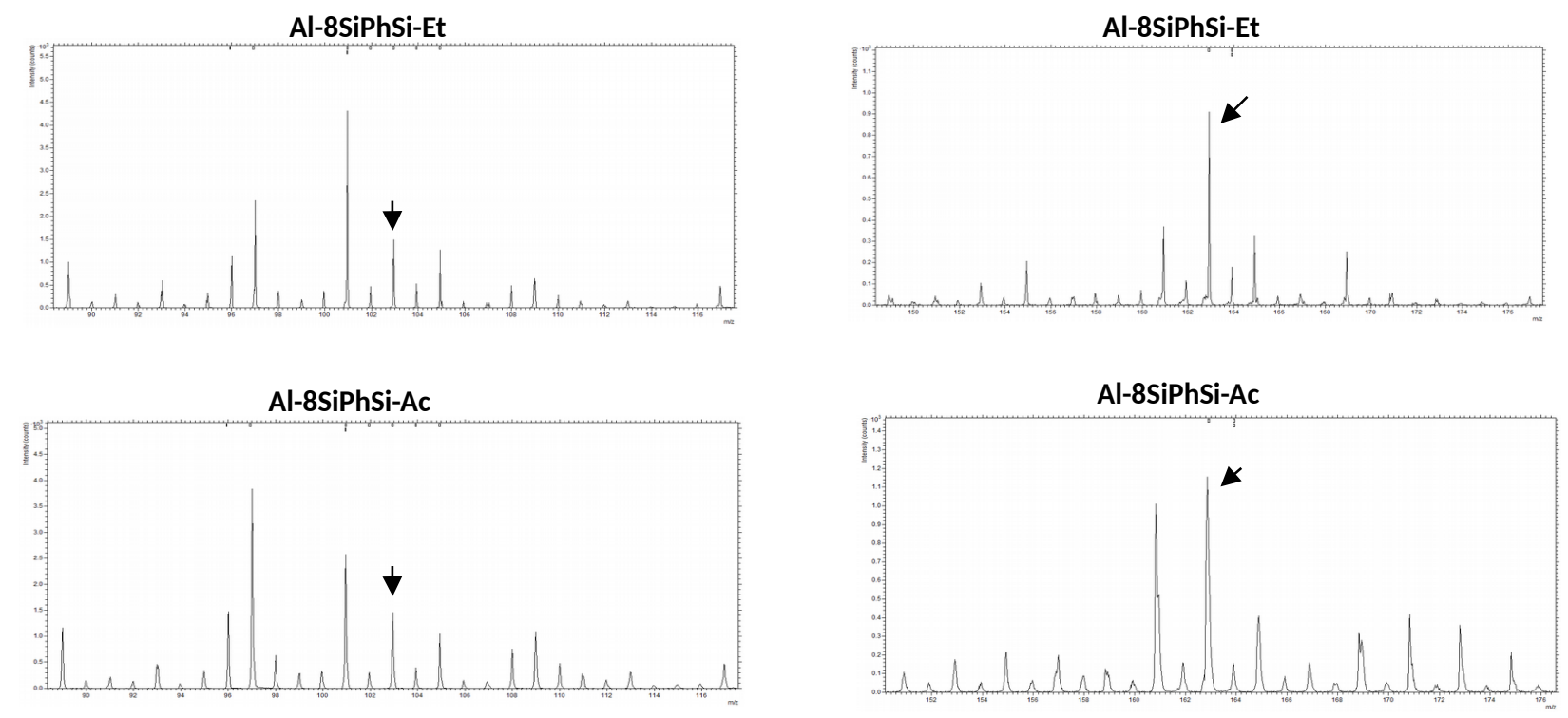

Fig. 10S: Relevant parts of mass spectra used for homogeneity analysis by ToF-SIMS. 
Styskalik Debecker - Stability of hybrid metallosilicate - pre... (1.00 MiB) view on ChemRxiv • download file 